\title{
A test of the hypothesis that the spatial scale of effect of the landscape context on an ecological response increases with increasing time scale over which the response is regulated
}

by

Andrew D. Moraga

A thesis submitted to the Faculty of Graduate and Postdoctoral Affairs in partial fulfillment of the requirements for the degree of

Master of Science

in

Biology

Carleton University

Ottawa, Ontario

July 2017

(C)2017

Andrew D. Moraga 


\section{Abstract:}

To detect an effect of landscape context on an ecological response, researchers need to measure the landscape variable(s) at the appropriate spatial extent around the response (the 'scale of effect' of the landscape variable). However, it is unknown whether it is possible to select the appropriate scale of effect a priori as there are many factors hypothesized to affect it. One of these is that the scale of effect should increase with the temporal scale regulating the ecological response. To test this hypothesis we compared the scale of effect of two landscape predictors on three responses with increasing temporal scales of regulation - fecundity, population abundance, and occurrence - for wood frogs (Lithobates sylvaticus). We surveyed wood frog egg masses in 34 ponds at the centers of landscapes varying in the surrounding road density and proportion of forest (our landscape context variables). We predicted that the scale of effect would be smallest for fecundity (number of eggs per egg mass), larger for abundance (number of egg masses per pond), and largest for occurrence (presence/absence of egg masses in a pond). We found that the scale of effect differed among responses, from $0.2 \mathrm{~km}$ to $2.6 \mathrm{~km}$ radius, but not vary in the predicted order, and not consistently for the two landscape predictors. These results suggest that the scale of effect of the landscape can differ for different response variables of the same species, but they do not support the hypothesis that the scale of effect increases with the timescale regulating the response. Thus, predicting the scale of effect $a$ priori based on the type of response is likely not possible. This suggests that studies of landscape context effects should measure the landscape variable(s) at multiple extents and estimate the scale of effect empirically, rather than conducting the analyses at a single spatial scale that is 'guestimated' a priori. 


\section{Acknowledgements:}

We thank the private landowners whose collaboration made access to ponds for this study possible. We thank Joseph Bennett and Jeremy Kerr for helpful comments and suggestions. This work was supported by a Natural Sciences and Engineering Research Council of Canada Grant to Lenore Fahrig. Erik Pervin and Caitlin Brunton were indispensable field assistants. 


\section{Table of Contents}

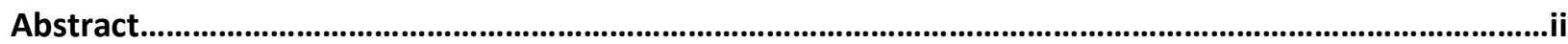

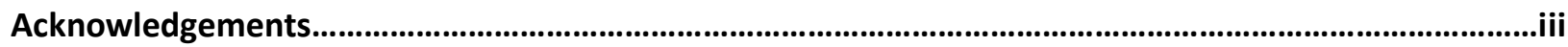

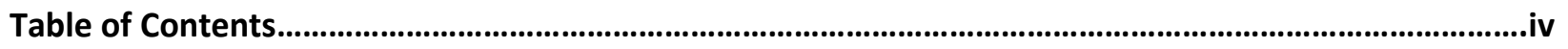

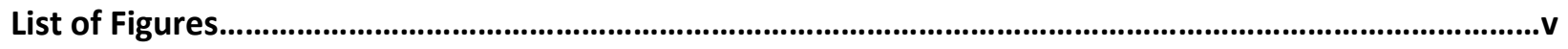

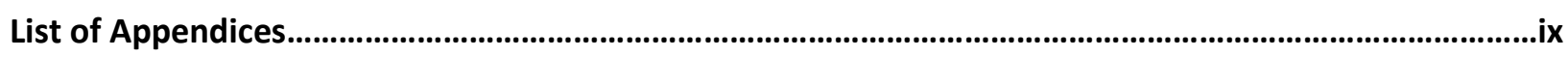

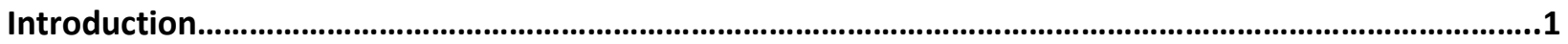

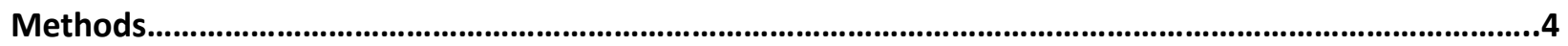

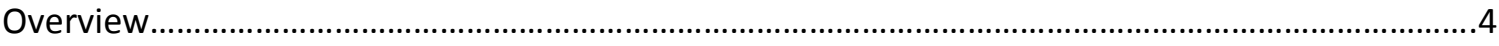

Wood frog fecundity, abundance, and occurrence...........................................................................

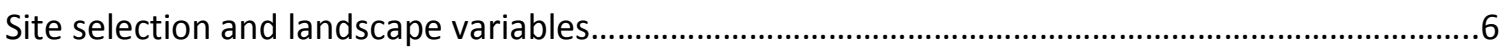

Potentially confounding variables..............................................................................................

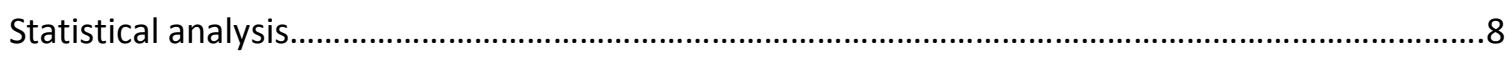

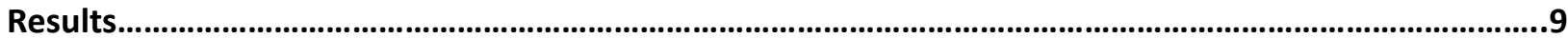

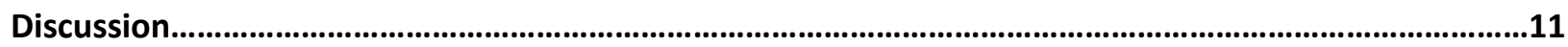

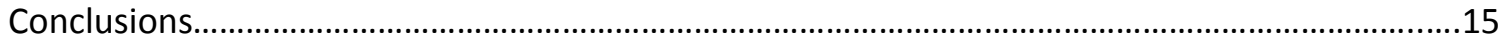

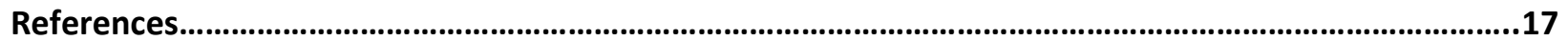




\section{List of Figures}

Figure 1: Example showing how to empirically estimate the scale of effect using a multi-scale focal sample site study design. a) Select a set of landscapes that vary in the predictor (e.g. forest amount). Each landscape is centered on a focal sample site. Landscapes should be non-overlapping at the largest likely scale of effect. b) Measure the ecological response at the focal sample sites (point in the center of each landscape). Measure the landscape context predictor variable within multiple spatial extents around each focal site. c) Calculate model fit from a regression of the ecological response measured at the focal sample sites on the landscape context predictor measured at a given spatial extent, and repeat for each spatial extent. d) Compare the model fits across spatial extents and estimate the scale of effect as the spatial extent with the best model fit (here, lowest $\Delta \mathrm{AIC}$ ). .22

Figure 2: Knowledge of the scale of effect a priori allows researchers to maximize the number of nonoverlapping landscapes sampled within a region. a) When the scale of effect is not known the landscapes must be non-overlapping at the largest extent believed to possibly influence the ecological response. However, b) when the scale of effect is known a priori then landscapes need only be large enough to encompass the true scale of effect. This allows for more non-overlapping landscapes to be sampled in a region, thus increasing the sample size and the power of the study.......

Figure 3: Wood frog fecundity was estimated using an Ovagram. Each egg mass was gently compressed between two transparent basins, a photograph was taken (example shown) and the egg mass was then returned unharmed to the pond. The number of eggs in each egg mass was counted from the photos.

Figure 4: Mean and variation (SD) of road density $\left(\mathrm{km} / \mathrm{km}^{2}\right)$ across 34 landscapes in Eastern Ontario, Canada, measured at each of 30 spatial extents (radius in $\mathrm{km}$ ) around the sampled pond in the center of

each landscape. .25 
Figure 5: Mean and variation (SD) of proportion of forest across 34 landscapes in Eastern Ontario, Canada, measured at each of 30 spatial extents (radius in $\mathrm{km}$ ) around the sampled pond in the center of each landscape. . .26

Figure 6: Model fit for general linear models relating wood frog fecundity measured in 17 wetlands to road density measured in the surrounding landscapes at each of 30 spatial extents $(0.1$ to $3.0 \mathrm{~km}$ radius from the centers of the sampled ponds). We estimated model fit as the mean $\Delta \mathrm{AIC}$ and $95 \%$ confidence interval for each spatial extent, based on 1000 bootstrapped samples. To calculate the $\triangle \mathrm{AIC}$ for each bootstrapped sample at each extent, we calculated the difference between the strongest model, or estimated scale of effect for that bootstrap sample, $(\triangle A I C=0)$ and the remaining models including landscape measures from the other 29 spatial extents. The estimated scale of effect is indicated with a red arrow and is based on the full complement of bootstrapped samples. The frequency histogram shows the distribution of 1000 estimated scale of effect from the bootstrapped samples described above. .27

Figure 7: Model fit for general linear models relating wood frog abundance measured in 21 wetlands to road density measured in the surrounding landscapes at each of 30 spatial extents $(0.1$ to $3.0 \mathrm{~km}$ radius from the centers of the sampled ponds). We estimated model fit as the mean $\Delta$ AIC and $95 \%$ confidence interval for each spatial extent, based on 1000 bootstrapped samples. To calculate the $\triangle \mathrm{AIC}$ for each bootstrapped sample at each extent, we calculated the difference between the strongest model, or estimated scale of effect for that bootstrap sample, $(\triangle A I C=0)$ and the remaining models including landscape measures from the other 29 spatial extents. The estimated scale of effect is indicated with a red arrow and is based on the full complement of bootstrapped samples. The frequency histogram shows the distribution of 1000 estimated scale of effect from the bootstrapped samples described above. .28 
Figure 8: Model fit for generalized linear models relating wood frog occurrence measured in 34 wetlands to road density measured in the surrounding landscapes at each of 30 spatial extents ( 0.1 to $3.0 \mathrm{~km}$ radius from the centers of the sampled ponds). We estimated model fit as the mean $\triangle \mathrm{AIC}$ and $95 \%$ confidence interval for each spatial extent, based on 1000 bootstrapped samples. To calculate the $\Delta$ AIC for each bootstrapped sample at each extent, we calculated the difference between the strongest model, or estimated scale of effect for that bootstrap sample, $(\triangle \mathrm{AIC}=0)$ and the remaining models including landscape measures from the other 29 spatial extents. The estimated scale of effect is indicated with a red arrow and is based on the full complement of bootstrapped samples. The frequency histogram shows the distribution of 1000 estimated scale of effect from the bootstrapped samples described above.

Figure 9: Model fit for general linear models relating wood frog fecundity measured in 17 wetlands to forest proportion measured in the surrounding landscapes at each of 30 spatial extents (0.1 to $3.0 \mathrm{~km}$ radius from the centers of the sampled ponds). We estimated model fit as the mean $\triangle \mathrm{AIC}$ and $95 \%$ confidence interval for each spatial extent, based on 1000 bootstrapped samples. To calculate the $\Delta$ AIC for each bootstrapped sample at each extent, we calculated the difference between the strongest model, or estimated scale of effect for that bootstrap sample, $(\triangle A I C=0)$ and the remaining models including landscape measures from the other 29 spatial extents. The estimated scale of effect is indicated with a red arrow and is based on the full complement of bootstrapped samples. The frequency histogram shows the distribution of 1000 estimated scale of effect from the bootstrapped samples described above. .30

Figure 10: Model fit for general linear models relating wood frog abundance measured in 21 wetlands to forest proportion measured in the surrounding landscapes at each of 30 spatial extents ( 0.1 to $3.0 \mathrm{~km}$ radius from the centers of the sampled ponds). We estimated model fit as the mean $\triangle \mathrm{AIC}$ and $95 \%$ confidence interval for each spatial extent, based on 1000 bootstrapped samples. To calculate the $\Delta$ AIC 
for each bootstrapped sample at each extent, we calculated the difference between the strongest model, or estimated scale of effect for that bootstrap sample, $(\triangle \mathrm{AIC}=0)$ and the remaining models including landscape measures from the other 29 spatial extents. The estimated scale of effect is indicated with a red arrow and is based on the full complement of bootstrapped samples. The frequency histogram shows the distribution of 1000 estimated scale of effect from the bootstrapped samples described above.

Figure 11: Model fit for generalized linear models relating wood frog occurrence measured in 34 wetlands to forest proportion measured in the surrounding landscapes at each of 30 spatial extents $(0.1$ to $3.0 \mathrm{~km}$ radius from the centers of the sampled ponds). We estimated model fit as the mean $\triangle \mathrm{AIC}$ and $95 \%$ confidence interval for each spatial extent, based on 1000 bootstrapped samples. To calculate the $\Delta \mathrm{AIC}$ for each bootstrapped sample at each extent, we calculated the difference between the strongest model, or estimated scale of effect for that bootstrap sample, $(\triangle \mathrm{AIC}=0)$ and the remaining models including landscape measures from the other 29 spatial extents. The estimated scale of effect is indicated with a red arrow and is based on the full complement of bootstrapped samples. The frequency histogram shows the distribution of 1000 estimated scale of effect from the bootstrapped samples described above. 


\section{List of Appendices}

Table A: Statistical significance of the effects of each of the two landscape context predictors on each of the three wood frog response variables, where the landscape predictor is measured at its estimated scale of effect for each relationship. Shown are the $r^{2}$ for abundance and fecundity, the Nagelkerke's $r^{2}$ for occurrence which had a binomial distribution, the p-value, and the direction of effect of the relationship between the predictor and response.

Table B: Pearson correlations (P) and Spearman rank (S) correlations between measured local habitat variables and three ecological response variables, fecundity $(P)$, abundance $(P)$, and occurrence $(S)$, for wood frogs. Local habitat variables are: dissolved oxygen (DO), pH, electrical conductivity (EC), temperature (Temp), submergent and emergent vegetative cover (Veg), pond depth (Depth), pond perimeter (Perim), pond area (Area))

Table C: Model fit ( $\triangle \mathrm{AIC}$ ) for general and generalized linear models relating wood frog fecundity ( $n=17)$, abundance $(n=21)$, and occurrence $(n=34)$ measured in 34 wetlands to road density measured in the surrounding landscapes at each of 30 spatial extents $(0.1$ to $3.0 \mathrm{~km}$ radius from the centers of the sampled ponds) and the local habitat variable that was most strongly correlated to each response. Two of the three responses, abundance and occurrence, had the same scale of effect estimated in the analysis with and without the local habitat variable. The scale of effect for fecundity was smaller when we included the local habitat variable; however, in each analysis the scale of effect varied in the same order: abundance $<$ occurrence $<$ fecundity.........

Table D: Model fit ( $\triangle \mathrm{AIC}$ ) for general and generalized linear models relating wood frog fecundity, abundance, and occurrence measured in 34 wetlands to forest proportion measured in the surrounding landscapes at each of 30 spatial extents ( 0.1 to $3.0 \mathrm{~km}$ radius from the centers of the sampled ponds) 
and the local habitat variable that was most strongly correlated to each response. The same scales of effect were estimated with and without the local habitat variable. .34

Figure A: Quantile-quantile plot showing mean fecundity estimated per focal site, for a total of 17 sites, compared to a normal distribution suggesting that fecundity can be modelled using a Gaussian distribution since the majority of data points fall within the normal quantiles .35

Figure B: Quantile-quantile plot showing abundance measured per focal site, for a total of 21 sites, compared to a normal distribution suggesting that abundance can be modelled with a Gaussian distribution since the majority of data points fall within the normal quantiles

Table E: Egg count data for wood frog egg masses surveyed at selected landscapes in Eastern Ontario, estimates were obtained from software counts that occurred in the lab based on photographs taken of compressed masses in the field; photo ID corresponds to individual photographs taken for each mass

Table F: Surveyed wood frog egg masses that were missed by observer 1 but noticed by observer 2 during surveys of ponds in Eastern Ontario showing who was observer 1 and the number of masses missed.

Table G: Wood frog egg masses that were counted for abundance measures but could not be photographed because the masses were no longer intact and individuals were soon to emerge or had already begun emerging. . .50

Table H: Local habitat measurements for all 34 surveyed landscapes showing; DO as dissolved oxygen, $\mathrm{pH}, \mathrm{EC}$ as electrical conductivity, temperature, submergent and emergent vegetation estimated based on percent cover, pond depth, pond perimeter, and pond area 
Table I: Landscape predictor measurements of road density measured in $\mathrm{km} / \mathrm{km} 2$ for all 34 landscapes where wood frog egg masses were surveyed

Table I (continued): Landscape predictor measurements of road density measured in $\mathrm{km} / \mathrm{km} 2$ for all 34 landscapes where wood frog egg masses were surveyed. .53

Table J: Landscape predictor measurements for forest proportion in the landscape for all 34 landscapes where wood frog egg masses were surveyed. .54

Table J (continued): Landscape predictor measurements for forest proportion in the landscape for all 34 landscapes where wood frog egg masses were surveyed. .55

Figure C: Map of the study region in Eastern Ontario, Canada. The 34 study landscapes are shown as red circles and roads are grey lines the black dots in the center represents the focal sites at which wetlands were sampled for wood frog egg masses. .56 


\section{Introduction:}

Landscape context, the composition and configuration of land cover types surrounding a given site, has important effects on ecological responses such as presence-absence, abundance, and density for populations reviewed in terrestrial systems by Thornton et al. (2011). Knowledge of these landscape context effects is necessary for making appropriate land management decisions (Prach \& Rehounkova, 2006; Burel \& Baudry, 2005). For example, in Australia reptilian presence was affected by the landscape context at multiple spatial extents that differed depending on the species being examined with some like the four-fingered skink preferring woodlands and grassy areas whereas others like the Southern water skink prefer rocky areas near flowing water (Fischer et al., 2004). Effects were not found at every spatial extent (microhabitat, site, landscape) for some species like the striped skink they were only significantly affected at the microhabitat level, whereas other species like the four-finger skink and Boulenger's skink were significantly affected at the landscape level (Fischer et al., 2004). This would suggest that a focus on a single species or spatial extent would be insufficient for management of reptiles in these studied systems. Similarly, managing or preventing the spread of invasive species requires consideration of the effects of landscape context, for example With (2004) performed a risk analysis for the spread of invasive plants and found that disturbed landscapes, affected by habitat loss and fragmentation, were more likely to become invaded. Thus, understanding landscape context effects on ecological responses is important when making land management decisions for species conservation and maintenance of landscape structure.

To detect an effect of landscape context on an ecological response, researchers need to measure the landscape context variables at the appropriate spatial extent ('scale of effect') around the response. This is because the direction and size of the landscape context effect can vary greatly depending on the spatial extent selected. For example, Holland et al. (2004) found the effect of surrounding forest amount on beetle abundance at focal sites ranged from strongly positive to negligible 
depending on the spatial extent used for estimating forest amount. Moreover, in a review of multi-scale studies, Jackson \& Fahrig (2015) found that many studies find the strongest landscape context effect at the largest or smallest spatial extent examined; this indicates that the true scale of effect was likely smaller or larger still. These studies suggest that landscape context effects are often under-estimated, and highlight the importance of conducting research at the appropriate spatial extent.

The scale of effect can be estimated empirically using a multi-scale focal sample site study design (Brennan et al., 2002). This involves selecting a set of landscapes in a given region (Figure 1a) that vary in the landscape context predictor of interest. Each landscape is centered on a focal sample site. Landscapes should be non-overlapping at the largest likely scale of effect. The ecological response is measured at the focal sample site of each landscape. The landscape context predictor is measured at multiple spatial extents radiating outward from the focal sample sites (Figure 1b). Model fit is calculated from a regression of the ecological response measured at the focal sample sites on the landscape context predictor measured at a given spatial extent, and this process is then repeated for each spatial extent. The coefficient of model fit should then be compared across spatial extents to estimate the scale of effect as the scale with the best model fit between the landscape context predictor and the ecological response (Figure 1c, d).

While this multi-scale study design can be used to estimate the scale of effect after the study has been completed, the sample size and thus the power of the study to detect landscape context effects would be higher if the scale of effect were known before the study was conducted. The set of selected landscapes should be non-overlapping at the scale of effect to avoid low cross-landscape variability in the predictor at that spatial extent, which would reduce the power to detect an effect (Pasher et al., 2013). If the scale of effect is unknown before the study is conducted, sample points need to be far enough apart to accommodate a multi-scale analysis (Figure 2a) such that the largest spatial extents evaluated are thought to be larger than the anticipated scale of effect. These larger spatial 
extents are necessary to account for the possibility that the scale of effect is larger than was anticipated a priori. This reduces the number of sample sites that can be visited, for a given sampling effort. In contrast, if the scale of effect is known in advance the number of sample sites can be maximized because sample sites need only be far enough apart to avoid overlapping landscapes at the true scale of effect (Figure 2b).

Authors assume the scale of effect can be selected a priori based on some attribute of the organism's movement scale, e.g. typical or maximum dispersal distance (Bowman, 2003) or typical or maximum territory size (e.g. Hendriks et al., 2009). However, there are several other factors that have been hypothesized to influence the scale of effect, including population density and various indirect effects such as predator-prey interactions (summarized in Miguet et al., 2016). Most of these hypotheses have not yet been tested.

One such hypothesis is that the scale of effect of the landscape depends on the temporal scale over which the response variable is regulated. In particular, it has been predicted that the scale of effect should be smallest for fecundity, larger for population abundance, larger still for occurrence, and largest for genetic diversity (Miguet et al., 2016). Fecundity is thought to be mainly affected by within-territory resource acquisition during a single season (Miguet et al., 2016), which is influenced over a short time scale and small spatial extent. Abundance is believed to be largely affected by reproduction and mortality in the population over one or two generations (Miguet et al., 2016) which occurs over a longer time scale and larger spatial extent. Occurrence is understood to be the result of longer-term and largerscale extinction-colonization dynamics which occur over even larger time scales and spatial extents (Miguet et al., 2016). Genetic diversity is influenced by infrequent long-distance movements that contribute new alleles to the population over many generations (Miguet et al., 2016) which represents the longest time scale and largest spatial extent of the response variables presented here. If true, this 
idea would mean that the scale of effect of the landscape context on a given species changes depending on the particular response variable measured.

We tested this hypothesis using wood frog (Lithobates sylvaticus) fecundity, abundance, and occurrence responses to the landscape context surrounding each of 34 ponds in Eastern Ontario, Canada. The landscape context predictor variables were proportion of the landscape in forest ('forest proportion') and road density $\left(\mathrm{km} / \mathrm{km}^{2}\right)$ in the landscapes. We predicted that the scale of effect of these landscape predictors would be smallest for fecundity, larger for abundance, and largest for occurrence. By using two landscape predictors, we also tested whether the order of the scale of effect (fecundity $<$ abundance < occurrence) is consistent across different predictor variables. The wood frog is an ideal species to test these predictions because it is relatively abundant in our region, its egg masses are relatively easy to identify and count, and its populations are known to respond to road density (negative response) and forest proportion (positive response) in the surrounding landscape (Findlay et al., 2001; Eigenbroad et al., 2009).

\section{Methods}

\section{Overview}

We carried out the study in Eastern Ontario, Canada, which is characterized by mixed hardwood forests, seasonal and permanently flooded wetlands, varying densities of roads that increase towards urban areas, and agricultural lands. We selected 34 ponds (mean area $1730 \mathrm{~m}^{2}$, range 149-6636 m²), within the known distribution of the wood frog, for which the surrounding landscapes represented gradients in road density and forest proportion. Each focal pond was surveyed for wood frog egg masses twice between April and May 2016. Wood frog masses are easily identifiable based on time period of laying, communal laying behaviour, their globular structure, and size of mass (Crouch \& Paton, 2000). Egg mass surveys were used to estimate fecundity, abundance, and occurrence at the survey ponds. We 
measured the two landscape context predictors (forest proportion and road density) at multiple spatial extents around each survey pond. We used general linear models to estimate the effect of each of the two landscape predictors on each of two responses (fecundity, abundance), and generalized linear models with a binomial distribution to estimate the effect of the two landscape context predictors on occurrence, at each spatial extent for the landscape context predictors. We then estimated the scale of effect for each predictor-response combination as the spatial extent with the smallest Akaike Information Criterion (AIC).

\section{Wood frog fecundity, abundance, and occurrence}

We surveyed for egg masses two times at each pond from April 13 to May 16 between $0900 \mathrm{~h}$ 18:00 $\mathrm{h}$. We surveyed three ponds per day, for $20 \mathrm{~min}$ to $2 \mathrm{~h}$ per survey depending on pond size and the number of egg masses present. We searched the ponds for egg masses by looking through the water's surface using polarized sunglasses. We started from the southern corner of the pond and we walked towards the northern corner of the pond moving back and forth across the pond until the entire pond had been surveyed. We used a double observer method to allow for estimates of detectability across observers (Grant et al., 2005). The pond was divided in half and observer 1 surveyed the first half for egg masses while observer 2 recorded the masses found by observer 1 and noted any masses missed by observer 1, without telling them. The observers then switched roles for the second half of the pond. Detectability was estimated as one minus (the number of egg masses not discovered by the primary observer (i.e. Observer 1 in the first half or Observer 2 in the second half of the pond) divided by the total number of masses present) then multiplied by one hundred, these values were then averaged across a total of eight observers throughout the sampling period.

When an egg mass was found by the primary observer, the egg mass was gently lifted from the water, placed in a plastic pouch and weighed to within $1 \mathrm{~g}$ using an AWS SR-1 hanging scale. The egg 
mass was then placed in an Ovagram (Karraker, 2007; Figure 3), which consisted of a flat-bottom plastic basin that contained the mass, and a second flat-bottom glass basin which was used to gently compress the egg mass such that individual eggs were distinguishable. A photograph was then taken of the compressed egg mass, using an Olympus Stylus TG-4 camera (Figure 3). Egg mass photos were uploaded to ImageJ, an open source image processing program (Schindelin et al., 2015). Eggs were counted using the Image "Multi-point" feature, where a point was manually placed on each egg in the photo. The software then tabulated the number of points present in the image.

Wood frog fecundity, abundance, and occurrence were estimated for each pond using the egg mass survey data from the visit with the most masses. Fecundity was the mean number of eggs per egg mass in a pond. We used the number of masses in a pond to index female abundance (Crouch \& Paton, 2000; Grant et al., 2005; Raithel et al., 2011). Occurrence was determined as presence/absence of egg masses in the pond.

\section{Site Selection and Landscape Variables}

We selected ponds such that their surrounding landscapes varied widely in road density, i.e. the total length of roads in the landscape divided by the landscape area. For pond selection road density was estimated within $1 \mathrm{~km}$ of the center of each pond, but for estimating the scale of effect, road density and forest proportion were calculated at each of 30 nested extents from $0.1 \mathrm{~km}$ to $3.0 \mathrm{~km}$ radii, in $0.1 \mathrm{~km}$ increments. Although landscapes were not selected to minimize the correlation between our two landscape context variables this correlation was $|r|<0.25$ at all spatial extents. Note that, because the extents were nested and the increment between scales was small $(0.1 \mathrm{~km})$, the landscape data at a given extent are highly correlated with the values at neighbouring extents. This leads to a smoothly increasing model fit with increasing extent, to the scale of effect, as more of the relevant landscape information is included in the predictor variable. This is followed by a gradual decrease in model fit, as 
irrelevant landscape information is added beyond the scale of effect (see Figure 1). We chose $3 \mathrm{~km}$ as the maximum extent to ensure that we included extents well beyond the dispersal range of the wood frog (Jackson \& Fahrig 2012, 2015). The estimated dispersal distance for wood frogs ranges from approximately 500 m (Groff et al., 2017) to 1000 m (Berven \& Gruidzien, 1990). We limited our initial selection of ponds to those having a road within $0.5 \mathrm{~km}$ and forest near the pond, to allow access to the pond and to ensure potential presence of a wood frog population (respectively). The pond data and forest data were provided by the Ontario Ministry of Natural Resources and Forestry. The road data were provided by Statistics Canada (Statistics Canada. Road Network File, 2011 Census). Mean road density across the 34 survey landscapes ranged from $1.6 \mathrm{~km} / \mathrm{km}^{2}$ to $5.3 \mathrm{~km} / \mathrm{km}^{2}$ depending on the spatial extent (Figure 4), and mean forest proportion ranged from 0.41 to 0.47 (Figure 5).

\section{Potentially Confounding Variables}

We measured local habitat variables that may influence wood frog fecundity, abundance, or occurrence at each sample pond. We intended to include any local variables that were correlated with our ecological response variables in the statistical models used to select the scales of effect (see Statistical Analysis, below). This is to avoid erroneously selecting a scale of effect where the apparent landscape context effect is not actually due to the landscape variable but rather to the effect of an important local variable that happens to be strongly correlated to the landscape variable at that particular extent. Water quality conditions, including dissolved oxygen, electrical conductivity, and water temperature, can influence the survival of developing embryonic and larval wood frogs (Babbit et al., 2006). Attachment sites for egg masses are important and are found in submerged and emergent vegetation in the pond, with egg masses unlikely to be found in areas with no such vegetation (Grant et al., 2005). Pond size, including area, perimeter, and depth, can influence survival (Rowe \& Dunson, 1995) as larger ponds support the presence of predatory fish (Raithel et al., 2011). 
We measured eight local habitat variables. Dissolved oxygen $(\mathrm{mg} / \mathrm{L})$ was measured once per pond during each visit using a LAQUA D-75 probe at approximately $15 \mathrm{~cm}$ below the water's surface and about 1-2 $\mathrm{m}$ from the pond edge. Electrical conductivity $(\mu \mathrm{S})$, temperature $\left({ }^{\circ} \mathrm{C}\right)$, and $\mathrm{pH}$ were measured once per pond during each visit using a Hannah Instruments probe at approximately $5 \mathrm{~cm}$ below the water's surface and 1-2 $\mathrm{m}$ from the pond edge. Pond depth $(\mathrm{cm})$ was measured using a meter stick placed in the deepest area of the pond as determined during the systematic egg survey (above). Emergent and submerged vegetation in each pond were visually estimated based on percent coverage of the pond: $0=0 \%, 1=1-10 \%, 2=11-25 \%, 3=25-50 \%, 4=51-75 \%, 6=>76 \%$ as per Grant et al. (2005). The pond perimeter and area were measured by walking the entire perimeter of the pond and saving the walked route on a Garmin GPSMAP 64st unit, which was later quantified in ArcGIS (ESRI 2011).

\section{Statistical Analysis}

We estimated six scales of effect, one for each combination of the two predictor variables (road density and forest proportion) and the three response variables (wood frog fecundity, abundance, and occurrence). To estimate the scale of effect for each combination, we modeled the relationship between the predictor at each of the 30 spatial extents and the response. We used a generalized linear model with a logit link function and binomial distribution for models of occurrence (presence/absence), and a general linear model with an identity link function with a Gaussian distribution. Although abundance and fecundity are count data, which is typically modeled with a Poisson distribution, we opted to use a Gaussian distribution for these variables because they were normally distributed (see Figure A, B in Appendix). The spatial extent with the strongest model fit, i.e. the lowest $\triangle A I C$ value, was determined to be the scale of effect for the given response-predictor combination.

To determine if local habitat variables affected our selection of the scales of effect, we measured Pearson's correlation between each of the eight local habitat variables and two of the three 
responses (fecundity and abundance) and used Spearman's rank correlation to compare the eight local habitat variables to occurrence. The strongest correlation found between a local habitat variable and ecological response was then included in the statistical models relating the response variables to the landscape variables, to determine if the local habitat variable affected the scales of effect of the landscape variables.

We used bootstrapping to obtain both $95 \%$ confidence intervals around the measures of model fit $(\triangle \mathrm{AIC})$ at each spatial extent and to estimate the uncertainty around the selected scales of effect. Bootstrapping involved sampling with replacement 34 landscapes from the set of 34 surveyed landscapes. We did this 1000 times to create 1000 re-sampled landscape sets. For each re-sampled landscape set, we estimated the scale of effect for each predictor-response combination as described above, resulting in 1000 estimates of the scale of effect for each predictor-response combination. To calculate the $\triangle \mathrm{AIC}$ for each bootstrapped sample at each extent, we calculated the difference between the strongest model, or estimated scale of effect for that bootstrap sample, $(\Delta \mathrm{AIC}=0)$ and the remaining models that included landscape measures from the other 29 spatial extents. We calculated mean $\triangle \mathrm{AIC}$ and $95 \%$ confidence interval for a given predictor-response combination at each spatial extent from these 1000 re-sampled datasets. For each of the 1000 resamples we also recorded the scale of effect as the spatial extent with the lowest $\Delta \mathrm{AIC}$. We then summed the total number of times that each spatial extent was selected as the scale of effect.

\section{Results}

The number of sites included in each analysis varied based on the response because egg masses were found at only 21 of the 34 sites. Occurrence (presence-absence of egg masses) was measured at all 34 sites. Abundance (number of egg masses) was measured for the 21 sites where egg masses were found. The number of wood frog egg masses varied from 1 to 401 across these 21 sites. Fecundity was 
measured only at 17 sites because not all egg masses could be use in the fecundity estimates. For some egg masses individuals had begun emerging by the time the mass was found. These could not be included in the measure of fecundity (number of eggs per egg mass) because the number of missing individuals was unknown. Fecundity was estimated for the 17 sites where at least one intact egg mass was found. Fecundity ranged from an average of 266 eggs per mass to 1220 eggs per mass across these 17 sites. The mean detectability of egg masses by all eight observers was an $88 \%$ likelihood of detection across all surveys, which were two per pond carried out by two observers, where at least one wood frog egg mass was found.

While the estimated scale of effect varied depending on the response variable, it did not vary in the order we predicted (fecundity < abundance < occurrence). Instead it varied in the order: abundance $<$ occurrence < fecundity. The strongest effect of road density on wood frog fecundity was positive and occurred within a spatial extent of $2.1 \mathrm{~km}\left(R^{2}=0.28, p=0.03\right.$; Figure 6$)$, for abundance the strongest effect was negative and occurred within a spatial extent of $0.4 \mathrm{~km}\left(R^{2}=0.11, p=0.15\right.$; Figure 7$)$, and for occurrence the strongest effect was negative and occurred within a spatial extent of $0.7 \mathrm{~km}$ (Nagelkerke's $R^{2}=0.22, p=0.04 ;$ Figure 8).

The estimated scale of effect for forest proportion also did not vary in the predicted order, instead it varied in the order: fecundity < occurrence $<$ abundance. The strongest effect of forest proportion on wood frog fecundity was negative and occurred within a spatial extent of $0.2 \mathrm{~km}\left(\mathrm{R}^{2}=\right.$ 0.53, $p=0.001$; Figure 9), for abundance the strongest effect was positive and occurred within a spatial extent of $2.6 \mathrm{~km}\left(R^{2}=0.30, p=0.01 ;\right.$ Figure 10), and for occurrence the strongest effect was positive and occurred within a spatial extent of $0.4 \mathrm{~km}$ (Nagelkerke's $\mathrm{R}^{2}=0.12, \mathrm{p}=0.1$; Figure 11).

The local habitat variables with strongest correlations to the response variables were further examined to determine if they could potentially lead to incorrect estimates of the of scales of effect 
given that variables were strongly correlated which suggests they would have the most noticeable effect. These local variables were; electrical conductivity for fecundity $(r=0.48)$, submergent and emergent pond vegetation for abundance $(r=0.43)$, and dissolved oxygen for occurrence ( $r$ o $=-0.38$ ) We included these variables in a second set of analyses as above but these included both the local habitat variable and landscape context predictor. The selected scales of effect for these analyses were not different, for five of the six predictor-response combinations, from the selected scales of effect for the analyses that included only the landscape predictor. The estimated scale of effect for road density on fecundity was slightly smaller than when the local habitat variable was included compared to when it was not; however, this did not change the order of the responses. Thus, the local habitat variables did not confound the selected scales of effect and were not included in the bootstrapping analysis (see Table 3, 4 in Appendix)

\section{Discussion:}

Our findings do not support the hypothesis that the scale of effect of landscape context increases with the timescale over which the response variable is regulated. Although the estimated scales of effect varied among the response variables, they did not vary in the predicted order, i.e. scale of effect for fecundity < abundance < occurrence. Instead, for road density the order of the scales of effect was abundance < occurrence $<$ fecundity, and for forest proportion the order of the scales of effect was fecundity < occurrence < abundance. We had expected that the timescale regulating a given response, relative to a given landscape context predictor, would affect the ability of individuals to disperse within a landscape and thus influence the resulting scale of effect. However, the order of the scales of effect were not only different from the predicted order but also different between the two landscape context predictors.

Another possible reason why our data do not support the hypothesis may be due to interactions between the response variables, which would obscure the differences in their relative scales. This is 
suggested by the fact that fecundity was positively related to road density and negatively related to forest amount (i.e. opposite to expected, and opposite to these relationships for abundance and occurrence). This could indicate a negative density-dependent effect of abundance on fecundity, which would obscure the expected difference between the two in their temporal scales of regulation. This is supported by an experimental study examining wood frog populations, which found that higher densities lead to delayed onset of sexual maturity and smaller individual egg masses (Harper \& Semlitsch, 2007).

However, this explanation seems unlikely. If the effects of the landscape variables on fecundity are indirect effects through their effects on population density, then we should have seen the same scale of effect of these landscape variables for both abundance and fecundity. We did not see this. What we found were largely different estimated scales of effect for fecundity and abundance when compared to either road density or forest proportion. This would suggest that there likely is another, or several, factors that are yet still contributing to the observed effects of road density and forest proportion on fecundity that were opposite to what was intuitively predicted.

There are several studies which provide support for the observed negative effects of road density on wood frog abundance and occurrence found in our study from direct of effects of road use by humans and through changes to the surrounding landscape due to road presence. Increasing road density in the landscape leads to greater road mortality of dispersing individuals (Eigenbroad et al., 2009) and causes avoidance along high traffic roads with these effects contributing to habitat patch isolation, thus limiting dispersal in these areas (Crosby et al., 2009; Gravel et al., 2012). Higher road density is connected to increased conductivity with changes to $\mathrm{pH}$ and dissolved oxygen in surrounding wetlands caused by runoff from the roads, a main source being the municipal application of salt. When there is any or all of high conductivity with low $\mathrm{pH}$ and dissolved oxygen there is lower survival rates in larval and juvenile wood frogs (Milotic et al., 2017). These studies would suggest that wood frog survival 
and dispersal is decreased in landscapes with greater road density which would lead to observed negative effects to wood frog abundance and occurrence.

Forested areas act as important foraging and dispersal habitat for the wood frog as this species is likely to be found in forested areas surrounding vernal ponds after the breeding period. This would suggest that forest, other than freshwater wetlands, is the preferred habitats for this species (Regosin et al., 2003). A critical threshold study by Homan et al. (2004) suggests that wood frogs require high forest cover near vernal pools at around $90 \%$ cover to avoid adverse effects to the population, while this requirement decreases with increasing distance from the pond edge. In order to avoid desiccation during the driest portions of the year wood frogs will persist in moisture-containing habitat like sphagnum mosses, deep leaf litter, and similar forms of forest floor recluses found in forested areas (Baldwin et al., 2006). It would seem that wood frogs rely on forested areas in order to persist and complete their life cycle with decreases in forest proportion likely connected negative outcomes for the population, which we observed with positive effect of forest presence for abundance and occurrence.

Although the ranking of the scales of effect was not consistent with our predicted ranking, the scales of effect did vary substantially depending on the response variable measured, and the ranking differed between the two landscape context predictor variables with previous studies provide some support for this finding. For example, a study of urbanization effects on the spotted salamander (Ambystoma maculatum) found that species occurrence was best predicted with a model that contained road length measured at $1 \mathrm{~km}$, whereas population abundance was best predicted with a model that contained road length measured at $0.3 \mathrm{~km}$ (Clark et al., 2008). Similarly, in a study of forest effects on the European common frog (Rana temporaria), researchers found species occurrence was most strongly affected by forest amount at $400 \mathrm{~m}$, and population abundance was most strongly affected by forest amount at $1000 \mathrm{~m}$ (Boissinot et al., 2015). Our conclusion is further supported by comparing the scales of effect identified for wood frogs in different studies that used different response variables. For 
example, studies show varying scales of effect of road density on wood frog abundance ranging from 0.3 km to $1 \mathrm{~km}$ (Veysey et al., 2011; Homan et al., 2004) and forest proportion on wood frog abundance, and occurrence ranging from $0.2 \mathrm{~km}$ to $2 \mathrm{~km}$ (Porej et al., 2004; Hermann et al., 2005; Clark et al., 2008).

One might imagine that the lack of support for our prediction occurred because we did not include a wide enough range of spatial extents to encompass the scales of effect for all responses; however, this is unlikely. We measured spatial extents from $0.1 \mathrm{~km}$ to $3.0 \mathrm{~km}$ and used a fine resolution of extents in $0.1 \mathrm{~km}$ increments to accurately estimate the scale of effect. Moreover, none of the predictor-response relationships were strongest at the smallest or largest tested extents, suggesting that the scales of effect were between the smallest and largest extent measured (see Jackson and Fahrig 2015; Figure 6 to Figure 11). Even if the range of scales is sufficient and the species does show a response to the landscape context variables, there might be very little evidence for definite scales of effect, which would again result in arbitrary scales selected. This was the reason we conducted the bootstrap estimate of uncertainty around the scales of effect. The results demonstrated high confidence around the selected scales (Figure 6 to Figure 11) through a convergence of extents selected as the scale of effect during the bootstrap around the estimated scales of effect.

One might also argue that the landscape context variables did not actually affect the response, leading to arbitrarily estimated scales of effect. However, this is not the case in our study. We found statistically significant $(p<0.05)$ effects of road density/forest proportion for four of the six predictorresponse combinations (see Table 1 in Appendix). These results are also consistent with previous studies, which found significant effects of both forest proportion (positive) and road density (negative) on wood frog abundance and occurrence (Findlay et al., 2001; Homan et al., 2004; Porej et al., 2004; Herrmann et al., 2005; Clark et al., 2008; Veysey et al., 2011). These known effects were in fact one reason why we selected the wood frog as our study species. 
It remains possible that, for a given landscape predictor, the rank order of the scales of effect for different ecological responses is consistent across species or species group. For organisms which share similar dispersal patterns and/or life histories it seems likely that the effect of a landscape predictor consistently impacts the population response(s) due to their common habitat use and dispersal patterns. For example, roads create a barrier to dispersal and lead to direct mortality in dispersing wood frogs but would likely have similar effects on other anuran species. In fact, other multi-scale studies have estimated the same order for scales of effect of road density and forest amount on amphibian abundance and occurrence as we did, i.e. scale of effect of road density abundance < occurrence and the scale of effect of forest amount on occurrence < abundance. Clark et al. (2008) found the scale of effect of road density on A. maculatum abundance < occurrence, and Boissinot et al. (2015) found the scale of effect of forest amount on $R$. temporaria occurrence $<$ abundance. This provides at least preliminary support for an interaction between the response type and the landscape context predictor, as the order for scale of effect on abundance and occurrence seems to be consistent for a given predictor across the three amphibian species.

\section{Conclusions}

This result - that the same species can show very different scales of effect depending on the response variable and depending on the landscape context predictor variable - has important

implications for land management and landscape ecological research. Land management decisions could be better informed if based on range of spatial extents that capture known effects instead of a discrete scale of effect for a single response and/or predictor that might not encompass the range of potential effects. Future multi-scale studies are needed to determine whether our findings are generalizable to other taxa, study systems, and landscape predictors. Unless it turns out that wood frogs are an exception, it appears that predicting the scale of effect $a$ priori is likely impossible, due to the multitude of interacting factors thought to influence scale of effect, as suggested by Miguet et al. (2016). Thus, we 
recommend that future research should empirically estimate the scale of effect with a multi-scale focal site study whenever possible. 


\section{References:}

Babbit, K.J., M.J. Baber, and L.A. Brandt. 2006. The effect of woodland proximity and wetland characteristics on larval anuran assemblages in an agricultural landscape. Canadian Journal of Zoology, 84(4):510-519

Baldwin, R.F., A.J.K. Calhoun, and P.G. deMaynadier. 2006. Conservation planning for amphibian species with complex habitat requirements: a case studying using movements and habitat selection of the wood frog Rana sylvatica. Journal of Herpetology, 40(4):442-453

Boissinot, A., P. Grillet, A. Besnard, and O. Lourdais. 2015. Small words positively influence the occurrence and abundance of the common frog (Rana temporaria) in a traditional farming landscape. Amphibia-Reptilia, 36(4):417-424

Berven, K.A., and T.A. Gruidzien. 1990. Dispersal in the wood frog (Rana sy/vatica): implications for genetic population structure. Evolution, 44(8):2047-2056

Bowman, J. 2003. Is dispersal distance of birds proportional to territory size? Canadian Journal of Zoology, 81:195-202

Burel, F., and J. Baudry. 2005. Habitat quality and connectivity in agricultural landscapes: the role of land use systems at various scales in time. Ecological Indicators, 5:305-313

Brennan, J.M., D.J. Bender, T.A. Contreras, and L. Fahrig. 2002. Focal patch landscape studies for wildlife management: optimizing sampling effort across scales. Integrating landscape ecology into natural resource management (ed. by J. Liu and W.W. Taylor), pp. 68-91. Cambridge University Press, Cambridge. 
Clark, P.J., J.M. Reed, B.G. Tavernia, B.S. Windmiller, and J.V. Regosin. 2008. Urbanization effects on spotted salamander and wood frog presence and abundance for the study of amphibians and reptiles. Herpetological Conservation and Biology, 3:67-75

Crosby, M.K.A., L.E. Licht, and J. Fu. 2009. The effect of habitat fragmentation on finescale population structure of wood frogs (Rana sylvatica). Conservation Genetics, 10(6):1707-1718

Crouch, W.B., and P.W.C. Paton. 2000. Using egg-mass counts to monitor wood frog populations. Wildlife Society Bulletin, 28(4):895-901

Dananay, K.L., K.L. Krynak, T.J. Krynak, and M.F. Bernard. 2015. Legacy of road salt: apparent positive larval effects counteracted by negative post metamorphic effects in wood frogs. Environmental Toxicology, 34(10):2417-2424

Eigenbrod, F., S.J. Hecnar, and L. Fahrig. 2009. Quantifying the road-effect zone: threshold effects of a motorway on anuran population in Ontario, Canada. Ecology and Society, 14(1):24

ESRI 2011. ArcGIS Desktop: Release 10. Redlands, CA: Environmental Systems Research Institute

Findlay, C.S., J. Lenton, and L. Zheng. 2001. Land-use correlates of anuran community richness and composition in southeastern Ontario wetlands. Ecoscience, 8(3):336-343

Fischer, J., D.B. Lindenmayer, and A. Cowling. 2004. The challenge of managing multiple species at multiple scales: reptiles in an Australian grazing landscape. Journal of Applied Ecology, 41:32-44

Grant, E.H.C., R.E. Jung, J.D. Nichols, and J.E. Hines. 2005. Double-observer approach to estimating egg mass abundance of pool-breeding amphibians. Wetlands Ecology and Management, $13: 305-320$ 
Gravel, M., M.J. Mazerolle, and M.A. Villard. 2012. Interactive effects of roads and weather on juvenile amphibian movements. Amphibia-Reptilia, 33:113-127

Groff, L.A., A.J.K. Calhoun, and C.S. Loftin. 2017. Amphibian terrestrial habitat selection and movement patterns vary with annual life-history period. Canadian Journal of Zoology, 95:433-442

Harper, E.B., and R.D. Semlitsch. 2007. Density dependence in the terrestrial life history stage of two anurans. Oecologia, 153:879-889

Hendriks, A.J., B.J.C. Willers, H.J.R. Lenders, and R.S.E.W. Leuvan. 2009. Towards a coherent allometric framework for individual home ranges, key population patches and geographic ranges. Ecography, 32:929-942

Herrmann, H.L., K.J. Babbit, M.J. Baber, and R.G. Congalton. 2005. Effects of landscape characteristics on amphibian distribution in a forest-dominated landscape. Biological Conservation, $123: 139-149$

Holland, J.D., D.G. Bert, and L. Fahrig. 2004. Determining the spatial scale of species' response to habitat. BioScience, 54(3):227-233

Homan, R.N., B.S. Windmiller, and J.M. Reed. 2004. Critical thresholds associated with habitat loss for two vernal pool-breeding amphibians. Ecological Applications, 14(5):1547-1553

Jackson, H.B., and L. Fahrig. 2012. What size is a biologically relevant landscape? Landscape Ecology, 27:929-941

Jackson, H.B., and L. Fahrig. 2015. Are ecologists conducting research at the optimal scale? Global Ecology and Biogeography, 24:52-63 
Jackson, N.D., and L. Fahrig. 2014. Landscape context affects genetic diversity at a much larger spatial extent than population abundance. Ecology, 95:871-881

Karraker, N.E. 2007. A new method for estimating clutch sizes of ambystomatid salamanders and ranid frogs: introducing the Ovagram. Herpetological Review, 38(1):46-48

Miguet, P., H.B. Jackson, N.D. Jackson, A.E. Martin, and L. Fahrig. 2016. What determines the spatial extent of landscape effects on species? Landscape Ecology, 31:1177-1194

Milotic, D., M. Milotic, and J. Koprivnikar. 2017. Effects of road salt on larval amphibian susceptibility to parasitism through behaviour and immunocompetence. Aquatic Toxicology, 189:42-49

Pasher, J., S.W. Mitchell, D.J. King, L. Fahrig, A.C. Smith, and K.E. Lindsay. Optimizing landscape selection for estimating relative effects of landscape variables on ecological response. Landscape Ecology, 28(3):371-383

Porej, D., M. Micacchion, and T.E. Hetherington. 2004. Core terrestrial habitat for conservation of local populations of salamanders and wood frogs in agricultural landscapes. Biological Conservation, $120: 399-409$

Prach, K., and K. Rehounkova. 2006. Vegetation succession over broad geographical scales: which factors determine the patterns? Presclia, 78:469-480

R Development Core Team. 2008. R: a language and environment for statistical computing. $R$ Foundation for statistical computing, Vienna, Austria. ISBN 3-900051-07-0, URL http://www.Rproject.org

Raithel, C.J., P.W.C. Paton, P.S. Pooler, and F.C. Golet. 2011. Assessing long-term population trends of wood frogs using egg-mass counts. Journal of Herpetology, 45(1):23-27 
Regosin, J.V., B.S. Windmiller, and J.M. Reed. 2003. Terrestrial habitat use and winter densities of the wood frog (Rana sy/vatica). Journal of Herpetology, 37:390-394

Rowe, C.L., and W.A. Dunson. 1995. Impacts of hydroperiod on growth and survival of larval amphibians in temporary ponds of Central Pennsylvania, USA. Oceologia, 102:397-403

Schindelin, J., C.T. Rueden, M.C. Hiner, and K.W. Eliceiri. 2015. The ImageJ ecosystem: an open platform for biomedical image analysis. Molecular Reproduction and Development, 82:518-529

Thornton, D.H., L.C. Branch, and M.E. Sunquist. 2011. The influence of landscape, patch, and within-patch factors on species presence and abundance: a review of focal patch studies. Landscape Ecology, 26:7-18

Veysey, J.S., S.D. Mattfeldt, and K.J. Babbit. 2011. Comparative influence of isolation, landscape, and wetland characteristics on egg-mass abundance of two pool-breeding amphibian species. Landscape Ecology, 26:661-672

With, K.A. 2004. Assessing the risk of invasive spread in fragmented landscapes. Risk analysis, 24(4):803-815 
a)

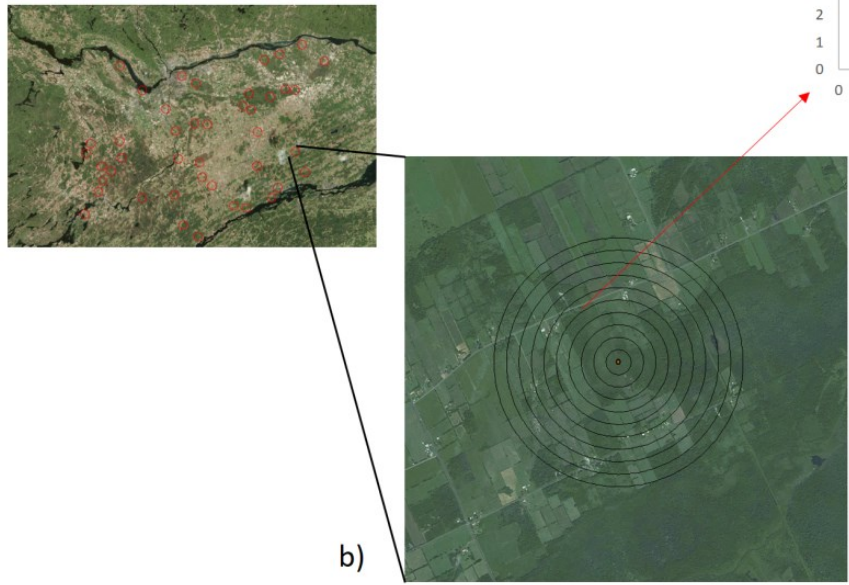

c)

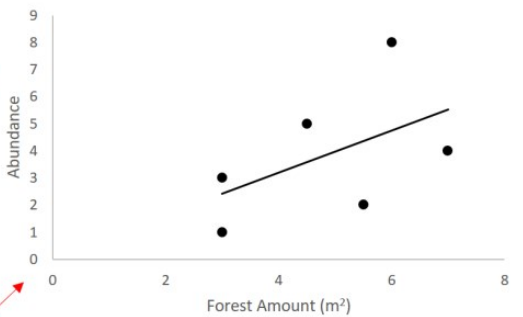

d)

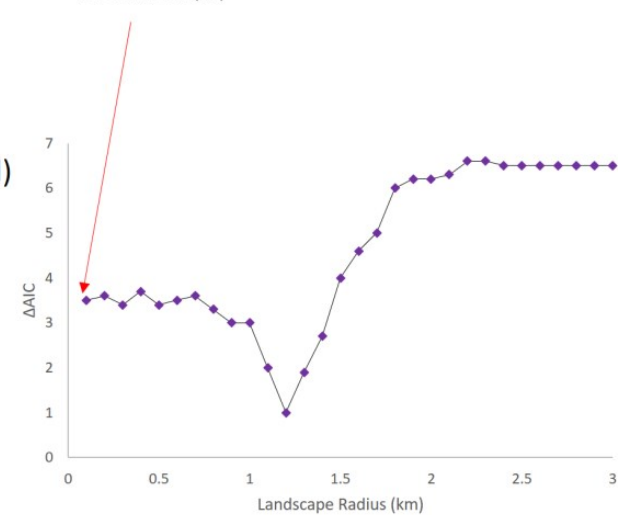

Figure 1: Example showing how to empirically estimate the scale of effect using a multi-scale focal sample site study design. a) Select a set of landscapes that vary in the predictor (e.g. forest amount). Each landscape is centered on a focal sample site. Landscapes should be non-overlapping at the largest likely scale of effect. b) Measure the ecological response at the focal sample sites (point in the center of each landscape). Measure the landscape context predictor variable within multiple spatial extents around each focal site. c) Calculate model fit from a regression of the ecological response measured at the focal sample sites on the landscape context predictor measured at a given spatial extent, and repeat for each spatial extent. d) Compare the model fits across spatial extents and estimate the scale of effect as the spatial extent with the best model fit (here, lowest $\Delta \mathrm{AIC}$ ) 

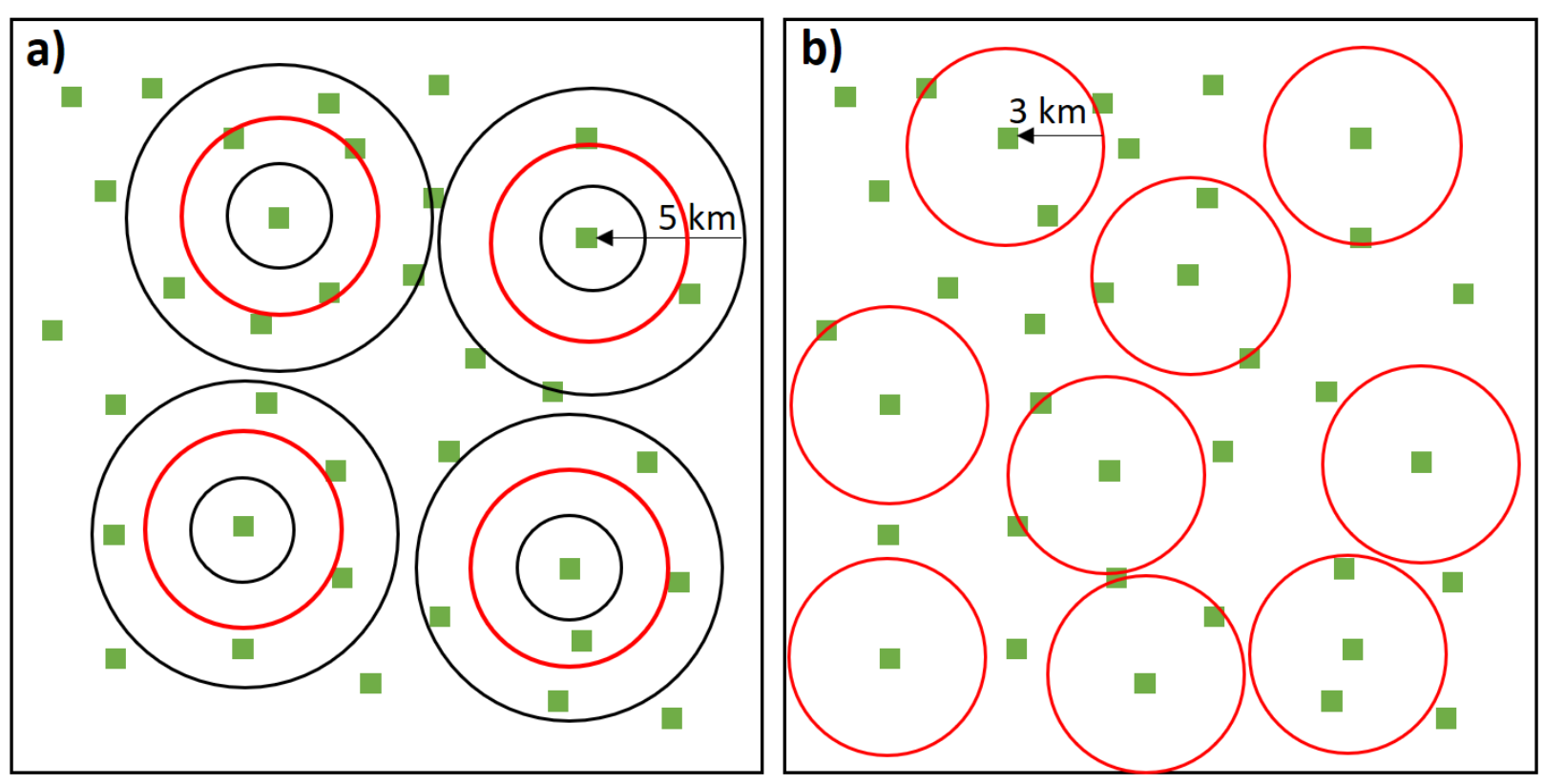

Figure 2: Knowledge of the scale of effect a priori allows researchers to maximize the number of nonoverlapping landscapes sampled within a region. The green squares represent habitat, the white areas represent matrix, the red circles represent the estimated scale of effect, the black circles represent multiple spatial extents tested that were not the scale of effect. a) When the scale of effect is not known the landscapes must be non-overlapping at the largest extent believed to possibly influence the ecological response. However, b) when the scale of effect is known a priori then landscapes need only be large enough to encompass the true scale of effect. This allows for more non-overlapping landscapes to be sampled in a region, thus increasing the sample size and the power of the study 


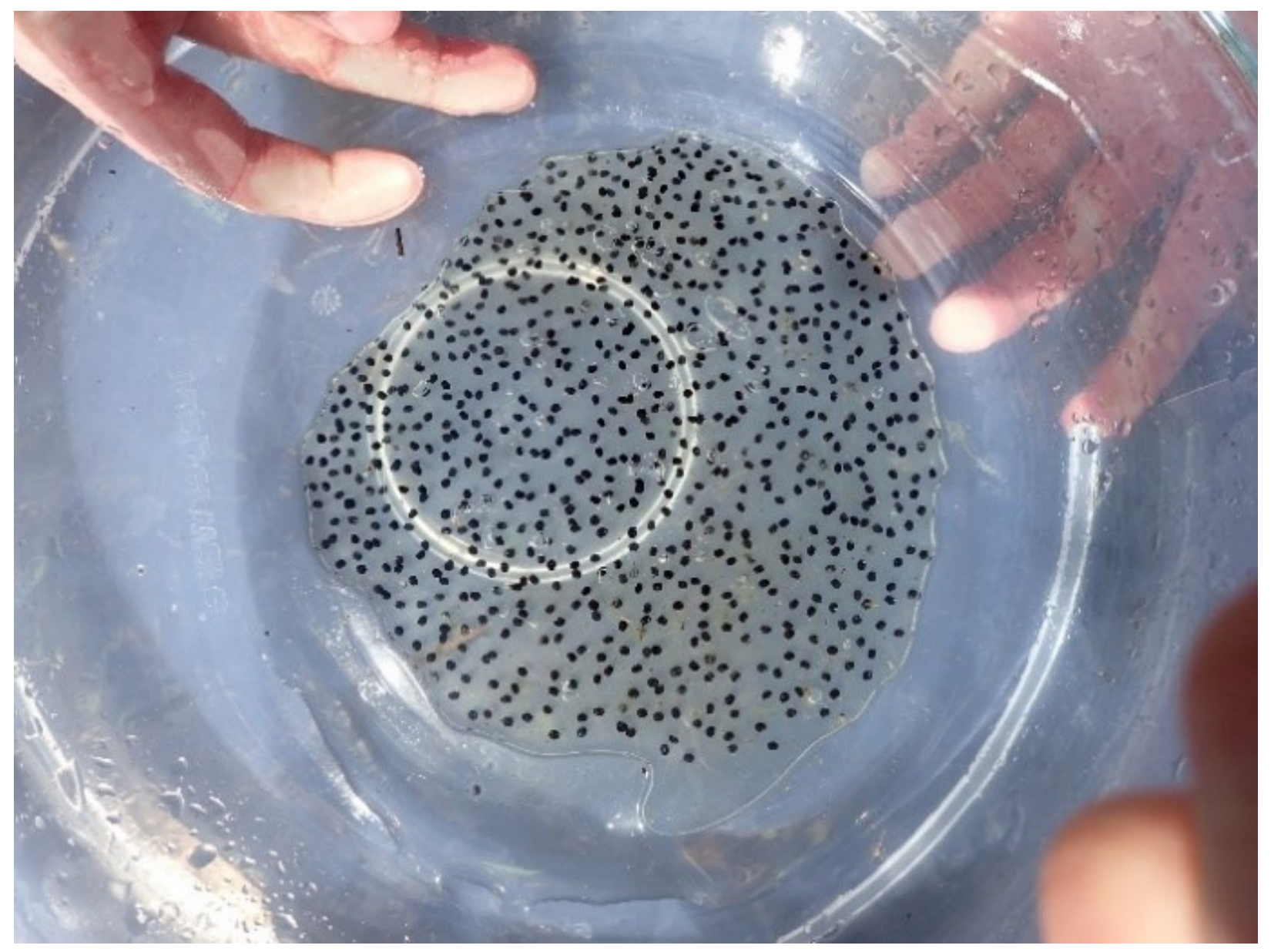

Figure 3: Wood frog fecundity was estimated using an Ovagram. Each egg mass was gently compressed between two transparent basins, a photograph was taken (example shown) and the egg mass was then returned unharmed to the pond. The number of eggs in each egg mass was counted from the photos. 


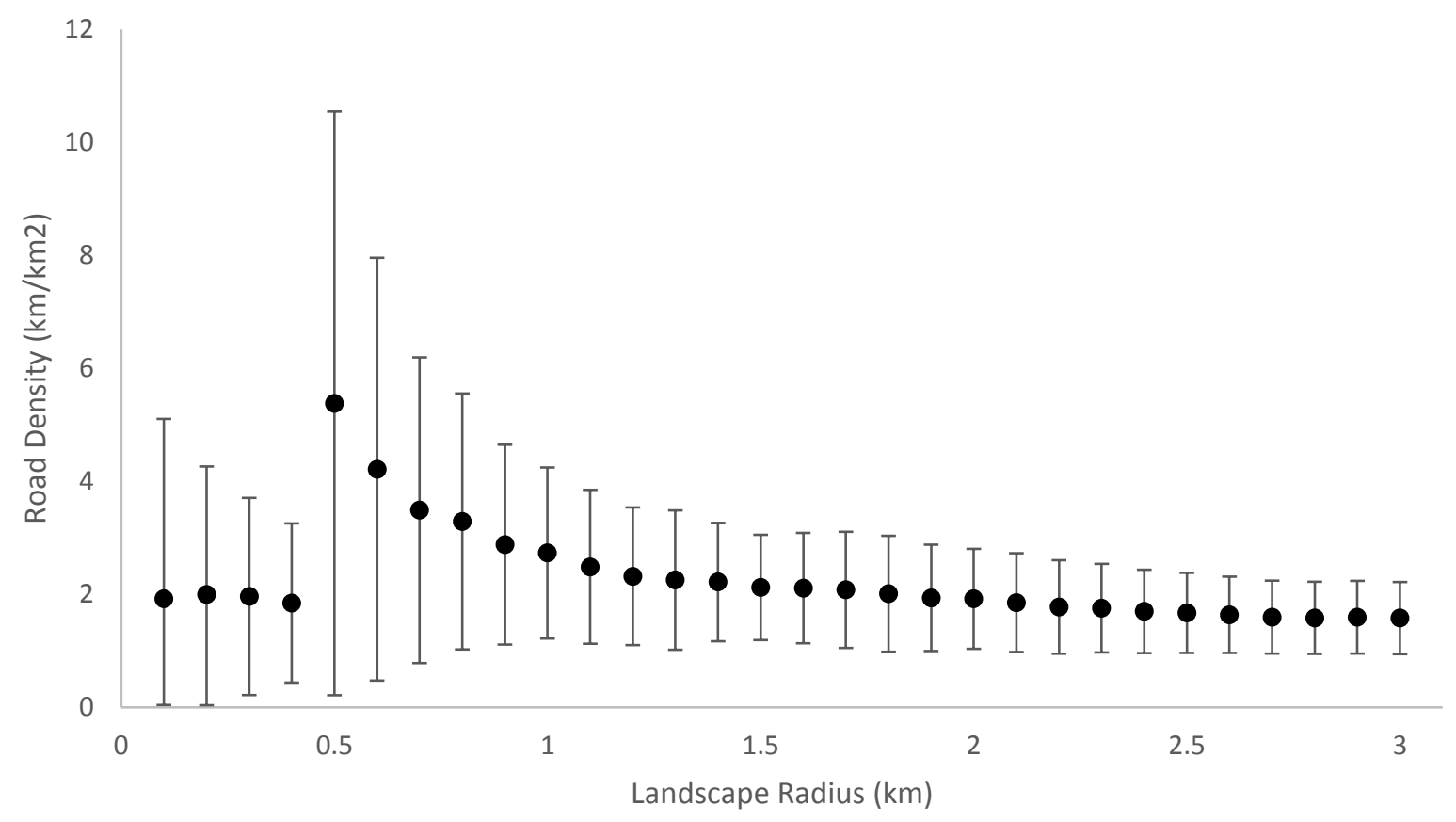

Figure 4: Mean and variation (SD) of road density in the landscape surrounding sampled ponds $(n=34)$ in $\mathrm{km} / \mathrm{km}^{2}$, measured at each of 30 spatial extents from $0.1 \mathrm{~km}$ to $3.0 \mathrm{~km}$ in 0.1 increments, for ponds found in Eastern Ontario, Canada 


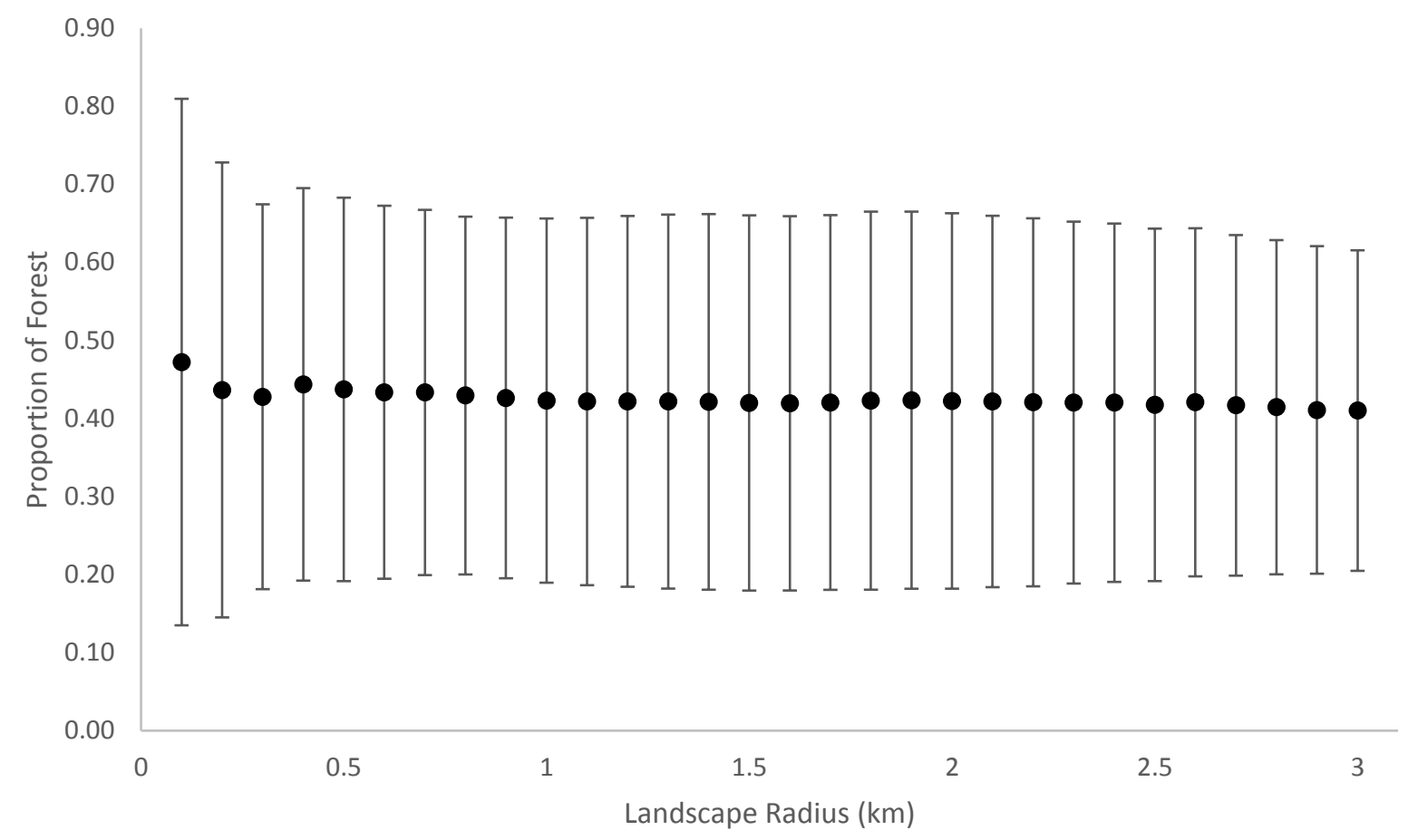

Figure 5: Mean and variation (SD) of proportion of forest in the landscape surrounding sampled ponds $(\mathrm{n}=34)$, measured at each of 30 spatial extents (radius in $\mathrm{km}$ ), for ponds found in Eastern Ontario, Canada 


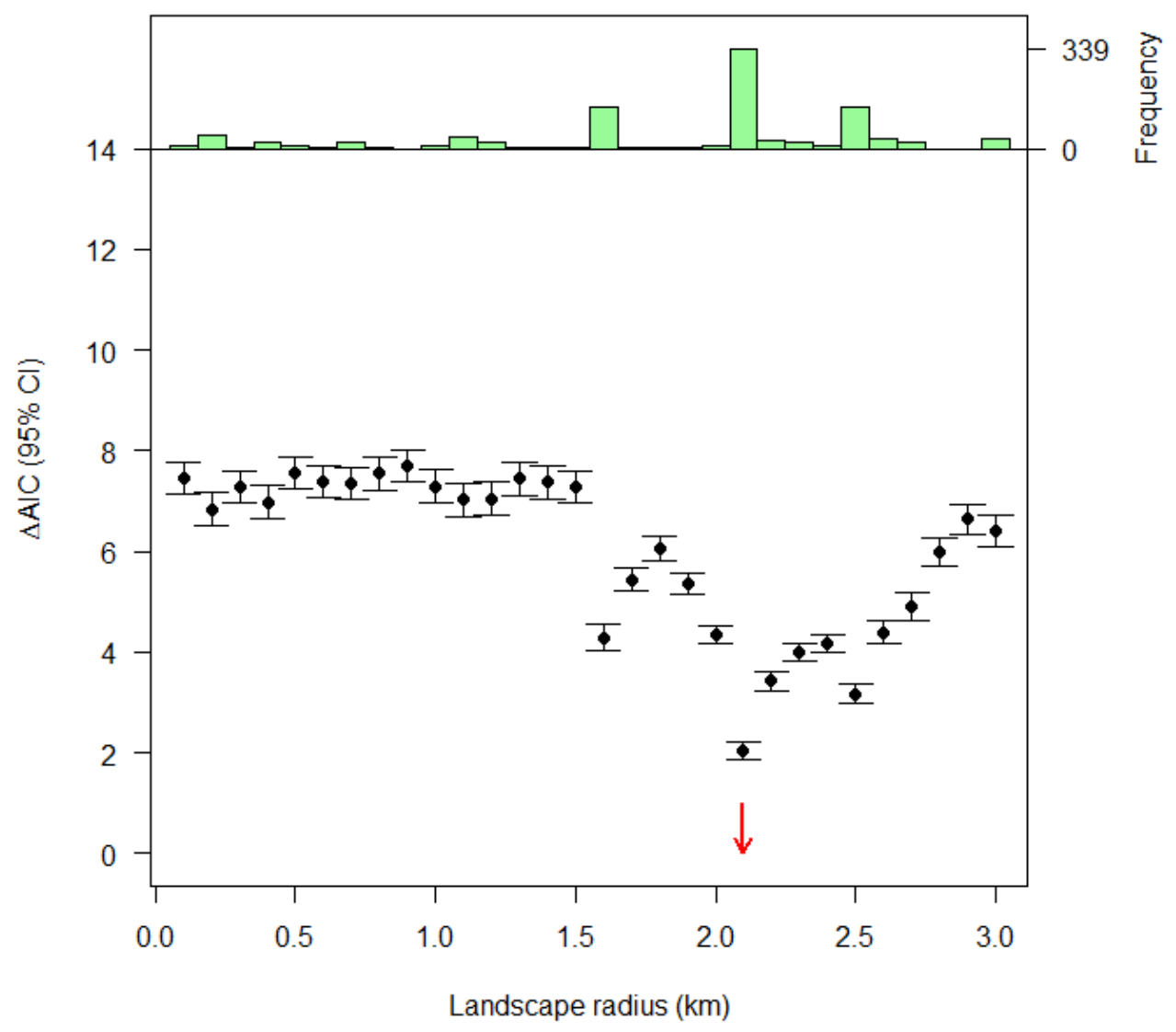

Figure 6: Model fit for generalized linear models relating wood frog fecundity measured in 17 wetlands to road density measured in the surrounding landscapes at each of 30 spatial extents $(0.1$ to $3.0 \mathrm{~km}$ radius from the centers of the sampled ponds). We estimated model fit as the mean $\triangle \mathrm{AIC}$ and $95 \%$ confidence interval for each spatial extent, based on 1000 bootstrapped samples. To calculate the $\Delta$ AIC for each bootstrapped sample at each extent, we calculated the difference between the strongest model, or estimated scale of effect for that bootstrap sample, $(\triangle \mathrm{AIC}=0)$ and the remaining models including landscape measures from the other 29 spatial extents. The estimated scale of effect is indicated with a red arrow and is based on the full complement of bootstrapped samples. The frequency histogram shows the distribution of 1000 estimated scale of effect from the bootstrapped samples described above 


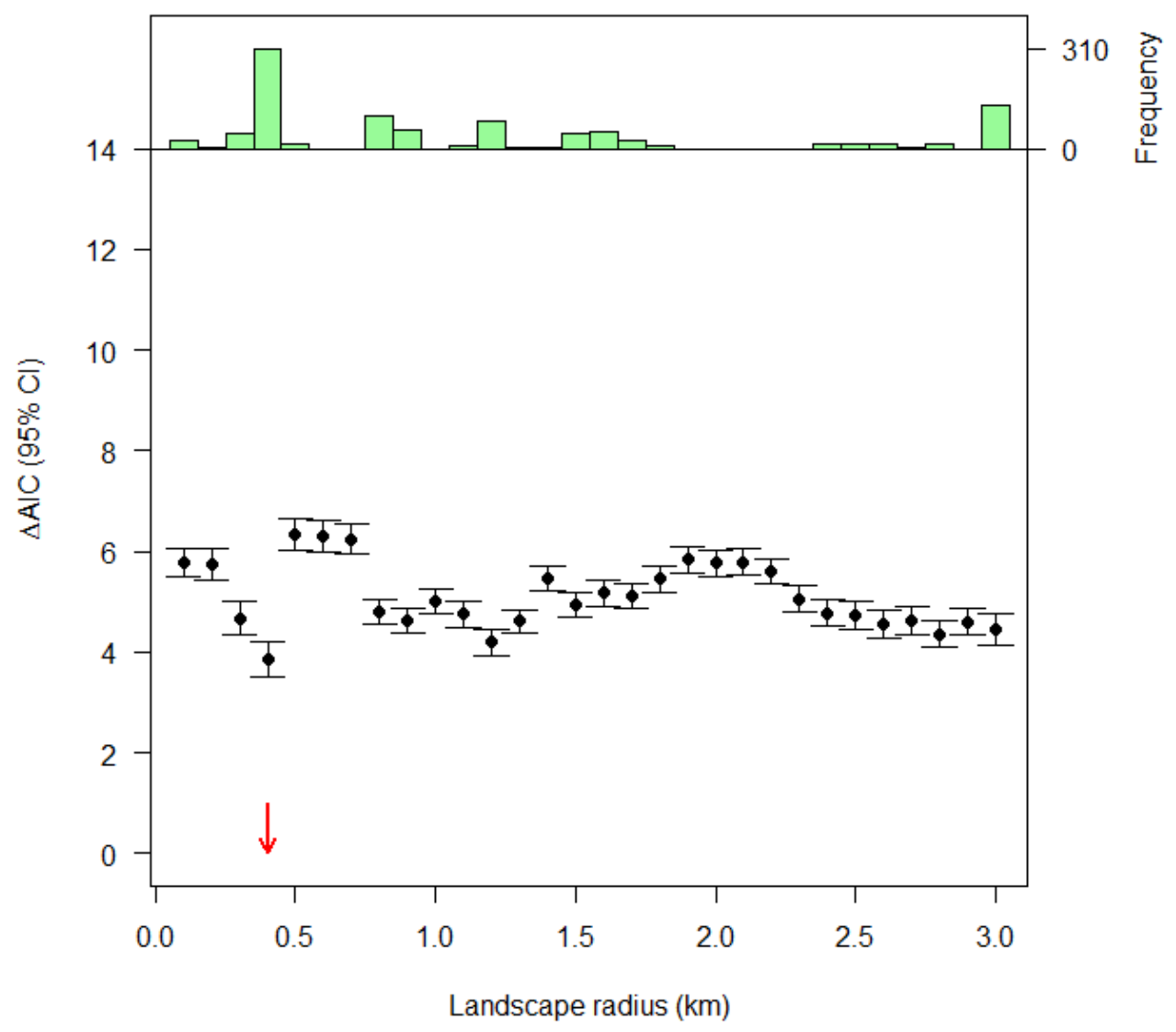

Figure 7: Model fit for generalized linear models relating wood frog abundance measured in 21 wetlands to road density measured in the surrounding landscapes at each of 30 spatial extents $(0.1$ to $3.0 \mathrm{~km}$ radius from the centers of the sampled ponds). We estimated model fit as the mean $\triangle \mathrm{AIC}$ and $95 \%$ confidence interval for each spatial extent, based on 1000 bootstrapped samples. To calculate the $\Delta$ AIC for each bootstrapped sample at each extent, we calculated the difference between the strongest model, or estimated scale of effect for that bootstrap sample, $(\triangle \mathrm{AIC}=0)$ and the remaining models including landscape measures from the other 29 spatial extents. The estimated scale of effect is indicated with a red arrow and is based on the full complement of bootstrapped samples. The frequency histogram shows the distribution of 1000 estimated scale of effect from the bootstrapped samples described above 


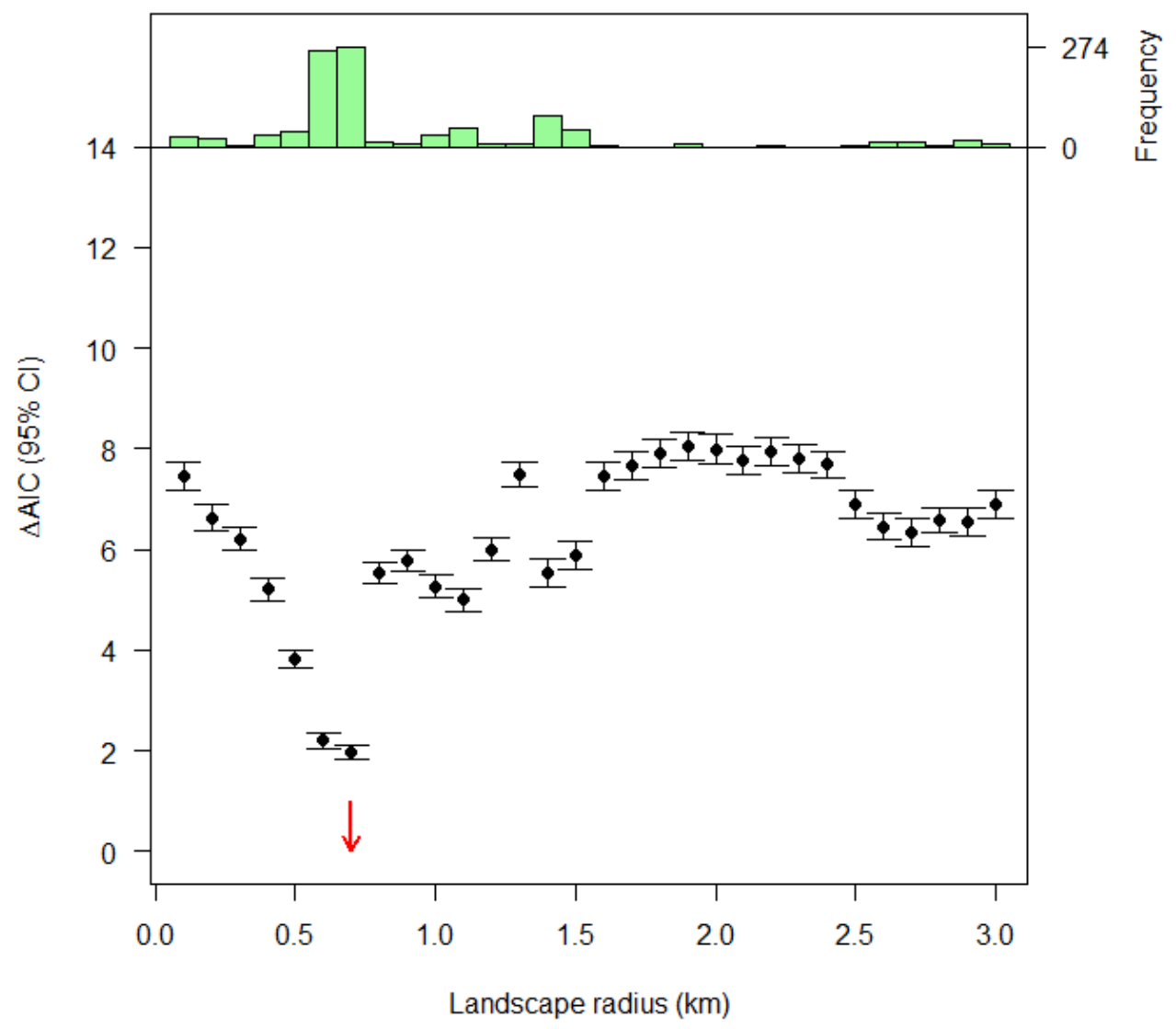

Figure 8: Model fit for generalized linear models relating wood frog occurrence measured in 34 wetlands to road density measured in the surrounding landscapes at each of 30 spatial extents $(0.1$ to $3.0 \mathrm{~km}$ radius from the centers of the sampled ponds). We estimated model fit as the mean $\triangle \mathrm{AIC}$ and $95 \%$ confidence interval for each spatial extent, based on 1000 bootstrapped samples. To calculate the $\Delta$ AIC for each bootstrapped sample at each extent, we calculated the difference between the strongest model, or estimated scale of effect for that bootstrap sample, $(\triangle \mathrm{AIC}=0)$ and the remaining models including landscape measures from the other 29 spatial extents. The estimated scale of effect is indicated with a red arrow and is based on the full complement of bootstrapped samples. The frequency histogram shows the distribution of 1000 estimated scale of effect from the bootstrapped samples described above 


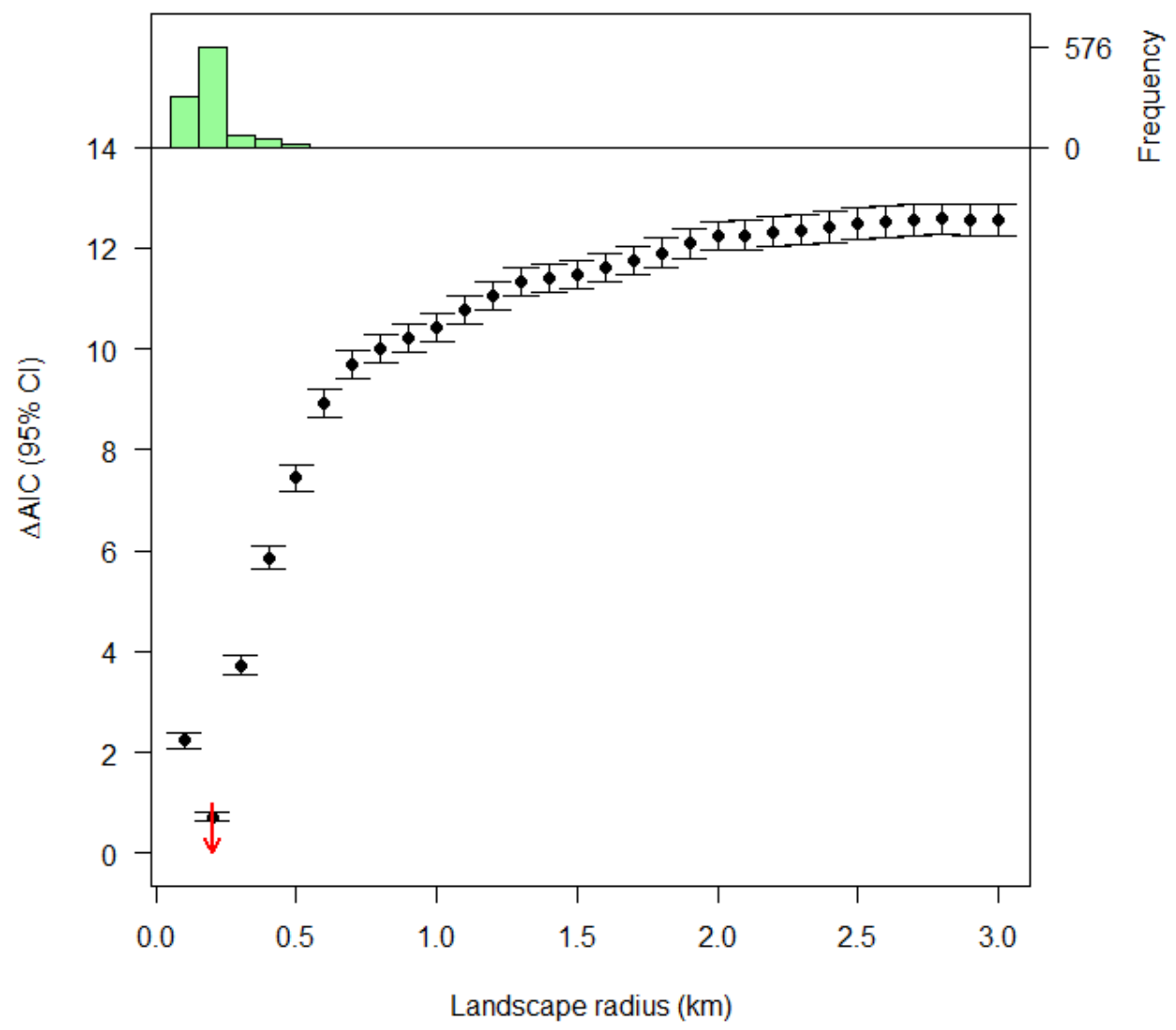

Figure 9: Model fit for generalized linear models relating wood frog fecundity measured in 17 wetlands to forest proportion measured in the surrounding landscapes at each of 30 spatial extents $(0.1$ to $3.0 \mathrm{~km}$ radius from the centers of the sampled ponds). We estimated model fit as the mean $\triangle \mathrm{AIC}$ and $95 \%$ confidence interval for each spatial extent, based on 1000 bootstrapped samples. To calculate the $\Delta$ AIC for each bootstrapped sample at each extent, we calculated the difference between the strongest model, or estimated scale of effect for that bootstrap sample, $(\triangle \mathrm{AIC}=0)$ and the remaining models including landscape measures from the other 29 spatial extents. The estimated scale of effect is indicated with a red arrow and is based on the full complement of bootstrapped samples. The frequency histogram shows the distribution of 1000 estimated scale of effect from the bootstrapped samples described above 


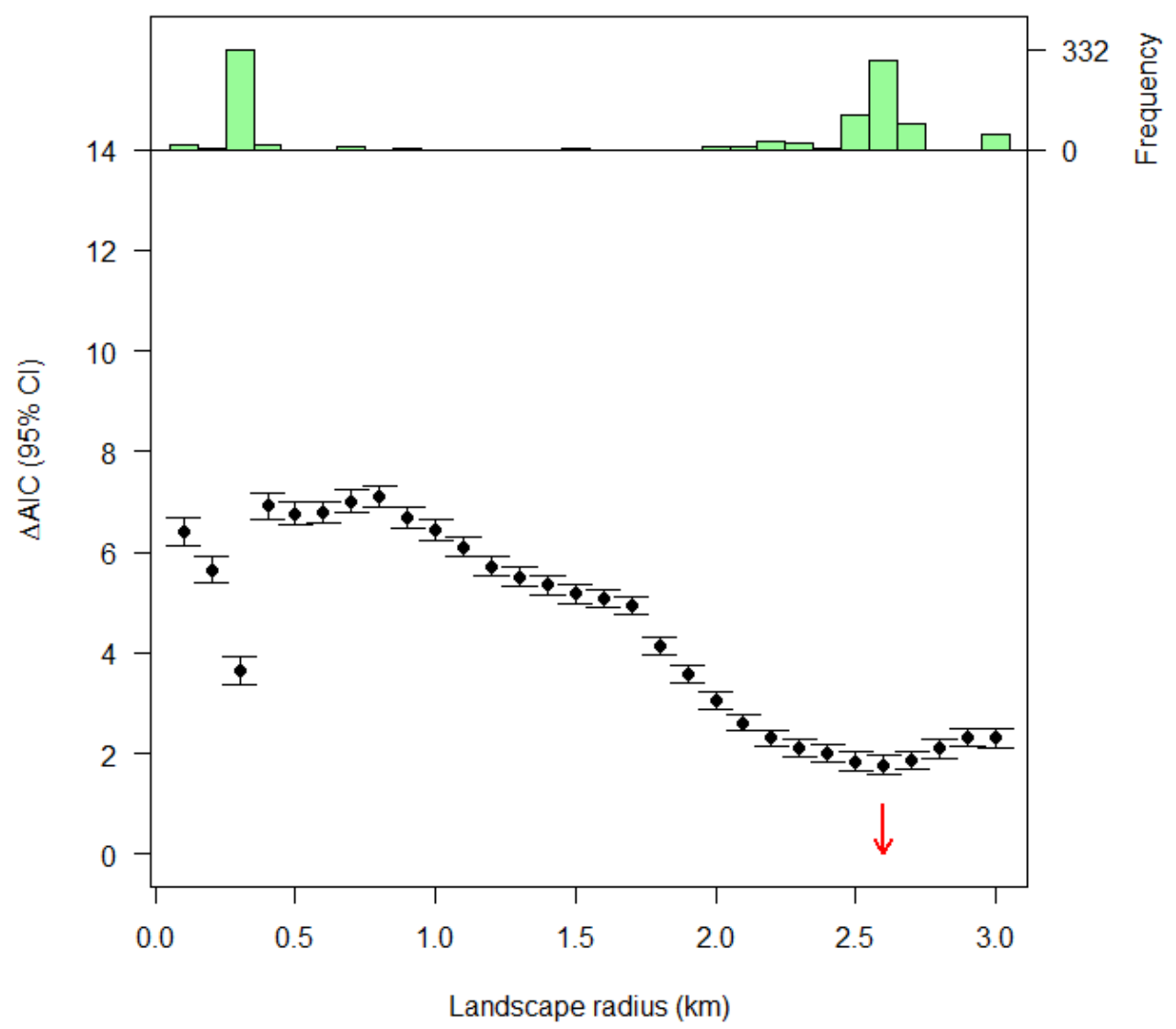

Figure 10: Model fit for generalized linear models relating wood frog abundance measured in 21 wetlands to forest proportion measured in the surrounding landscapes at each of 30 spatial extents $(0.1$ to $3.0 \mathrm{~km}$ radius from the centers of the sampled ponds). We estimated model fit as the mean $\triangle \mathrm{AIC}$ and $95 \%$ confidence interval for each spatial extent, based on 1000 bootstrapped samples. To calculate the $\triangle \mathrm{AIC}$ for each bootstrapped sample at each extent, we calculated the difference between the strongest model, or estimated scale of effect for that bootstrap sample, $(\triangle \mathrm{AIC}=0)$ and the remaining models including landscape measures from the other 29 spatial extents. The estimated scale of effect is indicated with a red arrow and is based on the full complement of bootstrapped samples. The frequency histogram shows the distribution of 1000 estimated scale of effect from the bootstrapped samples described above 


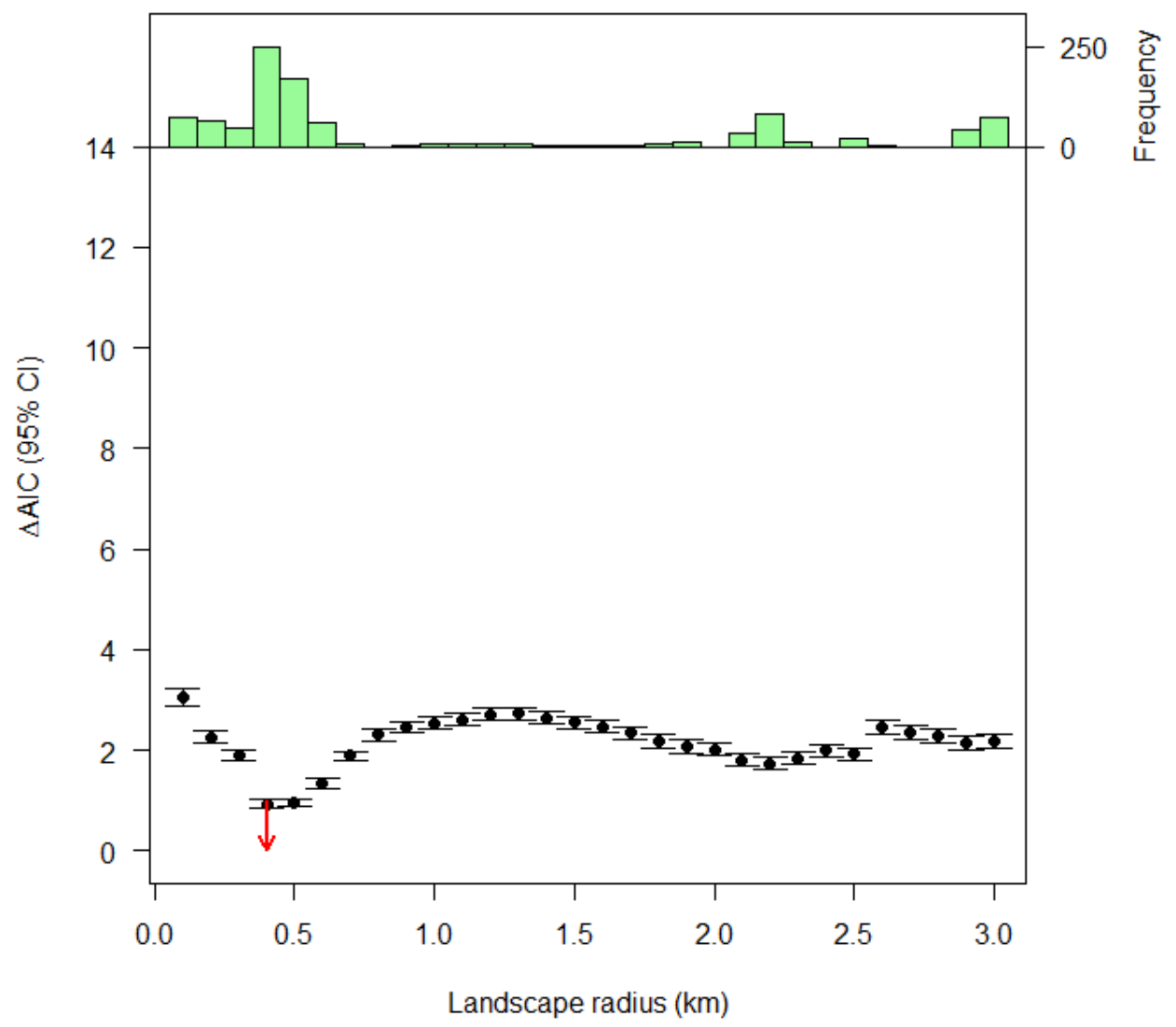

Figure 11: Model fit for generalized linear models relating wood frog occurrence measured in 34 wetlands to forest proportion measured in the surrounding landscapes at each of 30 spatial extents (0.1 to $3.0 \mathrm{~km}$ radius from the centers of the sampled ponds). We estimated model fit as the mean $\triangle \mathrm{AIC}$ and $95 \%$ confidence interval for each spatial extent, based on 1000 bootstrapped samples. To calculate the $\triangle \mathrm{AIC}$ for each bootstrapped sample at each extent, we calculated the difference between the strongest model, or estimated scale of effect for that bootstrap sample, $(\triangle \mathrm{AIC}=0)$ and the remaining models including landscape measures from the other 29 spatial extents. The estimated scale of effect is indicated with a red arrow and is based on the full complement of bootstrapped samples. The frequency histogram shows the distribution of 1000 estimated scale of effect from the bootstrapped samples described above 


\section{Appendix:}

Table A: Statistical significance of the selected scales of effect for the landscape context predictors on the three ecological responses for wood frogs; showing the coefficient of determination, the nagelkerke's $r^{2}$ was used for occurrence variables which had a binomial distribution, the $p$-value, and the direction of effect of the relationship between the predictor and response

\begin{tabular}{|c|c|c|c|}
\cline { 2 - 4 } \multicolumn{1}{c|}{} & Occurrence & Abundance & Fecundity \\
\hline Road Density & $R^{2}=0.22, p=0.04,(-)$ & $R^{2}=0.11, p=0.15,(-)$ & $R^{2}=0.28, p=0.03,(+)$ \\
\hline Forest Amount & $R^{2}=0.12, p=0.1,(+)$ & $R^{2}=0.30, p=0.01,(+)$ & $R^{2}=0.53, p=0.001,(-)$ \\
\hline
\end{tabular}

Table B: Pearson correlations (P) and Spearman rank (S) correlations between measured local habitat variables and three ecological response variables, fecundity $(P)$, abundance $(P)$, and occurrence $(S)$, for wood frogs. Local habitat variables are: dissolved oxygen (DO), $\mathrm{pH}$, electrical conductivity (EC), temperature (Temp), submergent and emergent vegetative cover (Veg), pond depth (Depth), pond perimeter (Perim), pond area (Area)

\begin{tabular}{|l|c|c|c|c|c|c|c|c|}
\hline & $\begin{array}{c}\text { DO } \\
(\mathbf{m g} / \mathbf{L})\end{array}$ & $\mathbf{p H}$ & $\begin{array}{c}\text { EC } \\
(\boldsymbol{\mu S})\end{array}$ & $\begin{array}{c}\text { Temp } \\
\left({ }^{\circ} \mathbf{C}\right)\end{array}$ & Veg & $\begin{array}{c}\text { Depth } \\
(\mathbf{c m})\end{array}$ & $\begin{array}{c}\text { Perimeter } \\
(\mathbf{m})\end{array}$ & $\begin{array}{c}\text { Area } \\
\left(\mathbf{m}^{\mathbf{2}}\right)\end{array}$ \\
\hline Fecundity & 0.21 & -0.25 & 0.48 & 0.34 & 0.24 & 0.21 & -0.15 & 0.07 \\
\hline Abundance & 0.06 & 0.01 & -0.24 & -0.28 & 0.43 & 0.06 & 0.22 & 0.17 \\
\hline Occurrence & -0.38 & -0.18 & -0.23 & -0.30 & -0.07 & -0.30 & 0.14 & 0.10 \\
\hline
\end{tabular}

Table C: Model fit $(\triangle \mathrm{AIC})$ for generalized linear models relating wood frog fecundity, abundance, and occurrence measured in 34 wetlands to road density measured in the surrounding landscapes at each of 30 spatial extents ( 0.1 to $3.0 \mathrm{~km}$ radius) from the centers of the sampled ponds and a local habitat variable that was strongly correlated to the responses. Two of the three responses had the same scale of effect selected with the inclusion of a local habitat variable. Although fecundity had a scale of effect slightly smaller than the original estimated this difference does not change the conclusions of this study.

\begin{tabular}{|l|c|c|c|c|c|c|c|c|c|c|}
\hline Landscape R. (m) & $\mathbf{1 0 0}$ & $\mathbf{2 0 0}$ & $\mathbf{3 0 0}$ & $\mathbf{4 0 0}$ & $\mathbf{5 0 0}$ & $\mathbf{6 0 0}$ & $\mathbf{7 0 0}$ & $\mathbf{8 0 0}$ & $\mathbf{9 0 0}$ & $\mathbf{1 0 0 0}$ \\
\hline Fecundity+EC & 7.35 & 7.80 & $\mathbf{7 . 3 5}$ & $\mathbf{7 . 1 5}$ & $\mathbf{7 . 8 7}$ & 7.89 & 7.88 & 7.89 & 7.89 & 7.73 \\
\hline Abundance+Veg & 2.54 & 1.44 & 0.50 & 0 & 2.55 & 2.56 & 2.63 & 2.92 & 2.88 & 2.55 \\
\hline Occurrence+DO & 5.61 & 4.54 & 3.99 & 2.72 & 1.33 & 0.48 & 0 & 3.39 & 3.95 & 3.27 \\
\hline & & & & & & & & & & \\
\hline Landscape R. (m) & $\mathbf{1 1 0 0}$ & $\mathbf{1 2 0 0}$ & $\mathbf{1 3 0 0}$ & $\mathbf{1 4 0 0}$ & $\mathbf{1 5 0 0}$ & $\mathbf{1 6 0 0}$ & $\mathbf{1 7 0 0}$ & $\mathbf{1 8 0 0}$ & $\mathbf{1 9 0 0}$ & $\mathbf{2 0 0 0}$ \\
\hline Fecundity+EC & 7.64 & 7.88 & $\mathbf{7 . 6 9}$ & 7.74 & 7.86 & 0 & 2.24 & 3.18 & 3.58 & 4.48 \\
\hline Abundance+Veg & 2.20 & 2.50 & 2.13 & 2.88 & 2.88 & 2.82 & 2.85 & 2.65 & 2.32 & 2.25 \\
\hline Occurrence+DO & 3.19 & 4.22 & 5.94 & 3.90 & 4.07 & 5.43 & 4.57 & 5.67 & 5.80 & 5.70 \\
\hline & & & & & & & & & & \\
\hline Landscape R. (m) & $\mathbf{2 1 0 0}$ & $\mathbf{2 2 0 0}$ & $\mathbf{2 3 0 0}$ & $\mathbf{2 4 0 0}$ & $\mathbf{2 5 0 0}$ & $\mathbf{2 6 0 0}$ & $\mathbf{2 7 0 0}$ & $\mathbf{2 8 0 0}$ & $\mathbf{2 9 0 0}$ & $\mathbf{3 0 0 0}$ \\
\hline Fecundity+EC & 1.74 & 2.87 & 3.91 & 3.79 & 2.39 & 3.18 & 3.39 & 4.44 & 5.14 & 5.21 \\
\hline Abundance+Veg & 1.86 & 1.83 & 2.23 & 2.07 & 1.71 & 1.88 & 1.77 & 1.73 & 1.79 & 1.38 \\
\hline Occurrence+DO & 5.39 & 5.53 & 5.45 & 5.27 & 4.43 & 4.08 & 3.93 & 4.09 & 3.97 & 4.33 \\
\hline
\end{tabular}


Table D: Model fit ( $\triangle \mathrm{AIC}$ ) for generalized linear models relating wood frog fecundity, abundance, and occurrence measured in 34 wetlands to forest amount measured in the surrounding landscapes at each of 30 spatial extents ( 0.1 to $3.0 \mathrm{~km}$ radius) from the centers of the sampled ponds and a local habitat variable that was strongly correlated to the responses. The scales of effect selected with the inclusion of a local habitat variable were not different at all from those selected with just the landscape context predictor.

\begin{tabular}{|l|c|c|c|c|c|c|c|c|c|c|}
\hline Landscape R. (m) & $\mathbf{1 0 0}$ & $\mathbf{2 0 0}$ & $\mathbf{3 0 0}$ & $\mathbf{4 0 0}$ & $\mathbf{5 0 0}$ & $\mathbf{6 0 0}$ & $\mathbf{7 0 0}$ & $\mathbf{8 0 0}$ & $\mathbf{9 0 0}$ & $\mathbf{1 0 0 0}$ \\
\hline Fecundity+EC & 1.42 & 0 & 3.03 & 5.45 & 7.05 & 8.34 & 8.92 & 9.11 & 9.15 & 9.24 \\
\hline Abundance+Veg & 2.96 & 2.52 & 1.07 & 4.93 & 4.54 & 4.29 & 4.39 & 4.31 & 3.88 & 3.68 \\
\hline Occurrence+DO & 2.10 & 1.49 & 1.05 & 0 & 0.06 & 0.47 & 0.99 & 1.35 & 1.47 & 1.57 \\
\hline & & & & & & & & & & \\
\hline Landscape R. (m) & $\mathbf{1 1 0 0}$ & $\mathbf{1 2 0 0}$ & $\mathbf{1 3 0 0}$ & $\mathbf{1 4 0 0}$ & $\mathbf{1 5 0 0}$ & $\mathbf{1 6 0 0}$ & $\mathbf{1 7 0 0}$ & $\mathbf{1 8 0 0}$ & $\mathbf{1 9 0 0}$ & $\mathbf{2 0 0 0}$ \\
\hline Fecundity+EC & 9.44 & 9.56 & 9.69 & 9.70 & 9.73 & 9.79 & 9.86 & 9.91 & 9.98 & 10.04 \\
\hline Abundance+Veg & 3.56 & 3.34 & 3.17 & 3.01 & 2.86 & 2.79 & 2.65 & 1.87 & 1.42 & 1.04 \\
\hline Occurrence+DO & 1.63 & 1.70 & 1.70 & 1.63 & 1.54 & 1.46 & 1.34 & 1.17 & 1.05 & 1.98 \\
\hline & & & & & & & & & & \\
\hline Landscape R. (m) & $\mathbf{2 1 0 0}$ & $\mathbf{2 2 0 0}$ & $\mathbf{2 3 0 0}$ & $\mathbf{2 4 0 0}$ & $\mathbf{2 5 0 0}$ & $\mathbf{2 6 0 0}$ & $\mathbf{2 7 0 0}$ & $\mathbf{2 8 0 0}$ & $\mathbf{2 9 0 0}$ & $\mathbf{3 0 0 0}$ \\
\hline Fecundity+EC & 10.05 & 10.06 & 10.07 & 10.09 & 10.11 & 10.13 & 10.16 & 10.17 & 10.17 & 10.18 \\
\hline Abundance+Veg & 0.75 & 0.52 & 0.31 & 0.25 & 0.09 & 0 & 0.03 & 0.15 & 0.21 & 0.12 \\
\hline Occurrence+DO & 0.80 & 0.72 & 0.81 & 0.97 & 0.89 & 1.41 & 1.33 & 1.28 & 1.17 & 1.20 \\
\hline
\end{tabular}




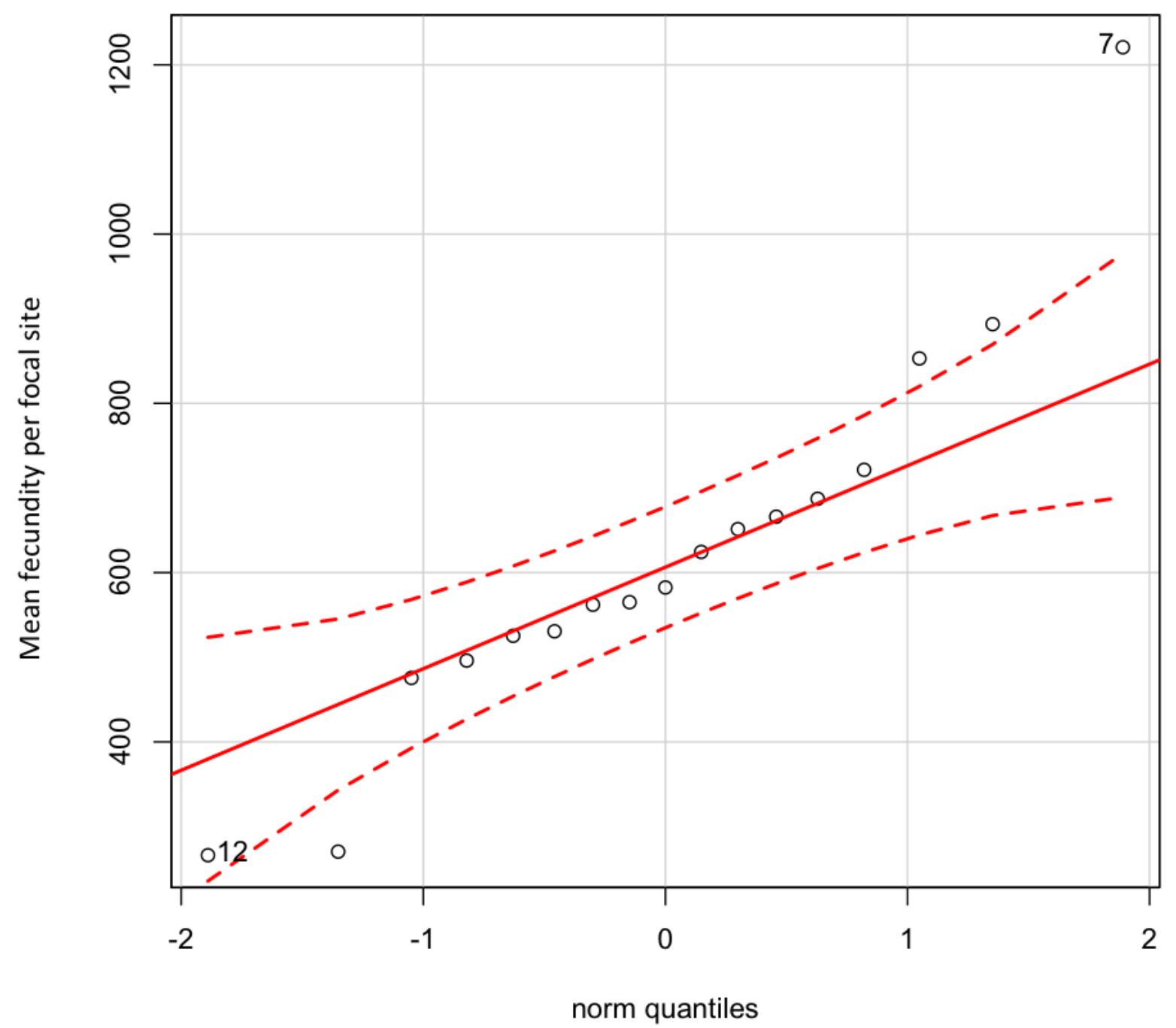

Figure A: Quantile-quantile plot showing mean fecundity estimated per focal site, for a total of 17 sites, compared to a normal distribution suggesting that fecundity can be modelled using a Gaussian distribution since the majority of data points fall within the normal quantiles 


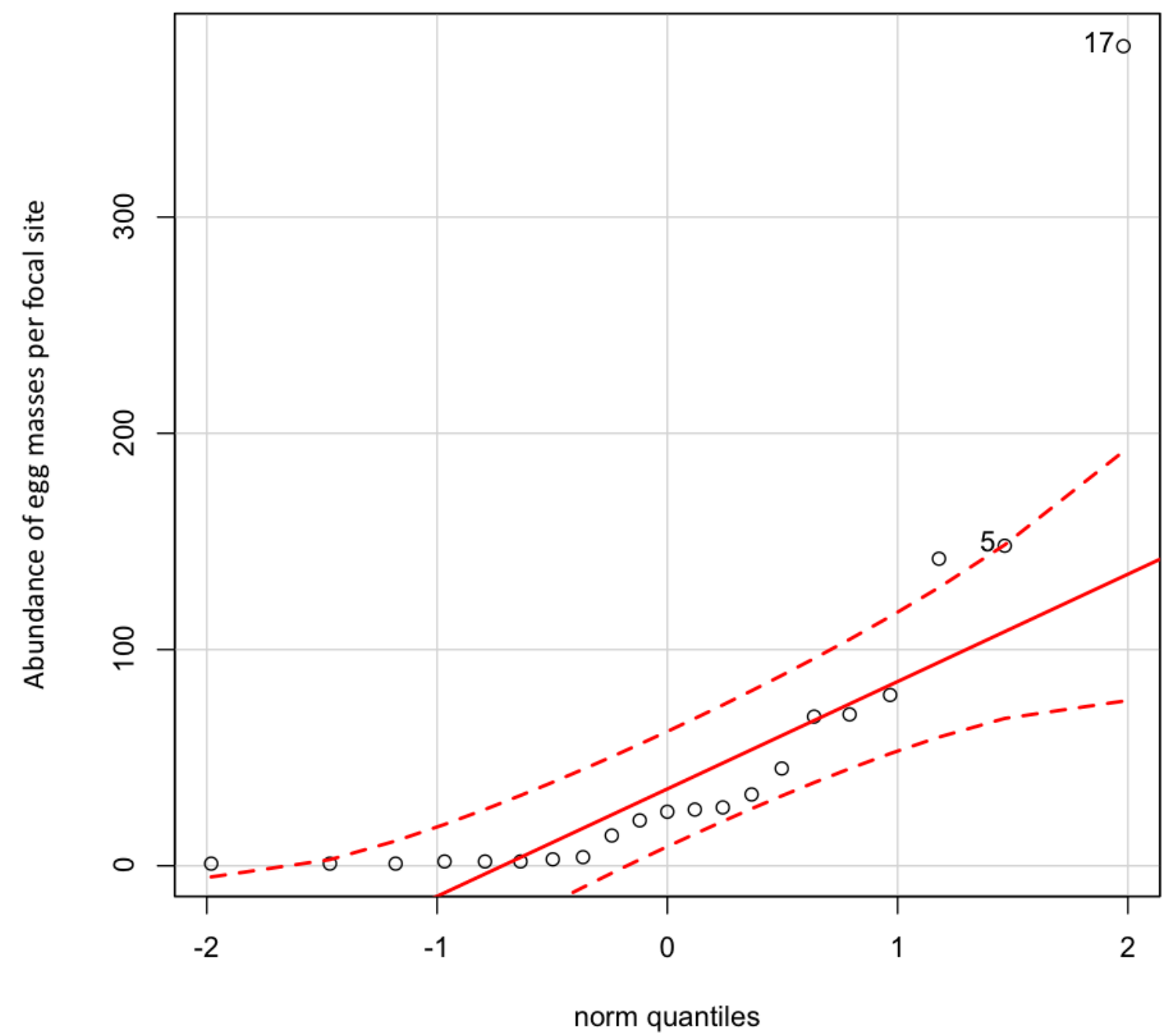

Figure B: Quantile-quantile plot showing abundance measured per focal site, for a total of 21 sites, compared to a normal distribution suggesting that abundance can be modelled with a Gaussian distribution since the majority of data points fall within the normal quantiles 
Table E: Egg count data for wood frog egg masses surveyed at selected landscapes in Eastern Ontario, estimates were obtained from software counts that occurred in the lab based on photographs taken of compressed masses in the field; photo ID corresponds to individual photographs taken for each mass

\begin{tabular}{|c|c|c|c|c|}
\hline Site & Photo ID & Egg Count & Observer & Date \\
\hline 39 & 4130002 & 751 & Andrew & $13 / 04$ \\
\hline 39 & 4130004 & 748 & Claire & $13 / 04$ \\
\hline 39 & 4130005 & 596 & Claire & $13 / 04$ \\
\hline 39 & 4130006 & 666 & Claire & $13 / 04$ \\
\hline 39 & 4130007 & 873 & Claire & $13 / 04$ \\
\hline 39 & 4130008 & 571 & Claire & $13 / 04$ \\
\hline 39 & 4130009 & 606 & Claire & $13 / 04$ \\
\hline 39 & 4130010 & 666 & Claire & $13 / 04$ \\
\hline 39 & 4130012 & 737 & Claire & $13 / 04$ \\
\hline 39 & 4130013 & 901 & Claire & $13 / 04$ \\
\hline 39 & 4130014 & 995 & Claire & $13 / 04$ \\
\hline 39 & 4130016 & 874 & Claire & $13 / 04$ \\
\hline 39 & 4130017 & 640 & Claire & $13 / 04$ \\
\hline 39 & 4130018 & 693 & Claire & $13 / 04$ \\
\hline 39 & 4130019 & 942 & Claire & $13 / 04$ \\
\hline 39 & 4130020 & 867 & Claire & $13 / 04$ \\
\hline 39 & 4130021 & 1003 & Claire & $13 / 04$ \\
\hline 39 & 4130022 & 764 & Claire & $13 / 04$ \\
\hline 39 & 4130023 & 914 & Claire & $13 / 04$ \\
\hline 39 & 4130025 & 553 & Claire & $13 / 04$ \\
\hline 39 & 4130026 & 922 & Claire & $13 / 04$ \\
\hline 39 & 4130027 & 436 & Claire & $13 / 04$ \\
\hline 39 & 4130028 & 745 & Claire & $13 / 04$ \\
\hline 39 & 4130029 & 723 & Claire & $13 / 04$ \\
\hline 39 & 4130030 & 248 & Claire & $13 / 04$ \\
\hline 39 & 4130031 & 559 & Claire & $13 / 04$ \\
\hline 39 & 4130032 & 485 & Claire & $13 / 04$ \\
\hline 11 & 4140002 & 360 & Andrew & $14 / 04$ \\
\hline 11 & 4140005 & 841 & Andrew & $14 / 04$ \\
\hline 11 & 4140006 & 489 & Andrew & $14 / 04$ \\
\hline 11 & 4140007 & 635 & Claire & $14 / 04$ \\
\hline 11 & 4140008 & 633 & Claire & $14 / 04$ \\
\hline 11 & 4140009 & 713 & Claire & $14 / 04$ \\
\hline 11 & 4140010 & 653 & Claire & $14 / 04$ \\
\hline 11 & 4140011 & 683 & Claire & $14 / 04$ \\
\hline 11 & 4140012 & 669 & Claire & $14 / 04$ \\
\hline 11 & 4140013 & 596 & Claire & $14 / 04$ \\
\hline 11 & 4140014 & 668 & Claire & $14 / 04$ \\
\hline 11 & 4140015 & 644 & Claire & $14 / 04$ \\
\hline 11 & 4140016 & 650 & Claire & $14 / 04$ \\
\hline
\end{tabular}




\begin{tabular}{|c|c|c|c|c|}
\hline 11 & 4140017 & 703 & Claire & $14 / 04$ \\
\hline 11 & 4140018 & 611 & Claire & $14 / 04$ \\
\hline 11 & 4140019 & 542 & Claire & $14 / 04$ \\
\hline 11 & 4140020 & 479 & Claire & $14 / 04$ \\
\hline 11 & 4140021 & 694 & Claire & $14 / 04$ \\
\hline 11 & 4140022 & 666 & Claire & $14 / 04$ \\
\hline 11 & 4140023 & 485 & Claire & $14 / 04$ \\
\hline 11 & 4140024 & 597 & Claire & $14 / 04$ \\
\hline 11 & 4140025 & 757 & Claire & $14 / 04$ \\
\hline 11 & 4140026 & 742 & Claire & $14 / 04$ \\
\hline 11 & 4140027 & 758 & Claire & $14 / 04$ \\
\hline 11 & 4140028 & 604 & Claire & $14 / 04$ \\
\hline 11 & 4140029 & 605 & Claire & $14 / 04$ \\
\hline 11 & 4140030 & 678 & Claire & $14 / 04$ \\
\hline 11 & 4140031 & 711 & Claire & $14 / 04$ \\
\hline 11 & 4140032 & 577 & Claire & $14 / 04$ \\
\hline 11 & 4140033 & 454 & Claire & $14 / 04$ \\
\hline 11 & 4140035 & 654 & Claire & $14 / 04$ \\
\hline 11 & 4140036 & 608 & Claire & $14 / 04$ \\
\hline 11 & 4140037 & 692 & Claire & $14 / 04$ \\
\hline 11 & 4140038 & 719 & Claire & $14 / 04$ \\
\hline 11 & 4140039 & 644 & Claire & $14 / 04$ \\
\hline 11 & 4140040 & 611 & Claire & $14 / 04$ \\
\hline 11 & 4140041 & 633 & Claire & $14 / 04$ \\
\hline 11 & 4140042 & 623 & Claire & $14 / 04$ \\
\hline 11 & 4140043 & 624 & Claire & $14 / 04$ \\
\hline 11 & 4140044 & 567 & Claire & $14 / 04$ \\
\hline 11 & 4140045 & 655 & Claire & $14 / 04$ \\
\hline 11 & 4140046 & 606 & Claire & $14 / 04$ \\
\hline 11 & 4140047 & 872 & Claire & $14 / 04$ \\
\hline 11 & 4140048 & 665 & Claire & $14 / 04$ \\
\hline 11 & 4140049 & 648 & Claire & $14 / 04$ \\
\hline 11 & 4140050 & 513 & Claire & $14 / 04$ \\
\hline 11 & 4140051 & 745 & Claire & $14 / 04$ \\
\hline 11 & 4140052 & 662 & Claire & $14 / 04$ \\
\hline 11 & 4140053 & 960 & Claire & $14 / 04$ \\
\hline 11 & 4140054 & 572 & Claire & $14 / 04$ \\
\hline 11 & 4140055 & 602 & Claire & $14 / 04$ \\
\hline 11 & 4140056 & 752 & Claire & $14 / 04$ \\
\hline 11 & 4140057 & 606 & Claire & $14 / 04$ \\
\hline 11 & 4140058 & 612 & Claire & $14 / 04$ \\
\hline 11 & 4140059 & 797 & Claire & $14 / 04$ \\
\hline 11 & 4140060 & 958 & Claire & $14 / 04$ \\
\hline 11 & 4140061 & 779 & Claire & $14 / 04$ \\
\hline 11 & 4140062 & 808 & Claire & $14 / 04$ \\
\hline 11 & 4140063 & 794 & Claire & $14 / 04$ \\
\hline
\end{tabular}




\begin{tabular}{|c|c|c|c|c|}
\hline 11 & 4140064 & 624 & Claire & $14 / 04$ \\
\hline 11 & 4140065 & 710 & Claire & $14 / 04$ \\
\hline 11 & 4140066 & 701 & Claire & $14 / 04$ \\
\hline 11 & 4140067 & 566 & Claire & $14 / 04$ \\
\hline 11 & 4140068 & 803 & Claire & $14 / 04$ \\
\hline 11 & 4140069 & 691 & Claire & $14 / 04$ \\
\hline 11 & 4140070 & 677 & Claire & $14 / 04$ \\
\hline 11 & 4140071 & 600 & Claire & $14 / 04$ \\
\hline 11 & 4140072 & 728 & Claire & $14 / 04$ \\
\hline 11 & 4140073 & 604 & Claire & $14 / 04$ \\
\hline 11 & 4140074 & 837 & Claire & $14 / 04$ \\
\hline 11 & 4140075 & 714 & Claire & $14 / 04$ \\
\hline 11 & 4140076 & 611 & Claire & $14 / 04$ \\
\hline 11 & 4140077 & 898 & Claire & $14 / 04$ \\
\hline 11 & 4140078 & 613 & Claire & $14 / 04$ \\
\hline 11 & 4140079 & 737 & Claire & $14 / 04$ \\
\hline 11 & 4140080 & 521 & Claire & $14 / 04$ \\
\hline 11 & 4140081 & 778 & Claire & $14 / 04$ \\
\hline 11 & 4140082 & 738 & Claire & $14 / 04$ \\
\hline 11 & 4140083 & 835 & Claire & $14 / 04$ \\
\hline 11 & 4140084 & 589 & Claire & $14 / 04$ \\
\hline 11 & 4140085 & 608 & Claire & 14/04 \\
\hline 11 & 4140086 & 783 & Claire & $14 / 04$ \\
\hline 11 & 4140087 & 606 & Claire & $14 / 04$ \\
\hline 11 & 4140088 & 238 & Claire & $14 / 04$ \\
\hline 11 & 4140089 & 922 & Claire & $14 / 04$ \\
\hline 11 & 4140090 & 312 & Claire & $14 / 04$ \\
\hline 11 & 4140091 & 683 & Claire & $14 / 04$ \\
\hline 11 & 4140092 & 668 & Claire & $14 / 04$ \\
\hline 11 & 4140093 & 691 & Claire & $14 / 04$ \\
\hline 11 & 4140094 & 626 & Claire & $14 / 04$ \\
\hline 11 & 4140095 & 471 & Claire & $14 / 04$ \\
\hline 11 & 4140096 & 529 & Claire & $14 / 04$ \\
\hline 11 & 4140097 & 710 & Claire & $14 / 04$ \\
\hline 11 & 4140098 & 646 & Claire & $14 / 04$ \\
\hline 11 & 4140099 & 587 & Claire & $14 / 04$ \\
\hline 11 & 4140100 & 664 & Claire & $14 / 04$ \\
\hline 11 & 4140101 & 725 & Claire & $14 / 04$ \\
\hline 11 & 4140102 & 662 & Claire & $14 / 04$ \\
\hline 11 & 4140103 & 669 & Claire & $14 / 04$ \\
\hline 11 & 4140104 & 802 & Claire & $14 / 04$ \\
\hline 11 & 4140105 & 586 & Claire & $14 / 04$ \\
\hline 11 & 4140106 & 684 & Claire & 14/04 \\
\hline 11 & 4140107 & 1004 & Claire & $14 / 04$ \\
\hline 11 & 4140108 & 684 & Claire & 14/04 \\
\hline 11 & 4140109 & 534 & Claire & $14 / 04$ \\
\hline
\end{tabular}




\begin{tabular}{|c|c|c|c|c|}
\hline 11 & 4140110 & 777 & Claire & $14 / 04$ \\
\hline 11 & 4140111 & 705 & Claire & $14 / 04$ \\
\hline 11 & 4140112 & 708 & Claire & $14 / 04$ \\
\hline 11 & 4140113 & 674 & Claire & $14 / 04$ \\
\hline 11 & 4140114 & 684 & Claire & $14 / 04$ \\
\hline 11 & 4140115 & 436 & Claire & $14 / 04$ \\
\hline 11 & 4140116 & 833 & Claire & $14 / 04$ \\
\hline 11 & 4140117 & 654 & Claire & $14 / 04$ \\
\hline 11 & 4140118 & 759 & Claire & $14 / 04$ \\
\hline 11 & 4140119 & 641 & Claire & $14 / 04$ \\
\hline 11 & 4140120 & 821 & Claire & $14 / 04$ \\
\hline 11 & 4140121 & 658 & Claire & $14 / 04$ \\
\hline 11 & 4140122 & 136 & Claire & $14 / 04$ \\
\hline 11 & 4140123 & 583 & Claire & $14 / 04$ \\
\hline 11 & 4140124 & 178 & Claire & $14 / 04$ \\
\hline 11 & 4140125 & 569 & Claire & $14 / 04$ \\
\hline 11 & 4140126 & 677 & Claire & $14 / 04$ \\
\hline 11 & 4140127 & 622 & Claire & $14 / 04$ \\
\hline 11 & 4140128 & 486 & Claire & $14 / 04$ \\
\hline 11 & 4140129 & 674 & Claire & $14 / 04$ \\
\hline 11 & 4140130 & 776 & Claire & $14 / 04$ \\
\hline 11 & 4140131 & 611 & Claire & 14/04 \\
\hline 11 & 4140134 & 897 & Claire & $14 / 04$ \\
\hline 11 & 4140135 & 556 & Claire & $14 / 04$ \\
\hline 11 & 4140136 & 547 & Claire & $14 / 04$ \\
\hline 11 & 4140137 & 694 & Claire & $14 / 04$ \\
\hline 11 & 4140138 & 567 & Claire & $14 / 04$ \\
\hline 11 & 4140139 & 696 & Claire & $14 / 04$ \\
\hline 11 & 4140140 & 555 & Claire & $14 / 04$ \\
\hline 11 & 4140141 & 390 & Claire & $14 / 04$ \\
\hline 11 & 4140142 & 552 & Claire & $14 / 04$ \\
\hline 11 & 4140143 & 791 & Claire & $14 / 04$ \\
\hline 11 & 4140144 & 810 & Claire & $14 / 04$ \\
\hline 11 & 4140145 & 604 & Claire & $14 / 04$ \\
\hline 11 & 4140146 & 668 & Claire & $14 / 04$ \\
\hline 11 & 4140147 & 668 & Claire & $14 / 04$ \\
\hline 11 & 4140148 & 435 & Claire & $14 / 04$ \\
\hline 11 & 4140149 & 761 & Claire & $14 / 04$ \\
\hline 11 & 4140150 & 928 & Claire & $14 / 04$ \\
\hline 11 & 4140151 & 917 & Claire & $14 / 04$ \\
\hline 11 & 4140152 & 625 & Claire & $14 / 04$ \\
\hline 11 & 4140153 & 586 & Claire & $14 / 04$ \\
\hline 11 & 4140154 & 507 & Claire & 14/04 \\
\hline 11 & 4140155 & 609 & Claire & $14 / 04$ \\
\hline 11 & 4140156 & 624 & Claire & 14/04 \\
\hline 11 & 4140157 & 743 & Claire & $14 / 04$ \\
\hline
\end{tabular}




\begin{tabular}{|c|c|c|c|c|}
\hline 11 & 4140158 & 763 & Claire & $14 / 04$ \\
\hline 11 & 4140159 & 518 & Claire & $14 / 04$ \\
\hline 11 & 4140160 & 904 & Claire & $14 / 04$ \\
\hline 11 & 4140161 & 432 & Claire & $14 / 04$ \\
\hline 11 & 4140162 & 563 & Claire & $14 / 04$ \\
\hline 11 & 4140163 & 873 & Claire & $14 / 04$ \\
\hline 11 & 4140164 & 723 & Claire & $14 / 04$ \\
\hline 11 & 4140165 & 907 & Claire & $14 / 04$ \\
\hline 11 & 4140166 & 688 & Claire & $14 / 04$ \\
\hline 11 & 4140167 & 440 & Claire & $14 / 04$ \\
\hline 11 & 4140168 & 432 & Claire & $14 / 04$ \\
\hline 11 & 4140169 & 709 & Claire & $14 / 04$ \\
\hline 11 & 4140170 & 576 & Claire & $14 / 04$ \\
\hline 11 & 4140171 & 672 & Claire & $14 / 04$ \\
\hline 11 & 4140172 & 680 & Claire & $14 / 04$ \\
\hline 11 & 4140173 & 97 & Claire & $14 / 04$ \\
\hline 11 & 4140174 & 591 & Claire & $14 / 04$ \\
\hline 11 & 4140175 & 729 & Claire & $14 / 04$ \\
\hline 11 & 4140176 & 678 & Claire & $14 / 04$ \\
\hline 11 & 4140177 & 611 & Claire & $14 / 04$ \\
\hline 11 & 4140178 & 509 & Claire & $14 / 04$ \\
\hline 11 & 4140179 & 562 & Claire & 14/04 \\
\hline 11 & 4140180 & 575 & Claire & $14 / 04$ \\
\hline 11 & 4140181 & 786 & Claire & $14 / 04$ \\
\hline 11 & 4140182 & 654 & Claire & $14 / 04$ \\
\hline 11 & 4140132 & 710 & Claire & $14 / 04$ \\
\hline 11 & 4140133 & 619 & Claire & $14 / 04$ \\
\hline 15 & 4150001 & 779 & Andrew & $15 / 04$ \\
\hline 15 & 4150002 & 658 & Andrew & $15 / 04$ \\
\hline 15 & 4150003 & 695 & Andrew & $15 / 04$ \\
\hline 15 & 4150004 & 751 & Andrew & $15 / 04$ \\
\hline 15 & 4150005 & 688 & Andrew & $15 / 04$ \\
\hline 15 & 4150006 & 790 & Andrew & $15 / 04$ \\
\hline 15 & 4150007 & 673 & Andrew & $15 / 04$ \\
\hline 15 & 4150008 & 567 & Andrew & $15 / 04$ \\
\hline 15 & 4150009 & 737 & Andrew & $15 / 04$ \\
\hline 15 & 4150010 & 692 & Andrew & $15 / 04$ \\
\hline 15 & 4150011 & 710 & Andrew & $15 / 04$ \\
\hline 15 & 4150012 & 1054 & Andrew & $15 / 04$ \\
\hline 15 & 4150013 & 806 & Andrew & $15 / 04$ \\
\hline 15 & 4150014 & 801 & Andrew & $15 / 04$ \\
\hline 15 & 4150015 & 578 & Andrew & $15 / 04$ \\
\hline 15 & 4150016 & 593 & Andrew & 15/04 \\
\hline 15 & 4150017 & 816 & Andrew & $15 / 04$ \\
\hline 15 & 4150018 & 629 & Andrew & 15/04 \\
\hline 15 & 4150019 & 701 & Andrew & $15 / 04$ \\
\hline
\end{tabular}




\begin{tabular}{|c|c|c|c|c|}
\hline 15 & 4150020 & 686 & Andrew & $15 / 04$ \\
\hline 15 & 4150021 & 659 & Andrew & $15 / 04$ \\
\hline 15 & 4150022 & 641 & Andrew & $15 / 04$ \\
\hline 15 & 4150023 & 713 & Andrew & $15 / 04$ \\
\hline 15 & 4150024 & 668 & Andrew & $15 / 04$ \\
\hline 15 & 4150025 & 753 & Andrew & $15 / 04$ \\
\hline 15 & 4150026 & 723 & Andrew & $15 / 04$ \\
\hline 15 & 4150027 & 850 & Andrew & $15 / 04$ \\
\hline 15 & 4150028 & 632 & Andrew & $15 / 04$ \\
\hline 15 & 4150029 & 691 & Andrew & $15 / 04$ \\
\hline 15 & 4150030 & 687 & Andrew & $15 / 04$ \\
\hline 15 & 4150031 & 623 & Andrew & $15 / 04$ \\
\hline 15 & 4150033 & 102 & Andrew & $15 / 04$ \\
\hline 109 & 4150001 & 1072 & Andrew & $15 / 04$ \\
\hline 109 & 4150002 & 933 & Andrew & $15 / 04$ \\
\hline 109 & 4150003 & 621 & Andrew & $15 / 04$ \\
\hline 109 & 4150004 & 1001 & Andrew & $15 / 04$ \\
\hline 109 & 4150005 & 785 & Andrew & $15 / 04$ \\
\hline 109 & 4150007 & 903 & Andrew & $15 / 04$ \\
\hline 109 & 4150008 & 838 & Andrew & $15 / 04$ \\
\hline 109 & 4150010 & 734 & Andrew & $15 / 04$ \\
\hline 109 & 4150011 & 987 & Andrew & $15 / 04$ \\
\hline 109 & 4150012 & 821 & Andrew & $15 / 04$ \\
\hline 109 & 4150013 & 991 & Andrew & $15 / 04$ \\
\hline 109 & 4150014 & 1104 & Andrew & $15 / 04$ \\
\hline 109 & 4150015 & 826 & Andrew & $15 / 04$ \\
\hline 97 & 4180018 & 553 & Andrew & $18 / 04$ \\
\hline 97 & 4180020 & 349 & Erik & $18 / 04$ \\
\hline 97 & 4180023 & 639 & Erik & $18 / 04$ \\
\hline 97 & 4180024 & 565 & Erik & $18 / 04$ \\
\hline 97 & 4180025 & 505 & Erik & $18 / 04$ \\
\hline 97 & 4180026 & 613 & Erik & $18 / 04$ \\
\hline 97 & 4180027 & 511 & Erik & $18 / 04$ \\
\hline 97 & 4180028 & 541 & Erik & $18 / 04$ \\
\hline 97 & 4180029 & 326 & Erik & $18 / 04$ \\
\hline 97 & 4180030 & 466 & Erik & $18 / 04$ \\
\hline 97 & 4180031 & 421 & Erik & $18 / 04$ \\
\hline 97 & 4180032 & 477 & Erik & $18 / 04$ \\
\hline 97 & 4180033 & 726 & Erik & $18 / 04$ \\
\hline 97 & 4180034 & 409 & Erik & $18 / 04$ \\
\hline 97 & 4180035 & 435 & Erik & $18 / 04$ \\
\hline 97 & 4180036 & 626 & Erik & $18 / 04$ \\
\hline 97 & 4180037 & 524 & Erik & $18 / 04$ \\
\hline 97 & 4180038 & 680 & Erik & $18 / 04$ \\
\hline 97 & 4180039 & 652 & Erik & 18/04 \\
\hline 97 & 4180040 & 626 & Erik & $18 / 04$ \\
\hline
\end{tabular}




\begin{tabular}{|c|c|c|c|c|}
\hline 97 & 4180041 & 583 & Erik & $18 / 04$ \\
\hline 97 & 4180042 & 498 & Erik & $18 / 04$ \\
\hline 97 & 4180043 & 747 & Erik & $18 / 04$ \\
\hline 97 & 4180044 & 409 & Erik & $18 / 04$ \\
\hline 97 & 4180045 & 542 & Erik & $18 / 04$ \\
\hline 97 & 4180046 & 615 & Erik & $18 / 04$ \\
\hline 97 & 4180047 & 493 & Erik & $18 / 04$ \\
\hline 97 & 4180048 & 446 & Erik & $18 / 04$ \\
\hline 97 & 4180049 & 553 & Erik & $18 / 04$ \\
\hline 97 & 4180050 & 574 & Erik & $18 / 04$ \\
\hline 97 & 4180051 & 481 & Erik & $18 / 04$ \\
\hline 97 & 4180052 & 509 & Erik & $18 / 04$ \\
\hline 97 & 4180053 & 415 & Erik & $18 / 04$ \\
\hline 97 & 4180054 & 238 & Erik & $18 / 04$ \\
\hline 97 & 4180055 & 459 & Erik & $18 / 04$ \\
\hline 97 & 4180056 & 504 & Erik & $18 / 04$ \\
\hline 97 & 4180057 & 593 & Erik & $18 / 04$ \\
\hline 97 & 4180058 & 742 & Erik & $18 / 04$ \\
\hline 97 & 4180059 & 491 & Erik & $18 / 04$ \\
\hline 97 & 4180060 & 209 & Erik & $18 / 04$ \\
\hline 97 & 4180061 & 471 & Erik & $18 / 04$ \\
\hline 97 & 4180062 & 417 & Erik & 18/04 \\
\hline 97 & 4180063 & 522 & Erik & $18 / 04$ \\
\hline 97 & 4180064 & 311 & Erik & $18 / 04$ \\
\hline 97 & 4180065 & 479 & Erik & $18 / 04$ \\
\hline 97 & 4180066 & 683 & Erik & $18 / 04$ \\
\hline 97 & 4180067 & 565 & Erik & $18 / 04$ \\
\hline 97 & 4180068 & 718 & Erik & $18 / 04$ \\
\hline 97 & 4180069 & 617 & Erik & $18 / 04$ \\
\hline 97 & 4180070 & 689 & Erik & $18 / 04$ \\
\hline 97 & 4180071 & 512 & Erik & $18 / 04$ \\
\hline 97 & 4180072 & 626 & Erik & $18 / 04$ \\
\hline 97 & 4180073 & 415 & Erik & $18 / 04$ \\
\hline 97 & 4180074 & 540 & Erik & $18 / 04$ \\
\hline 97 & 4180075 & 569 & Erik & $18 / 04$ \\
\hline 97 & 4180076 & 322 & Erik & $18 / 04$ \\
\hline 97 & 4180077 & 716 & Erik & $18 / 04$ \\
\hline 97 & 4180078 & 532 & Erik & $18 / 04$ \\
\hline 97 & 4180079 & 624 & Erik & $18 / 04$ \\
\hline 97 & 4180080 & 491 & Erik & $18 / 04$ \\
\hline 97 & 4180081 & 395 & Erik & $18 / 04$ \\
\hline 97 & 4180082 & 616 & Erik & $18 / 04$ \\
\hline 97 & 4180083 & 649 & Erik & $18 / 04$ \\
\hline 97 & 4180084 & 698 & Erik & $18 / 04$ \\
\hline 97 & 4180085 & 540 & Erik & 18/04 \\
\hline 97 & 4180086 & 583 & Erik & $18 / 04$ \\
\hline
\end{tabular}




\begin{tabular}{|c|c|c|c|c|}
\hline 97 & 4180087 & 597 & Erik & $18 / 04$ \\
\hline 97 & 4180088 & 495 & Erik & $18 / 04$ \\
\hline 97 & 4180089 & 474 & Erik & $18 / 04$ \\
\hline 97 & 4180090 & 533 & Erik & $18 / 04$ \\
\hline 40 & 4190003 & 701 & Andrew & 19/04 \\
\hline 40 & 4190004 & 727 & Andrew & 19/04 \\
\hline 40 & 4190005 & 363 & Andrew & 19/04 \\
\hline 40 & 4190006 & 535 & Andrew & 19/04 \\
\hline 40 & 4190007 & 702 & Andrew & 19/04 \\
\hline 40 & 4190008 & 430 & Andrew & 19/04 \\
\hline 40 & 4190009 & 418 & Andrew & 19/04 \\
\hline 40 & 4190010 & 473 & Andrew & 19/04 \\
\hline 40 & 4190011 & 474 & Andrew & 19/04 \\
\hline 40 & 4190012 & 462 & Andrew & $19 / 04$ \\
\hline 40 & 4190013 & 701 & Andrew & 19/04 \\
\hline 40 & 4190014 & 912 & Andrew & $19 / 04$ \\
\hline 40 & 4190015 & 415 & Andrew & $19 / 04$ \\
\hline 40 & 4190017 & 525 & Andrew & $19 / 04$ \\
\hline 40 & 4190018 & 449 & Andrew & 19/04 \\
\hline 40 & 4190019 & 619 & Andrew & 19/04 \\
\hline 40 & 4190020 & 343 & Andrew & 19/04 \\
\hline 40 & 4190021 & 577 & Andrew & 19/04 \\
\hline 40 & 4190022 & 686 & Andrew & 19/04 \\
\hline 40 & 4190023 & 377 & Andrew & 19/04 \\
\hline 40 & 4190024 & 466 & Andrew & $19 / 04$ \\
\hline 40 & 4190025 & 244 & Andrew & 19/04 \\
\hline 40 & 4190026 & 839 & Andrew & $19 / 04$ \\
\hline 40 & 4190027 & 1005 & Andrew & 19/04 \\
\hline 40 & 4190028 & 554 & Andrew & $19 / 04$ \\
\hline 40 & 4190029 & 587 & Andrew & 19/04 \\
\hline 40 & 4190030 & 764 & Andrew & $19 / 04$ \\
\hline 40 & 4190031 & 865 & Andrew & 19/04 \\
\hline 40 & 4190032 & 506 & Andrew & 19/04 \\
\hline 40 & 4190033 & 954 & Andrew & 19/04 \\
\hline 40 & 4190034 & 966 & Andrew & $19 / 04$ \\
\hline 40 & 4190035 & 774 & Andrew & 19/04 \\
\hline 40 & 4190036 & 522 & Andrew & $19 / 04$ \\
\hline 40 & 4190037 & 577 & Andrew & 19/04 \\
\hline 40 & 4190038 & 588 & Andrew & $19 / 04$ \\
\hline 40 & 4190039 & 661 & Andrew & 19/04 \\
\hline 40 & 4190040 & 496 & Andrew & 19/04 \\
\hline 40 & 4190041 & 484 & Andrew & 19/04 \\
\hline 40 & 4190043 & 517 & Andrew & 19/04 \\
\hline 40 & 4190044 & 676 & Andrew & $19 / 04$ \\
\hline 40 & 4190045 & 673 & Andrew & 19/04 \\
\hline 40 & 4190046 & 823 & Andrew & 19/04 \\
\hline
\end{tabular}




\begin{tabular}{|c|c|c|c|c|}
\hline 40 & 4190047 & 403 & Andrew & $19 / 04$ \\
\hline 40 & 4190048 & 758 & Andrew & $19 / 04$ \\
\hline 40 & 4190049 & 567 & Andrew & $19 / 04$ \\
\hline 40 & 4190050 & 907 & Andrew & $19 / 04$ \\
\hline 40 & 4190051 & 813 & Andrew & $19 / 04$ \\
\hline 40 & 4190052 & 661 & Andrew & $19 / 04$ \\
\hline 40 & 4190053 & 543 & Andrew & $19 / 04$ \\
\hline 40 & 4190054 & 646 & Andrew & $19 / 04$ \\
\hline 40 & 4190055 & 1179 & Andrew & $19 / 04$ \\
\hline 40 & 4190056 & 614 & Andrew & $19 / 04$ \\
\hline 40 & 4190057 & 445 & Andrew & $19 / 04$ \\
\hline 40 & 4190058 & 947 & Andrew & $19 / 04$ \\
\hline 40 & 4190059 & 570 & Andrew & $19 / 04$ \\
\hline 40 & 4190060 & 671 & Andrew & $19 / 04$ \\
\hline 40 & 4190061 & 520 & Andrew & $19 / 04$ \\
\hline 40 & 4190062 & 380 & Andrew & $19 / 04$ \\
\hline 40 & 4190063 & 617 & Andrew & $19 / 04$ \\
\hline 40 & 4190064 & 627 & Andrew & $19 / 04$ \\
\hline 40 & 4190065 & 541 & Andrew & $19 / 04$ \\
\hline 40 & 4190066 & 612 & Andrew & $19 / 04$ \\
\hline 40 & 4190067 & 513 & Andrew & $19 / 04$ \\
\hline 40 & 4190068 & 361 & Andrew & $19 / 04$ \\
\hline 40 & 4190069 & 575 & Andrew & $19 / 04$ \\
\hline 40 & 4190070 & 795 & Andrew & $19 / 04$ \\
\hline 40 & 4190071 & 954 & Andrew & $19 / 04$ \\
\hline 40 & 4190072 & 771 & Andrew & $19 / 04$ \\
\hline 40 & 4190073 & 662 & Andrew & $19 / 04$ \\
\hline 54 & 4200001 & 700 & Andrew & $20 / 04$ \\
\hline 54 & 4200002 & 414 & Andrew & $20 / 04$ \\
\hline 54 & 4200003 & 624 & Andrew & $20 / 04$ \\
\hline 54 & 4200004 & 532 & Andrew & $20 / 04$ \\
\hline 54 & 4200005 & 447 & Andrew & $20 / 04$ \\
\hline 54 & 4200006 & 559 & Andrew & $20 / 04$ \\
\hline 54 & 4200007 & 571 & Andrew & $20 / 04$ \\
\hline 54 & 4200008 & 667 & Andrew & $20 / 04$ \\
\hline 54 & 4200009 & 454 & Andrew & $20 / 04$ \\
\hline 54 & 4200010 & 564 & Andrew & $20 / 04$ \\
\hline 54 & 4200011 & 696 & Andrew & $20 / 04$ \\
\hline 54 & 4200012 & 763 & Andrew & $20 / 04$ \\
\hline 54 & 4200013 & 512 & Andrew & $20 / 04$ \\
\hline 54 & 4200014 & 626 & Andrew & $20 / 04$ \\
\hline 54 & 4200015 & 461 & Andrew & $20 / 04$ \\
\hline 54 & 4200016 & 536 & Andrew & $20 / 04$ \\
\hline 54 & 4200017 & 637 & Andrew & $20 / 04$ \\
\hline 54 & 4200018 & 602 & Andrew & $20 / 04$ \\
\hline 54 & 4200019 & 562 & Andrew & $20 / 04$ \\
\hline
\end{tabular}




\begin{tabular}{|c|c|c|c|c|}
\hline 54 & 4200020 & 598 & Andrew & $20 / 04$ \\
\hline 54 & 4200021 & 543 & Andrew & $20 / 04$ \\
\hline 54 & 4200022 & 823 & Andrew & $20 / 04$ \\
\hline 54 & 4200023 & 371 & Andrew & $20 / 04$ \\
\hline 54 & 4200024 & 875 & Andrew & $20 / 04$ \\
\hline 54 & 4200025 & 653 & Andrew & $20 / 04$ \\
\hline 54 & 4200026 & 545 & Andrew & $20 / 04$ \\
\hline 54 & 4200027 & 600 & Andrew & $20 / 04$ \\
\hline 54 & 4200028 & 504 & Andrew & $20 / 04$ \\
\hline 54 & 4200029 & 360 & Andrew & $20 / 04$ \\
\hline 54 & 4200030 & 625 & Andrew & $20 / 04$ \\
\hline 54 & 4200031 & 580 & Andrew & $20 / 04$ \\
\hline 54 & 4200032 & 653 & Andrew & $20 / 04$ \\
\hline 54 & 4200033 & 776 & Andrew & $20 / 04$ \\
\hline 54 & 4200034 & 581 & Andrew & $20 / 04$ \\
\hline 54 & 4200035 & 554 & Tristan & $20 / 04$ \\
\hline 54 & 4200036 & 515 & Tristan & $20 / 04$ \\
\hline 54 & 4200037 & 554 & Tristan & $20 / 04$ \\
\hline 54 & 4200038 & 223 & Tristan & $20 / 04$ \\
\hline 54 & 4200039 & 663 & Tristan & $20 / 04$ \\
\hline 54 & 4200040 & 597 & Tristan & $20 / 04$ \\
\hline 54 & 4200041 & 415 & Tristan & $20 / 04$ \\
\hline 54 & 4200042 & 794 & Tristan & $20 / 04$ \\
\hline 54 & 4200043 & 586 & Tristan & $20 / 04$ \\
\hline 54 & 4200044 & 695 & Tristan & $20 / 04$ \\
\hline 54 & 4200045 & 663 & Tristan & $20 / 04$ \\
\hline 54 & 4200046 & 816 & Tristan & $20 / 04$ \\
\hline 54 & 4200047 & 383 & Tristan & $20 / 04$ \\
\hline 54 & 4200048 & 211 & Tristan & $20 / 04$ \\
\hline 54 & 4200049 & 470 & Tristan & $20 / 04$ \\
\hline 54 & 4200050 & 499 & Tristan & $20 / 04$ \\
\hline 54 & 4200051 & 471 & Tristan & $20 / 04$ \\
\hline 54 & 4200052 & 809 & Tristan & $20 / 04$ \\
\hline 54 & 4200053 & 602 & Tristan & $20 / 04$ \\
\hline 54 & 4200054 & 412 & Tristan & $20 / 04$ \\
\hline 54 & 4200055 & 631 & Tristan & $20 / 04$ \\
\hline 54 & 4200056 & 663 & Tristan & $20 / 04$ \\
\hline 54 & 4200057 & 553 & Tristan & $20 / 04$ \\
\hline 54 & 4200058 & 559 & Tristan & $20 / 04$ \\
\hline 54 & 4200059 & 751 & Tristan & $20 / 04$ \\
\hline 54 & 4200060 & 633 & Tristan & $20 / 04$ \\
\hline 54 & 4200061 & 728 & Tristan & $20 / 04$ \\
\hline 54 & 4200062 & 690 & Tristan & $20 / 04$ \\
\hline 54 & 4200063 & 436 & Tristan & $20 / 04$ \\
\hline 54 & 4200064 & 575 & Tristan & $20 / 04$ \\
\hline 54 & 4200065 & 590 & Tristan & $20 / 04$ \\
\hline
\end{tabular}




\begin{tabular}{|c|c|c|c|c|}
\hline 54 & 4200066 & 979 & Tristan & $20 / 04$ \\
\hline 54 & 4200067 & 836 & Tristan & $20 / 04$ \\
\hline 54 & 4200068 & 473 & Tristan & $20 / 04$ \\
\hline 54 & 4200069 & 550 & Tristan & $20 / 04$ \\
\hline 54 & 4200070 & 405 & Tristan & $20 / 04$ \\
\hline 54 & 4200071 & 704 & Tristan & $20 / 04$ \\
\hline 54 & 4200072 & 652 & Tristan & $20 / 04$ \\
\hline 54 & 4200073 & 418 & Tristan & $20 / 04$ \\
\hline 54 & 4200074 & 363 & Tristan & $20 / 04$ \\
\hline 54 & 4200075 & 580 & Tristan & $20 / 04$ \\
\hline 54 & 4200076 & 614 & Tristan & $20 / 04$ \\
\hline 54 & 4200077 & 582 & Tristan & $20 / 04$ \\
\hline 54 & 4200078 & 506 & Tristan & $20 / 04$ \\
\hline 54 & 4200079 & 405 & Tristan & $20 / 04$ \\
\hline 54 & 4200080 & 770 & Tristan & $20 / 04$ \\
\hline 58 & 4200086 & 266 & Tristan & $20 / 04$ \\
\hline 3 & 4210010 & 853 & Andrew & $21 / 04$ \\
\hline 20 & 4220001 & 697 & Andrew & $22 / 04$ \\
\hline 20 & 4220002 & 254 & Andrew & $22 / 04$ \\
\hline 28 & 4220044 & 617 & Andrew & $22 / 04$ \\
\hline 28 & 4220045 & 764 & Sara & $22 / 04$ \\
\hline 28 & 4220046 & 729 & Sara & $22 / 04$ \\
\hline 28 & 4220078 & 880 & Sara & $22 / 04$ \\
\hline 28 & 4220079 & 533 & Sara & $22 / 04$ \\
\hline 28 & 4220080 & 584 & Sara & $22 / 04$ \\
\hline 28 & 4220083 & 611 & Sara & $22 / 04$ \\
\hline 28 & 4220084 & 520 & Sara & $22 / 04$ \\
\hline 28 & 4220085 & 540 & Sara & $22 / 04$ \\
\hline 28 & 4220095 & 843 & Sara & $22 / 04$ \\
\hline 28 & 4220096 & 626 & Sara & $22 / 04$ \\
\hline 28 & 4220097 & 1033 & Sara & $22 / 04$ \\
\hline 89 & 4250005 & 563 & Andrew & $25 / 04$ \\
\hline 89 & 4250006 & 369 & Andrew & $25 / 04$ \\
\hline 89 & 4250007 & 96 & Andrew & $25 / 04$ \\
\hline 89 & 4250008 & 412 & Andrew & $25 / 04$ \\
\hline 89 & 4250009 & 439 & Andrew & $25 / 04$ \\
\hline 89 & 4250010 & 867 & Andrew & $25 / 04$ \\
\hline 89 & 4250011 & 274 & Andrew & $25 / 04$ \\
\hline 89 & 4250012 & 372 & Andrew & $25 / 04$ \\
\hline 89 & 4250013 & 559 & Andrew & $25 / 04$ \\
\hline 89 & 4250014 & 572 & Andrew & $25 / 04$ \\
\hline 89 & 4250015 & 487 & Andrew & $25 / 04$ \\
\hline 89 & 4250016 & 601 & Andrew & $25 / 04$ \\
\hline 89 & 4250017 & 777 & Andrew & $25 / 04$ \\
\hline 89 & 4250018 & 402 & Andrew & $25 / 04$ \\
\hline 89 & 4250019 & 543 & Andrew & $25 / 04$ \\
\hline
\end{tabular}




\begin{tabular}{|c|c|c|c|c|}
\hline 89 & 4250020 & 969 & Andrew & $25 / 04$ \\
\hline 89 & 4250021 & 558 & Andrew & $25 / 04$ \\
\hline 89 & 4250022 & 557 & Andrew & $25 / 04$ \\
\hline 89 & 4250023 & 575 & Andrew & $25 / 04$ \\
\hline 89 & 4250024 & 693 & Andrew & $25 / 04$ \\
\hline 89 & 4250025 & 513 & Andrew & $25 / 04$ \\
\hline 89 & 4250026 & 527 & Andrew & $25 / 04$ \\
\hline 89 & 4250027 & 787 & Andrew & $25 / 04$ \\
\hline 89 & 4250028 & 529 & Andrew & $25 / 04$ \\
\hline 89 & 4250029 & 577 & Andrew & $25 / 04$ \\
\hline 89 & 4250030 & 405 & Andrew & $25 / 04$ \\
\hline 89 & 4250031 & 654 & Andrew & $25 / 04$ \\
\hline 89 & 4250032 & 850 & Andrew & $25 / 04$ \\
\hline 89 & 4250033 & 509 & Andrew & $25 / 04$ \\
\hline 89 & 4250034 & 251 & Andrew & $25 / 04$ \\
\hline 89 & 4250035 & 561 & Andrew & $25 / 04$ \\
\hline 89 & 4250036 & 531 & Andrew & $25 / 04$ \\
\hline 89 & 4250037 & 536 & Andrew & $25 / 04$ \\
\hline 89 & 4250038 & 587 & Andrew & $25 / 04$ \\
\hline 89 & 4250039 & 603 & Andrew & $25 / 04$ \\
\hline 89 & 4250040 & 543 & Andrew & $25 / 04$ \\
\hline 89 & 4250041 & 404 & Andrew & $25 / 04$ \\
\hline 89 & 4250042 & 620 & Andrew & $25 / 04$ \\
\hline 89 & 4250043 & 590 & Andrew & $25 / 04$ \\
\hline 89 & 4250044 & 675 & Andrew & $25 / 04$ \\
\hline 89 & 4250045 & 858 & Andrew & $25 / 04$ \\
\hline 89 & 4250046 & 490 & Andrew & $25 / 04$ \\
\hline 89 & 4250047 & 611 & Andrew & $25 / 04$ \\
\hline 89 & 4250048 & 621 & Andrew & $25 / 04$ \\
\hline 89 & 4250049 & 235 & Andrew & $25 / 04$ \\
\hline 89 & 4250050 & 239 & Andrew & $25 / 04$ \\
\hline 89 & 4250051 & 437 & Andrew & $25 / 04$ \\
\hline 89 & 4250052 & 445 & Andrew & $25 / 04$ \\
\hline 89 & 4250053 & 722 & Andrew & $25 / 04$ \\
\hline 89 & 4250054 & 547 & Andrew & $25 / 04$ \\
\hline 89 & 4250055 & 448 & Andrew & $25 / 04$ \\
\hline 89 & 4250056 & 565 & Andrew & $25 / 04$ \\
\hline 89 & 4250057 & 211 & Andrew & $25 / 04$ \\
\hline 89 & 4250058 & 283 & Andrew & $25 / 04$ \\
\hline 89 & 4250059 & 588 & Andrew & $25 / 04$ \\
\hline 89 & 4250060 & 327 & Andrew & $25 / 04$ \\
\hline 89 & 4250061 & 621 & Andrew & $25 / 04$ \\
\hline 89 & 4250062 & 286 & Andrew & $25 / 04$ \\
\hline 89 & 4250063 & 784 & Andrew & $25 / 04$ \\
\hline 89 & 4250064 & 530 & Andrew & $25 / 04$ \\
\hline 89 & 4250065 & 326 & Andrew & $25 / 04$ \\
\hline
\end{tabular}




\begin{tabular}{|c|c|c|c|c|}
\hline 89 & 4250066 & 437 & Andrew & $25 / 04$ \\
\hline 89 & 4250067 & 494 & Andrew & $25 / 04$ \\
\hline 89 & 4250068 & 546 & Andrew & $25 / 04$ \\
\hline 89 & 4250069 & 621 & Andrew & $25 / 04$ \\
\hline 89 & 4250070 & 461 & Andrew & $25 / 04$ \\
\hline 56 & 4280044 & 317 & Erik & $28 / 04$ \\
\hline 56 & 4280063 & 280 & Erik & $28 / 04$ \\
\hline 56 & 4280064 & 514 & Erik & $28 / 04$ \\
\hline 56 & 4280072 & 189 & Erik & $28 / 04$ \\
\hline 56 & 4280073 & 177 & Erik & $28 / 04$ \\
\hline 56 & 4280074 & 237 & Erik & $28 / 04$ \\
\hline 56 & 4280075 & 422 & Erik & $28 / 04$ \\
\hline 56 & 4280078 & 255 & Erik & $28 / 04$ \\
\hline 56 & 4280085 & 299 & Erik & $28 / 04$ \\
\hline 56 & 4280086 & 269 & Erik & $28 / 04$ \\
\hline 91 & 4280089 & 565 & Andrew & $28 / 04$ \\
\hline 91 & 4310090 & 478 & Andrew & $28 / 04$ \\
\hline 91 & 4340092 & 445 & Andrew & $28 / 04$ \\
\hline 27 & 42900095 & 562 & Caitlyn & $29 / 04$ \\
\hline 66 & 42900096 & 436 & Caitlyn & $29 / 04$ \\
\hline 66 & 42900097 & 694 & Caitlyn & $29 / 04$ \\
\hline 12 & 5020038 & 870 & Andrew & $02 / 05$ \\
\hline 12 & 5020039 & 750 & Andrew & $02 / 05$ \\
\hline 12 & 5020040 & 662 & Andrew & $02 / 05$ \\
\hline 12 & 5020041 & 589 & Andrew & $02 / 05$ \\
\hline 12 & 5020042 & 565 & Andrew & $02 / 05$ \\
\hline
\end{tabular}

Table F: Surveyed wood frog egg masses that were missed by observer 1 but noticed by observer 2 during surveys of ponds in Eastern Ontario showing who was observer 1 and the number of masses missed

\begin{tabular}{|c|c|c|c|}
\hline Site & Observer & Missed Egg Masses & Date \\
\hline 11 & Andrew & 3 & $14 / 04$ \\
\hline 15 & Andrew & 1 & $15 / 04$ \\
\hline 89 & Erik & 4 & $25 / 04$ \\
\hline 89 & Andrew & 1 & $25 / 04$ \\
\hline 56 & Erik & 1 & $28 / 04$ \\
\hline 27 & Caitlyn & 13 & $29 / 04$ \\
\hline 40 & Andrew & 1 & $03 / 05$ \\
\hline 34 & Jessica & 1 & $04 / 05$ \\
\hline 109 & Andrew & 5 & $05 / 05$ \\
\hline
\end{tabular}


Table G: Wood frog egg masses that were counted for abundance measures but could not be photographed because the masses were no longer intact and individuals were soon to emerge or had already begun emerging

\begin{tabular}{|c|c|c|c|}
\hline Site & Egg Masses Counted (no picture) & Observer & Date \\
\hline 97 & 361 & Andrew & $18 / 04$ \\
\hline 40 & 6 & Andrew & $19 / 04$ \\
\hline 54 & 13 & Andrew & $20 / 04$ \\
\hline 3 & 1 & Andrew & $21 / 04$ \\
\hline 28 & 10 & Andrew & $22 / 04$ \\
\hline 90 & 2 & Andrew & $25 / 04$ \\
\hline 89 & 308 & Andrew & $25 / 04$ \\
\hline 56 & 12 & Andrew & $28 / 04$ \\
\hline 91 & 42 & Andrew & $28 / 04$ \\
\hline 66 & 2 & Caitlyn & $29 / 04$ \\
\hline 15 & 116 & Andrew & $02 / 05$ \\
\hline 13 & 26 & Erik & $02 / 05$ \\
\hline 42 & 3 & Andrew & $03 / 05$ \\
\hline 109 & 5 & Andrew & $05 / 05$ \\
\hline
\end{tabular}


Table H: Local habitat measurements for all 34 surveyed landscapes showing; DO as dissolved oxygen, $\mathrm{pH}$, EC as electrical conductivity, temperature, submergent and emergent vegetation estimated based on percent cover, pond depth, pond perimeter, and pond area.

\begin{tabular}{|c|c|c|c|c|c|c|c|c|}
\hline Site & $\mathrm{DO}(\mathrm{mg} / \mathrm{L})$ & $\mathrm{pH}$ & $\mathrm{EC}(\mathrm{uS})$ & Temperature $\left({ }^{\circ} \mathrm{C}\right)$ & Vegetation (0-5) & Depth $(\mathrm{cm})$ & Perimeter (m) & $\operatorname{Area}\left(\mathrm{m}^{2}\right)$ \\
\hline 3 & 7.93 & 7.26 & 258 & 8.4 & 4 & 28.0 & 102 & 617 \\
\hline 6 & 8.00 & 8.05 & 494 & 15.1 & 1 & 59.5 & 114 & 738 \\
\hline 7 & 6.99 & 7.21 & 122 & 19.3 & 4 & 150.0 & 320 & 4890 \\
\hline 8 & 9.12 & 7.39 & 87 & 11.9 & 4 & 67.0 & 239 & 2507 \\
\hline 10 & 6.36 & 7.92 & 57 & 8.6 & 4 & 118.0 & 279 & 1642 \\
\hline 11 & 8.77 & 7.08 & 84 & 13.3 & 4 & 17.0 & 175 & 1677 \\
\hline 12 & 3.17 & 6.51 & 150 & 11.1 & 3 & 61.0 & 260 & 2145 \\
\hline 13 & 1.25 & 4.34 & 22 & 7.3 & 2 & 29.0 & 184 & 737 \\
\hline 15 & 6.17 & 6.46 & 78 & 11.8 & 3 & 45.0 & 110 & 330 \\
\hline 20 & 4.18 & 7.83 & 295 & 14.1 & 4 & 46.5 & 200 & 1237 \\
\hline 22 & 8.19 & 7.62 & 377 & 13.4 & 5 & 33.5 & 50 & 149 \\
\hline 27 & 5.83 & 7.35 & 306 & 9.7 & 2 & 18.0 & 77 & 279 \\
\hline 28 & 2.91 & 7.72 & 389 & 15.1 & 5 & 48.0 & 334 & 6636 \\
\hline 31 & 2.09 & 7.40 & 1866 & 12.0 & 3 & 19.0 & 77 & 178 \\
\hline 32 & 3.71 & 6.96 & 51 & 10.7 & 4 & 10.0 & 197 & 675 \\
\hline 34 & 7.21 & 7.26 & 258 & 8.4 & 4 & 28.0 & 102 & 617 \\
\hline 38 & 10.22 & 7.60 & 301 & 6.8 & 3 & 82.5 & 100 & 535 \\
\hline 39 & 6.84 & 7.85 & 304 & 10.0 & 4 & 40.0 & 184 & 1700 \\
\hline 40 & 5.70 & 8.1 & 7.2 & 16.4 & 3 & 22.5 & 194 & 1780 \\
\hline 42 & 6.47 & 7.93 & 715 & 16.3 & 2 & 74.0 & 80 & 432 \\
\hline 54 & 2.32 & 7.5 & 293 & 9.2 & 5 & 29.0 & 357 & 5070 \\
\hline 56 & 2.79 & 7.72 & 69 & 4.6 & 2 & 24.0 & 332 & 1445 \\
\hline 58 & 6.70 & 7.46 & 236 & 14.6 & 2 & 25.0 & 224 & 1791 \\
\hline 59 & 8.00 & 7.66 & 368 & 11.7 & 4 & 38.0 & 107 & 509 \\
\hline 66 & 8.75 & 7.72 & 272 & 11.0 & 3 & 100.0 & 110 & 840 \\
\hline 88 & 8.30 & 8.58 & 1257 & 14.6 & 4 & 28.0 & 199 & 2213 \\
\hline 89 & 5.97 & 7.78 & 230 & 6.6 & 5 & 60.5 & 284 & 2724 \\
\hline 90 & 8.33 & 8.06 & 585 & 10.9 & 4 & 22.5 & 198 & 1232 \\
\hline 91 & 6.40 & 7.36 & 149 & 14.5 & 4 & 16.5 & 108 & 554 \\
\hline 92 & 5.99 & 7.64 & 521 & 17.1 & 5 & 68.0 & 174 & 1700 \\
\hline 97 & 4.94 & 7.50 & 185 & 13 & 4 & 64.0 & 379 & 4795 \\
\hline 99 & 20.0 & 9.54 & 278 & 15.9 & 1 & 50.0 & 251 & 3453 \\
\hline 109 & 5.57 & 7.18 & 421 & 11.5 & 4 & 45.5 & 310 & 2720 \\
\hline 122 & 8.12 & 7.72 & 379 & 17 & 4 & 100.0 & 197 & 871 \\
\hline
\end{tabular}


Table I: Landscape predictor measurements of road density measured in $\mathrm{km} / \mathrm{km}^{2}$ for all 34 landscapes where wood frog egg masses were surveyed

\begin{tabular}{|c|c|c|c|c|c|c|c|c|c|c|c|c|c|c|c|}
\hline L.R $(\mathrm{km}) \rightarrow$ & 0.1 & 0.2 & 0.3 & 0.4 & 0.5 & 0.6 & 0.7 & 0.8 & 0.9 & 1.0 & 1.1 & 1.2 & 1.3 & 1.4 & 1.5 \\
\hline \multicolumn{16}{|l|}{ Site $\downarrow$} \\
\hline 3 & 8.73 & 5.64 & 4.02 & 3.12 & 5.98 & 5.44 & 4.94 & 4.10 & 3.24 & 2.62 & 2.17 & 1.82 & 1.55 & 1.63 & 1.42 \\
\hline 6 & 3.69 & 2.91 & 2.05 & 1.56 & 3.40 & 2.36 & 1.73 & 1.33 & 1.05 & 0.85 & 0.70 & 0.59 & 0.50 & 2.22 & 1.94 \\
\hline 7 & 0.00 & 2.31 & 4.42 & 3.65 & 6.59 & 4.57 & 5.09 & 5.15 & 4.07 & 4.80 & 4.68 & 3.93 & 3.40 & 3.52 & 3.30 \\
\hline 8 & 0.00 & 2.45 & 1.92 & 1.51 & 3.90 & 2.71 & 1.99 & 2.81 & 2.22 & 1.80 & 1.48 & 1.25 & 1.06 & 1.60 & 1.82 \\
\hline 10 & 0.00 & 2.35 & 1.90 & 2.54 & 7.84 & 5.44 & 4.00 & 3.06 & 2.42 & 1.96 & 1.62 & 1.36 & 1.16 & 1.29 & 1.29 \\
\hline 11 & 5.59 & 3.10 & 2.10 & 1.59 & 5.65 & 3.93 & 2.89 & 3.77 & 2.98 & 2.41 & 2.00 & 1.68 & 2.00 & 1.73 & 2.39 \\
\hline 12 & 0.00 & 0.00 & 0.00 & 0.54 & 2.31 & 1.60 & 1.18 & 0.90 & 1.57 & 3.40 & 3.33 & 2.80 & 2.38 & 2.06 & 1.79 \\
\hline 13 & 0.00 & 0.00 & 1.60 & 1.39 & 2.85 & 1.98 & 2.04 & 1.56 & 1.24 & 1.00 & 0.83 & 0.70 & 0.59 & 1.02 & 0.89 \\
\hline 15 & 0.00 & 0.00 & 0.00 & 1.05 & 4.40 & 4.48 & 4.53 & 4.38 & 4.10 & 3.79 & 3.55 & 3.69 & 3.80 & 3.46 & 3.19 \\
\hline 20 & 11.80 & 7.47 & 5.60 & 4.04 & 11.99 & 8.32 & 6.12 & 4.68 & 3.76 & 3.27 & 2.82 & 2.55 & 2.40 & 2.15 & 1.97 \\
\hline 22 & 0.00 & 0.00 & 0.84 & 1.52 & 4.46 & 3.10 & 2.28 & 1.74 & 1.38 & 2.03 & 1.94 & 2.25 & 1.92 & 2.84 & 2.47 \\
\hline 27 & 0.00 & 0.00 & 0.00 & 0.97 & 3.00 & 2.08 & 1.53 & 1.17 & 1.92 & 2.80 & 2.31 & 1.94 & 1.66 & 1.43 & 1.90 \\
\hline 28 & 0.00 & 0.00 & 0.00 & 0.00 & 3.43 & 2.38 & 1.75 & 1.34 & 1.92 & 1.55 & 1.35 & 1.13 & 1.42 & 1.23 & 1.07 \\
\hline 31 & 7.86 & 7.67 & 5.67 & 4.42 & 15.54 & 12.10 & 8.89 & 6.80 & 5.38 & 4.35 & 3.60 & 3.02 & 2.58 & 2.22 & 2.33 \\
\hline 32 & 0.00 & 0.00 & 0.00 & 0.96 & 2.25 & 1.65 & 1.31 & 1.85 & 1.46 & 3.85 & 3.18 & 2.67 & 2.28 & 1.96 & 1.80 \\
\hline 34 & 0.00 & 4.32 & 3.69 & 2.74 & 2.51 & 2.74 & 3.34 & 3.77 & 3.52 & 4.15 & 3.56 & 3.09 & 5.81 & 5.32 & 4.84 \\
\hline 38 & 0.00 & 0.00 & 1.56 & 1.37 & 5.09 & 7.35 & 5.40 & 4.13 & 3.26 & 2.64 & 3.79 & 3.19 & 2.72 & 2.34 & 2.04 \\
\hline 39 & 0.00 & 0.00 & 1.46 & 1.34 & 4.59 & 4.66 & 3.72 & 2.85 & 2.71 & 3.10 & 3.06 & 2.74 & 2.33 & 2.01 & 1.96 \\
\hline 40 & 0.00 & 1.79 & 1.77 & 1.45 & 2.24 & 1.73 & 1.56 & 5.66 & 5.01 & 4.22 & 3.80 & 4.19 & 3.81 & 3.77 & 3.46 \\
\hline 42 & 0.00 & 2.59 & 3.12 & 2.50 & 3.60 & 2.50 & 3.27 & 2.58 & 2.32 & 1.88 & 1.55 & 2.04 & 1.74 & 1.50 & 1.31 \\
\hline 54 & 5.42 & 2.99 & 2.04 & 1.69 & 6.36 & 4.99 & 3.97 & 3.04 & 2.40 & 1.95 & 1.61 & 1.66 & 1.41 & 1.22 & 1.06 \\
\hline 56 & 0.00 & 0.00 & 1.20 & 1.26 & 2.11 & 1.46 & 1.17 & 1.32 & 2.32 & 2.12 & 1.93 & 2.67 & 2.59 & 2.23 & 1.95 \\
\hline 58 & 0.00 & 0.00 & 0.00 & 0.00 & 0.00 & 0.00 & 0.00 & 0.21 & 0.17 & 0.13 & 0.11 & 0.41 & 0.49 & 0.57 & 0.97 \\
\hline 59 & 1.55 & 2.76 & 1.99 & 2.10 & 26.17 & 18.17 & 13.35 & 10.22 & 8.08 & 6.54 & 5.41 & 4.79 & 4.08 & 3.52 & 3.07 \\
\hline 66 & 0.00 & 0.00 & 0.00 & 0.00 & 0.00 & 0.00 & 0.00 & 0.00 & 0.09 & 0.46 & 1.68 & 2.10 & 1.79 & 1.54 & 1.41 \\
\hline 88 & 3.34 & 2.91 & 3.13 & 2.98 & 14.65 & 11.15 & 8.19 & 6.27 & 4.96 & 4.01 & 3.32 & 2.79 & 2.38 & 2.05 & 1.78 \\
\hline 89 & 0.00 & 0.00 & 0.00 & 0.00 & 3.60 & 2.50 & 1.84 & 1.41 & 1.11 & 0.90 & 0.74 & 0.63 & 0.53 & 1.40 & 1.22 \\
\hline 90 & 0.00 & 0.00 & 1.05 & 2.37 & 5.69 & 3.98 & 3.10 & 2.66 & 2.10 & 1.71 & 1.77 & 1.62 & 1.48 & 1.37 & 1.73 \\
\hline 91 & 0.00 & 2.02 & 2.68 & 2.73 & 9.90 & 7.07 & 6.03 & 4.63 & 3.66 & 2.96 & 2.63 & 2.25 & 2.12 & 1.98 & 1.99 \\
\hline 92 & 6.26 & 6.18 & 6.57 & 6.75 & 8.31 & 6.78 & 5.57 & 5.30 & 5.17 & 5.46 & 5.75 & 5.41 & 5.03 & 5.02 & 4.77 \\
\hline 97 & 0.00 & 0.00 & 1.31 & 1.29 & 1.62 & 1.12 & 1.63 & 8.23 & 6.51 & 5.27 & 4.35 & 3.66 & 3.12 & 2.69 & 2.68 \\
\hline 99 & 5.86 & 3.13 & 2.11 & 1.59 & 1.82 & 4.40 & 3.23 & 2.48 & 4.03 & 3.26 & 2.70 & 3.07 & 3.21 & 2.77 & 2.41 \\
\hline 109 & 1.44 & 4.01 & 2.53 & 1.86 & 2.06 & 1.75 & 1.28 & 1.78 & 1.55 & 1.72 & 1.60 & 1.64 & 1.59 & 1.73 & 1.66 \\
\hline 122 & 0.00 & 0.00 & 0.00 & 0.00 & 0.00 & 0.00 & 2.98 & 2.28 & 1.80 & 1.52 & 1.26 & 1.15 & 1.22 & 1.91 & 2.40 \\
\hline
\end{tabular}


Table I (continued): Landscape predictor measurements of road density measured in $\mathrm{km} / \mathrm{km}^{2}$ for all 34 landscapes where wood frog egg masses were surveyed

\begin{tabular}{|c|c|c|c|c|c|c|c|c|c|c|c|c|c|c|c|}
\hline L.R $(\mathrm{km}) \rightarrow$ & 1.6 & 1.7 & 1.8 & 1.9 & 2.0 & 2.1 & 2.2 & 2.3 & 2.4 & 2.5 & 2.6 & 2.7 & 2.8 & 2.9 & 3.0 \\
\hline \multicolumn{16}{|l|}{ Site $\downarrow$} \\
\hline 3 & 1.25 & 1.11 & 0.99 & 1.41 & 1.97 & 1.78 & 1.63 & 1.63 & 1.50 & 1.38 & 1.27 & 1.18 & 1.11 & 1.04 & 1.02 \\
\hline 6 & 1.70 & 1.51 & 1.34 & 1.21 & 1.09 & 0.99 & 0.97 & 1.39 & 1.31 & 1.21 & 1.11 & 1.31 & 1.24 & 1.30 & 1.21 \\
\hline 7 & 2.90 & 2.57 & 2.73 & 2.64 & 2.53 & 2.30 & 2.27 & 2.08 & 1.99 & 2.23 & 2.07 & 1.92 & 1.78 & 1.66 & 1.55 \\
\hline 8 & 1.60 & 1.70 & 1.52 & 1.36 & 1.48 & 1.35 & 1.23 & 1.12 & 1.33 & 1.38 & 1.28 & 1.20 & 1.12 & 1.23 & 1.32 \\
\hline 10 & 2.06 & 1.83 & 1.94 & 1.95 & 1.76 & 1.60 & 1.45 & 1.33 & 1.22 & 1.26 & 1.29 & 1.20 & 1.30 & 1.55 & 1.49 \\
\hline 11 & 2.10 & 1.86 & 1.66 & 1.49 & 1.34 & 1.22 & 1.11 & 1.03 & 1.03 & 0.96 & 1.17 & 1.19 & 1.11 & 1.20 & 1.19 \\
\hline 12 & 1.57 & 1.56 & 1.39 & 1.62 & 1.46 & 1.32 & 1.27 & 1.16 & 1.31 & 1.34 & 1.24 & 1.15 & 1.07 & 1.20 & 1.30 \\
\hline 13 & 1.15 & 1.52 & 1.45 & 1.31 & 1.35 & 1.29 & 1.38 & 1.26 & 1.30 & 1.20 & 1.11 & 1.04 & 1.00 & 1.02 & 1.03 \\
\hline 15 & 2.89 & 3.70 & 3.30 & 3.04 & 3.10 & 2.82 & 2.71 & 3.16 & 2.90 & 2.72 & 2.66 & 2.54 & 2.57 & 2.46 & 2.30 \\
\hline 20 & 1.87 & 2.36 & 2.47 & 2.60 & 2.47 & 2.24 & 2.09 & 1.91 & 1.75 & 1.67 & 1.58 & 1.47 & 1.49 & 1.50 & 1.51 \\
\hline 22 & 2.17 & 1.92 & 1.72 & 1.91 & 2.01 & 2.07 & 1.88 & 1.72 & 1.58 & 1.92 & 1.77 & 1.64 & 1.53 & 1.54 & 1.51 \\
\hline 27 & 1.67 & 1.48 & 1.71 & 1.68 & 1.80 & 1.64 & 1.60 & 1.46 & 1.34 & 1.24 & 1.19 & 1.12 & 1.05 & 1.00 & 1.03 \\
\hline 28 & 3.09 & 2.74 & 2.59 & 2.38 & 2.29 & 2.57 & 2.49 & 2.28 & 2.09 & 1.93 & 1.78 & 1.76 & 1.74 & 1.74 & 1.79 \\
\hline 31 & 2.14 & 1.99 & 1.88 & 1.88 & 2.07 & 2.61 & 2.58 & 2.42 & 2.37 & 2.33 & 2.19 & 2.25 & 2.57 & 2.57 & 2.41 \\
\hline 32 & 1.59 & 1.63 & 1.69 & 1.52 & 1.69 & 1.54 & 1.44 & 1.45 & 1.33 & 1.27 & 1.21 & 1.29 & 1.33 & 1.24 & 1.17 \\
\hline 34 & 5.76 & 5.58 & 5.79 & 5.44 & 5.10 & 4.82 & 4.49 & 4.13 & 3.83 & 3.53 & 3.27 & 3.08 & 2.87 & 2.81 & 2.65 \\
\hline 38 & 1.79 & 2.10 & 1.87 & 1.68 & 1.51 & 1.37 & 1.25 & 1.30 & 1.30 & 1.50 & 1.89 & 1.77 & 1.84 & 1.72 & 1.61 \\
\hline 39 & 1.99 & 2.09 & 1.86 & 1.67 & 1.51 & 1.37 & 1.25 & 1.46 & 1.36 & 1.41 & 1.40 & 1.61 & 1.73 & 1.70 & 1.66 \\
\hline 40 & 3.29 & 3.11 & 3.02 & 2.91 & 2.74 & 2.59 & 2.72 & 2.58 & 2.38 & 2.20 & 2.05 & 1.90 & 2.11 & 2.06 & 1.94 \\
\hline 42 & 1.39 & 1.32 & 1.22 & 1.42 & 1.60 & 1.79 & 1.71 & 1.81 & 1.89 & 1.89 & 1.90 & 1.80 & 1.72 & 1.72 & 1.80 \\
\hline 54 & 1.23 & 1.35 & 1.56 & 1.52 & 1.43 & 1.63 & 1.74 & 1.65 & 1.58 & 1.52 & 1.45 & 1.63 & 1.54 & 1.49 & 1.41 \\
\hline 56 & 1.71 & 1.52 & 1.62 & 1.52 & 1.37 & 1.24 & 1.13 & 1.20 & 1.30 & 1.20 & 1.39 & 1.34 & 1.51 & 1.51 & 1.52 \\
\hline 58 & 0.86 & 0.77 & 0.72 & 0.65 & 0.73 & 0.70 & 1.09 & 1.00 & 0.99 & 0.96 & 0.94 & 1.16 & 1.14 & 1.52 & 1.73 \\
\hline 59 & 2.70 & 2.50 & 2.23 & 2.00 & 1.80 & 1.97 & 1.89 & 2.14 & 2.12 & 2.03 & 2.13 & 2.08 & 2.06 & 2.28 & 2.55 \\
\hline 66 & 1.24 & 1.10 & 0.98 & 1.26 & 1.14 & 1.03 & 1.02 & 1.41 & 1.30 & 1.19 & 1.10 & 1.02 & 0.95 & 0.89 & 0.88 \\
\hline 88 & 1.57 & 1.82 & 1.63 & 1.46 & 1.32 & 1.53 & 1.39 & 1.28 & 1.17 & 1.10 & 1.18 & 1.21 & 1.15 & 1.07 & 1.00 \\
\hline 89 & 2.02 & 1.79 & 1.60 & 1.43 & 1.29 & 1.17 & 1.07 & 0.98 & 0.90 & 0.83 & 0.76 & 0.76 & 0.71 & 0.76 & 0.73 \\
\hline 90 & 1.52 & 1.50 & 1.40 & 1.32 & 1.56 & 1.42 & 1.29 & 1.18 & 1.22 & 1.20 & 1.17 & 1.09 & 1.28 & 1.22 & 1.14 \\
\hline 91 & 1.87 & 1.66 & 1.48 & 1.51 & 1.41 & 1.33 & 1.23 & 1.18 & 1.09 & 1.02 & 1.12 & 1.04 & 1.00 & 1.00 & 1.01 \\
\hline 92 & 4.81 & 5.45 & 5.16 & 4.83 & 4.59 & 4.62 & 4.42 & 4.31 & 4.23 & 4.09 & 4.06 & 4.00 & 3.86 & 4.00 & 3.96 \\
\hline 97 & 2.36 & 2.11 & 2.28 & 2.05 & 1.85 & 1.68 & 1.53 & 1.40 & 1.28 & 1.18 & 1.09 & 1.01 & 1.15 & 1.07 & 1.00 \\
\hline 99 & 2.16 & 1.91 & 1.79 & 1.61 & 1.50 & 1.38 & 1.26 & 1.55 & 1.46 & 1.41 & 1.45 & 1.35 & 1.25 & 1.22 & 1.18 \\
\hline 109 & 1.58 & 1.66 & 1.74 & 1.81 & 1.79 & 1.77 & 1.74 & 1.65 & 1.64 & 2.09 & 2.07 & 2.03 & 2.01 & 2.08 & 2.25 \\
\hline 122 & 2.20 & 2.07 & 1.87 & 1.80 & 2.33 & 2.11 & 2.00 & 1.95 & 1.91 & 2.05 & 1.95 & 1.89 & 1.78 & 1.67 & 1.59 \\
\hline
\end{tabular}


Table J: Landscape predictor measurements for forest proportion in the landscape for all 34 landscapes where wood frog egg masses were surveyed

\begin{tabular}{|c|c|c|c|c|c|c|c|c|c|c|c|c|c|c|c|}
\hline L.R $(\mathrm{km}) \rightarrow$ & 0.1 & 0.2 & 0.3 & 0.4 & 0.5 & 0.6 & 0.7 & 0.8 & 0.9 & 1.0 & 1.1 & 1.2 & 1.3 & 1.4 & 1.5 \\
\hline \multicolumn{16}{|l|}{ Site $\downarrow$} \\
\hline 3 & 0.000 & 0.044 & 0.034 & 0.036 & 0.036 & 0.030 & 0.037 & 0.051 & 0.061 & 0.060 & 0.051 & 0.043 & 0.036 & 0.031 & 0.028 \\
\hline 6 & 0.000 & 0.000 & 0.000 & 0.017 & 0.033 & 0.044 & 0.048 & 0.048 & 0.040 & 0.035 & 0.037 & 0.039 & 0.035 & 0.033 & 0.034 \\
\hline 7 & 0.000 & 0.073 & 0.094 & 0.092 & 0.079 & 0.078 & 0.101 & 0.120 & 0.120 & 0.113 & 0.112 & 0.106 & 0.106 & 0.112 & 0.121 \\
\hline 8 & 0.736 & 0.648 & 0.624 & 0.636 & 0.640 & 0.651 & 0.672 & 0.667 & 0.659 & 0.657 & 0.654 & 0.656 & 0.664 & 0.659 & 0.650 \\
\hline 10 & 0.798 & 0.783 & 0.736 & 0.684 & 0.681 & 0.683 & 0.670 & 0.655 & 0.664 & 0.689 & 0.700 & 0.696 & 0.677 & 0.648 & 0.629 \\
\hline 11 & 0.630 & 0.753 & 0.810 & 0.819 & 0.799 & 0.774 & 0.732 & 0.704 & 0.726 & 0.737 & 0.746 & 0.763 & 0.772 & 0.769 & 0.754 \\
\hline 12 & 0.877 & 0.634 & 0.537 & 0.522 & 0.541 & 0.596 & 0.631 & 0.640 & 0.630 & 0.619 & 0.623 & 0.626 & 0.628 & 0.631 & 0.630 \\
\hline 13 & 0.137 & 0.208 & 0.252 & 0.370 & 0.481 & 0.549 & 0.579 & 0.579 & 0.577 & 0.587 & 0.591 & 0.593 & 0.603 & 0.604 & 0.595 \\
\hline 15 & 0.700 & 0.748 & 0.728 & 0.634 & 0.563 & 0.504 & 0.477 & 0.488 & 0.498 & 0.502 & 0.507 & 0.518 & 0.529 & 0.547 & 0.562 \\
\hline 20 & 0.476 & 0.333 & 0.310 & 0.288 & 0.289 & 0.277 & 0.271 & 0.252 & 0.236 & 0.214 & 0.187 & 0.169 & 0.152 & 0.139 & 0.126 \\
\hline 22 & 0.501 & 0.163 & 0.141 & 0.214 & 0.237 & 0.270 & 0.281 & 0.284 & 0.293 & 0.302 & 0.317 & 0.336 & 0.348 & 0.345 & 0.335 \\
\hline 27 & 0.720 & 0.413 & 0.373 & 0.363 & 0.337 & 0.333 & 0.348 & 0.336 & 0.329 & 0.322 & 0.320 & 0.326 & 0.340 & 0.360 & 0.377 \\
\hline 28 & 0.000 & 0.014 & 0.112 & 0.280 & 0.351 & 0.386 & 0.401 & 0.393 & 0.372 & 0.364 & 0.368 & 0.365 & 0.370 & 0.367 & 0.369 \\
\hline 31 & 0.734 & 0.702 & 0.600 & 0.608 & 0.593 & 0.595 & 0.587 & 0.570 & 0.546 & 0.520 & 0.497 & 0.486 & 0.470 & 0.458 & 0.449 \\
\hline 32 & 0.809 & 0.642 & 0.498 & 0.409 & 0.385 & 0.369 & 0.373 & 0.359 & 0.342 & 0.310 & 0.283 & 0.266 & 0.256 & 0.248 & 0.239 \\
\hline 34 & 0.677 & 0.566 & 0.482 & 0.426 & 0.412 & 0.437 & 0.446 & 0.441 & 0.436 & 0.452 & 0.466 & 0.463 & 0.455 & 0.447 & 0.434 \\
\hline 38 & 0.146 & 0.255 & 0.253 & 0.187 & 0.130 & 0.093 & 0.069 & 0.053 & 0.042 & 0.034 & 0.028 & 0.024 & 0.023 & 0.020 & 0.018 \\
\hline 39 & 0.107 & 0.044 & 0.133 & 0.157 & 0.170 & 0.184 & 0.180 & 0.181 & 0.182 & 0.181 & 0.186 & 0.188 & 0.189 & 0.192 & 0.201 \\
\hline 40 & 0.943 & 0.742 & 0.704 & 0.702 & 0.684 & 0.659 & 0.616 & 0.577 & 0.541 & 0.495 & 0.446 & 0.396 & 0.347 & 0.312 & 0.290 \\
\hline 42 & 0.016 & 0.196 & 0.355 & 0.385 & 0.417 & 0.445 & 0.477 & 0.506 & 0.524 & 0.530 & 0.517 & 0.517 & 0.528 & 0.536 & 0.544 \\
\hline 54 & 0.790 & 0.760 & 0.623 & 0.534 & 0.484 & 0.439 & 0.426 & 0.435 & 0.467 & 0.508 & 0.555 & 0.594 & 0.614 & 0.632 & 0.645 \\
\hline 56 & 1.005 & 0.906 & 0.629 & 0.646 & 0.648 & 0.651 & 0.659 & 0.668 & 0.663 & 0.657 & 0.640 & 0.626 & 0.613 & 0.606 & 0.599 \\
\hline 58 & 1.005 & 1.006 & 1.002 & 0.967 & 0.904 & 0.811 & 0.754 & 0.712 & 0.687 & 0.669 & 0.653 & 0.641 & 0.634 & 0.632 & 0.627 \\
\hline 59 & 0.709 & 0.463 & 0.470 & 0.514 & 0.511 & 0.548 & 0.606 & 0.664 & 0.688 & 0.701 & 0.709 & 0.708 & 0.710 & 0.711 & 0.704 \\
\hline 66 & 0.327 & 0.337 & 0.380 & 0.376 & 0.347 & 0.321 & 0.287 & 0.261 & 0.232 & 0.207 & 0.190 & 0.172 & 0.163 & 0.164 & 0.175 \\
\hline 88 & 0.196 & 0.116 & 0.243 & 0.246 & 0.248 & 0.271 & 0.322 & 0.357 & 0.393 & 0.416 & 0.434 & 0.463 & 0.492 & 0.520 & 0.538 \\
\hline 89 & 0.961 & 0.795 & 0.755 & 0.686 & 0.735 & 0.763 & 0.764 & 0.746 & 0.759 & 0.763 & 0.776 & 0.790 & 0.804 & 0.817 & 0.827 \\
\hline 90 & 0.514 & 0.608 & 0.475 & 1.049 & 1.042 & 1.012 & 1.009 & 0.991 & 0.984 & 0.962 & 0.950 & 0.940 & 0.935 & 0.936 & 0.935 \\
\hline 91 & 0.357 & 0.517 & 0.581 & 0.627 & 0.547 & 0.447 & 0.361 & 0.298 & 0.258 & 0.238 & 0.233 & 0.228 & 0.224 & 0.217 & 0.213 \\
\hline 92 & 0.531 & 0.504 & 0.457 & 0.367 & 0.329 & 0.304 & 0.306 & 0.318 & 0.331 & 0.344 & 0.346 & 0.359 & 0.366 & 0.370 & 0.359 \\
\hline 97 & 0.459 & 0.485 & 0.480 & 0.435 & 0.358 & 0.318 & 0.313 & 0.318 & 0.329 & 0.341 & 0.368 & 0.400 & 0.429 & 0.464 & 0.488 \\
\hline 99 & 0.000 & 0.058 & 0.099 & 0.103 & 0.108 & 0.128 & 0.145 & 0.185 & 0.197 & 0.192 & 0.199 & 0.208 & 0.210 & 0.218 & 0.219 \\
\hline 109 & 0.173 & 0.088 & 0.164 & 0.171 & 0.151 & 0.156 & 0.180 & 0.170 & 0.152 & 0.142 & 0.130 & 0.130 & 0.133 & 0.135 & 0.130 \\
\hline 122 & 0.233 & 0.273 & 0.359 & 0.432 & 0.480 & 0.476 & 0.465 & 0.434 & 0.394 & 0.374 & 0.373 & 0.372 & 0.361 & 0.355 & 0.363 \\
\hline
\end{tabular}


Table J (continued): Landscape predictor measurements for forest proportion in the landscape for all 34 landscapes where wood frog egg masses were surveyed

\begin{tabular}{|c|c|c|c|c|c|c|c|c|c|c|c|c|c|c|c|}
\hline L.R $(\mathrm{km}) \rightarrow$ & 1.6 & 1.7 & 1.8 & 1.9 & 2.0 & 2.1 & 2.2 & 2.3 & 2.4 & 2.5 & 2.6 & 2.7 & 2.8 & 2.9 & 3.0 \\
\hline \multicolumn{16}{|l|}{ Site $\downarrow$} \\
\hline 3 & 0.026 & 0.033 & 0.039 & 0.050 & 0.064 & 0.074 & 0.085 & 0.098 & 0.109 & 0.116 & 0.122 & 0.127 & 0.131 & 0.135 & 0.139 \\
\hline 6 & 0.032 & 0.032 & 0.041 & 0.053 & 0.063 & 0.067 & 0.074 & 0.080 & 0.086 & 0.091 & 0.094 & 0.095 & 0.097 & 0.100 & 0.104 \\
\hline 7 & 0.128 & 0.130 & 0.131 & 0.134 & 0.140 & 0.149 & 0.160 & 0.173 & 0.181 & 0.188 & 0.197 & 0.205 & 0.209 & 0.213 & 0.216 \\
\hline 8 & 0.649 & 0.652 & 0.659 & 0.660 & 0.653 & 0.644 & 0.631 & 0.617 & 0.600 & 0.585 & 0.571 & 0.558 & 0.546 & 0.537 & 0.528 \\
\hline 10 & 0.616 & 0.618 & 0.614 & 0.611 & 0.609 & 0.602 & 0.596 & 0.585 & 0.634 & 0.606 & 0.578 & 0.553 & 0.528 & 0.503 & 0.479 \\
\hline 11 & 0.742 & 0.744 & 0.755 & 0.764 & 0.764 & 0.751 & 0.735 & 0.716 & 0.699 & 0.685 & 0.670 & 0.660 & 0.640 & 0.625 & 0.631 \\
\hline 12 & 0.642 & 0.656 & 0.670 & 0.675 & 0.676 & 0.679 & 0.682 & 0.683 & 0.684 & 0.686 & 0.690 & 0.694 & 0.699 & 0.701 & 0.699 \\
\hline 13 & 0.588 & 0.589 & 0.593 & 0.596 & 0.597 & 0.600 & 0.601 & 0.601 & 0.598 & 0.595 & 0.591 & 0.588 & 0.589 & 0.591 & 0.592 \\
\hline 15 & 0.570 & 0.580 & 0.596 & 0.604 & 0.605 & 0.606 & 0.602 & 0.595 & 0.579 & 0.573 & 0.570 & 0.567 & 0.565 & 0.568 & 0.571 \\
\hline 20 & 0.113 & 0.101 & 0.092 & 0.084 & 0.076 & 0.069 & 0.063 & 0.058 & 0.053 & 0.049 & 0.047 & 0.044 & 0.042 & 0.041 & 0.039 \\
\hline 22 & 0.326 & 0.323 & 0.323 & 0.329 & 0.334 & 0.335 & 0.337 & 0.338 & 0.335 & 0.329 & 0.323 & 0.316 & 0.313 & 0.310 & 0.310 \\
\hline 27 & 0.389 & 0.401 & 0.407 & 0.409 & 0.411 & 0.417 & 0.424 & 0.432 & 0.437 & 0.436 & 0.433 & 0.429 & 0.427 & 0.428 & 0.428 \\
\hline 28 & 0.370 & 0.373 & 0.373 & 0.380 & 0.387 & 0.391 & 0.392 & 0.391 & 0.398 & 0.402 & 0.404 & 0.409 & 0.413 & 0.412 & 0.412 \\
\hline 31 & 0.444 & 0.440 & 0.434 & 0.429 & 0.424 & 0.418 & 0.412 & 0.447 & 0.441 & 0.436 & 0.435 & 0.431 & 0.426 & 0.417 & 0.405 \\
\hline 32 & 0.234 & 0.229 & 0.224 & 0.220 & 0.216 & 0.213 & 0.211 & 0.206 & 0.210 & 0.212 & 0.262 & 0.263 & 0.263 & 0.261 & 0.259 \\
\hline 34 & 0.422 & 0.410 & 0.398 & 0.392 & 0.391 & 0.387 & 0.383 & 0.378 & 0.370 & 0.361 & 0.355 & 0.349 & 0.344 & 0.338 & 0.330 \\
\hline 38 & 0.020 & 0.023 & 0.025 & 0.028 & 0.028 & 0.027 & 0.032 & 0.038 & 0.043 & 0.049 & 0.054 & 0.058 & 0.065 & 0.073 & 0.081 \\
\hline 39 & 0.223 & 0.243 & 0.259 & 0.267 & 0.264 & 0.256 & 0.245 & 0.237 & 0.231 & 0.225 & 0.220 & 0.217 & 0.214 & 0.209 & 0.203 \\
\hline 40 & 0.280 & 0.276 & 0.278 & 0.287 & 0.297 & 0.304 & 0.312 & 0.318 & 0.322 & 0.327 & 0.336 & 0.342 & 0.347 & 0.355 & 0.360 \\
\hline 42 & 0.549 & 0.548 & 0.544 & 0.527 & 0.500 & 0.478 & 0.463 & 0.450 & 0.435 & 0.420 & 0.409 & 0.400 & 0.392 & 0.385 & 0.377 \\
\hline 54 & 0.654 & 0.662 & 0.664 & 0.662 & 0.659 & 0.654 & 0.651 & 0.640 & 0.626 & 0.611 & 0.597 & 0.583 & 0.572 & 0.562 & 0.557 \\
\hline 56 & 0.587 & 0.579 & 0.578 & 0.572 & 0.565 & 0.556 & 0.547 & 0.538 & 0.530 & 0.522 & 0.515 & 0.508 & 0.502 & 0.497 & 0.492 \\
\hline 58 & 0.623 & 0.622 & 0.616 & 0.602 & 0.586 & 0.573 & 0.558 & 0.543 & 0.533 & 0.525 & 0.519 & 0.516 & 0.516 & 0.517 & 0.518 \\
\hline 59 & 0.693 & 0.684 & 0.669 & 0.651 & 0.642 & 0.630 & 0.619 & 0.612 & 0.606 & 0.595 & 0.586 & 0.573 & 0.563 & 0.551 & 0.540 \\
\hline 66 & 0.179 & 0.181 & 0.183 & 0.178 & 0.172 & 0.169 & 0.167 & 0.168 & 0.172 & 0.177 & 0.180 & 0.182 & 0.184 & 0.189 & 0.194 \\
\hline 88 & 0.545 & 0.548 & 0.549 & 0.540 & 0.525 & 0.502 & 0.486 & 0.470 & 0.459 & 0.448 & 0.625 & 0.613 & 0.604 & 0.597 & 0.592 \\
\hline 89 & 0.833 & 0.840 & 0.888 & 0.909 & 0.927 & 0.938 & 0.951 & 0.953 & 0.956 & 0.958 & 0.950 & 0.933 & 0.915 & 0.897 & 0.881 \\
\hline 90 & 0.932 & 0.928 & 0.926 & 0.923 & 0.923 & 0.923 & 0.924 & 0.914 & 0.910 & 0.901 & 0.886 & 0.867 & 0.849 & 0.832 & 0.814 \\
\hline 91 & 0.212 & 0.218 & 0.226 & 0.236 & 0.241 & 0.296 & 0.314 & 0.329 & 0.340 & 0.347 & 0.350 & 0.358 & 0.355 & 0.352 & 0.360 \\
\hline 92 & 0.352 & 0.347 & 0.338 & 0.326 & 0.314 & 0.309 & 0.308 & 0.310 & 0.313 & 0.317 & 0.314 & 0.309 & 0.306 & 0.302 & 0.367 \\
\hline 97 & 0.503 & 0.512 & 0.519 & 0.534 & 0.547 & 0.561 & 0.575 & 0.585 & 0.592 & 0.600 & 0.602 & 0.600 & 0.599 & 0.597 & 0.594 \\
\hline 99 & 0.221 & 0.223 & 0.229 & 0.235 & 0.239 & 0.239 & 0.239 & 0.240 & 0.242 & 0.243 & 0.244 & 0.244 & 0.245 & 0.246 & 0.246 \\
\hline 109 & 0.128 & 0.126 & 0.126 & 0.121 & 0.117 & 0.118 & 0.118 & 0.116 & 0.116 & 0.116 & 0.115 & 0.112 & 0.109 & 0.109 & 0.111 \\
\hline 122 & 0.369 & 0.364 & 0.359 & 0.362 & 0.366 & 0.371 & 0.379 & 0.389 & 0.399 & 0.404 & 0.409 & 0.413 & 0.416 & 0.412 & 0.405 \\
\hline
\end{tabular}




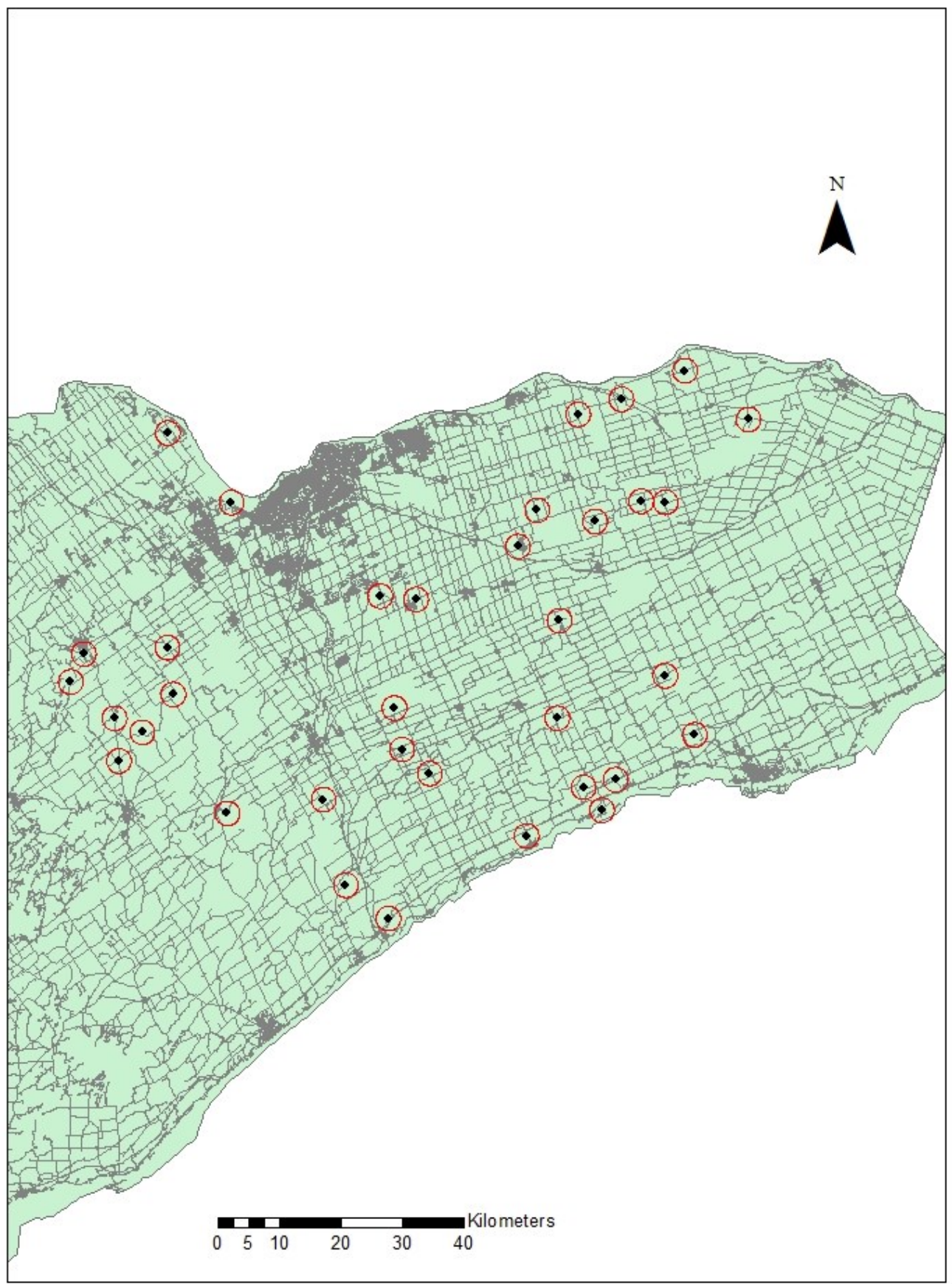

Figure C: Map of the study region found in Eastern Ontario, Canada, where the 34 landscapes selected, red circles, are shown based on road density, grey lines, with focal sites, black dots, displayed in the center of landscapes. Wood frog egg mass surveys were conducted at the focal sites to obtain estimates of fecundity, abundance, and occurrence for this species from April to May 2016. 